\title{
Landers 1992 "reloaded": Integrative dynamic earthquake rupture modeling
}

Corresponding author: Stephanie Wollherr (wollherr@geophysik.uni-muenchen.de)

\author{
Stephanie Wollherr ${ }^{1}$, Alice-Agnes Gabriel ${ }^{1}$, and P. Martin Mai ${ }^{2}$
}

\footnotetext{
${ }^{1}$ Department of Earth and Environmental Sciences, Ludwig-Maximilians-University, Munich, Germany ${ }^{2}$ Division of Physical Science and Engineering, King Abdullah University of Science and Technology,

Thuwal, Kingdom of Saudi Arabia
}

\section{Key Points:}

- Integrative physics-based simulations of the 1992 Landers earthquake reproduce a broad range of independent observations

- Mechanically viable dynamic rupture interconnecting the complex fault segments enables analysis of pre-stress and fault strength

- We discuss the interaction of fault geometry, regional stress, attenuation, and offfault plasticity 


\begin{abstract}
The $1992 M_{w} 7.3$ Landers earthquake is perhaps one of the best studied seismic events. However, many aspects of the dynamics of the rupture process are still puzzling, e.g. the rupture transfer between fault segments. We present 3D spontaneous dynamic rupture simulations, incorporating the interplay of fault geometry, topography, 3D rheology, offfault plasticity and viscoelastic attenuation. Our preferred scenario reproduces a broad range of observations, including final slip distribution, shallow slip deficits and mapped off-fault deformation patterns. We demonstrate good agreement between synthetic and observed waveform characteristics and associated peak ground velocities. Despite very complex rupture evolution, ground motion variability is close to what is commonly assumed in Ground Motion Prediction Equations. We examine the effects of variations in modeling parameterization within a suite of scenarios including purely elastic setups and models neglecting viscoelastic attenuation. Source dynamics of all models include dynamic triggering over large distances and direct branching; rupture terminates spontaneously on most of the principal fault segments. Sustained dynamic rupture of all fault segments in general, and rupture transfers in particular, constrain amplitude and orientation of initial fault stresses and friction. We conclude that physically consistent inscale earthquake rupture simulations can augment earthquake source observations towards improving the understanding of earthquake source physics of complex, segmented fault systems.
\end{abstract}




\section{Introduction}

The $M_{w} 7.3$ Landers earthquake of June 28, 1992 ruptured five distinct segments previously considered unconnected. Overlapping fault zones of $80 \mathrm{~km}$ length hosted large vertical slips, large surface strike-slip offsets and unusual high stress-drops (Kanamori et al., 1992; Sieh et al., 1993). Only two segments of the strike-slip fault system slipped over their respective total length, the previously unknown Kickapoo fault and the Homestead Valley fault (Fig. 1), while only parts of the other involved fault segments ruptured. The Landers event raised awareness of unexpectedly large magnitude earthquakes occurring on complicated fault networks; in particular in context of dynamic rupture transfer mechanisms that raise pressing questions of fault mechanics. Distinct ground shaking was recorded by a dense network of seismometers (Campbell \& Bozorgnia, 1994) including locations very close to the slipping faults (Chen, 1995; Sleep, 2012).

The wealth of observational data has been analyzed to shed light on the slip distribution from inversion of seismological and geodetic data (e.g., Wald \& Heaton, 1994; Cohee \& Beroza, 1994; Freymueller et al., 1994; Cotton \& Campillo, 1995; Fialko, 2004b; $\mathrm{Xu}$ et al., 2016) and to constrain rupture dynamics (e.g., Peyrat et al., 2001; Aochi \& Fukuyama, 2002; Fliss et al., 2005; Heinecke et al., 2014; Wollherr et al., 2018). Together with detailed analyses of the recorded strong ground motions (e.g., Campbell \& Bozorgnia, 1994), rupture transfer mechanisms (e.g., Wesnousky, 2006; Madden \& Pollard, 2012; Madden et al., 2013) and potential energy release (e.g., Dreger, 1994; Wald \& Heaton, 1994) a comprehensive picture of the source kinematics and macroscopic earthquake properties has been developed.

While the overall kinematics of the event are thought to be well understood, many observations regarding its complicated rupture dynamics are still puzzling. For instance, the Kickapoo-Landers fault unexpectedly connected the Johnson Valley fault and the Homestead Valley fault, which were previously assumed to be independent structures (Sowers et al., 1994). A well-recorded near-surface slip gap at the northern part of the Kickapoo fault, close to the junction to the Homestead Valley fault, suggests a disconnection between these faults. Thus, rupture is assumed to have propagated at depth and/or "jumped" via dynamic triggering to the adjacent fault segment (Spotila \& Sieh, 1995). Across the entire fault system, the rupture front is found to propagate at highly variable speeds (Cotton \& Campillo, 1995; Hernandez et al., 1999), slowing down at transitions between segments (Wald \& Heaton, 1994) and in regions of high slip (Cohee \& Beroza, 1994).

The orientation of geometrically complex faults in the tectonic stress field has a first-order impact on the mechanics of earthquakes and faulting (e.g., Kaven \& Pollard, 2013). The Landers fault geometry is characterized by nearly vertical dip but exhibits strike rotation by about $30^{\circ}$ from the direction of the segment on which the earthquake initiated (Bouchon \& Campillo, 1998). Of particular interest is the fact that the northern fault segments, including the Emerson fault and Camp Rock fault, are not well oriented with respect to the regional stress field, indicating locally higher fault strengths and lower initial shear stresses. This leads to the hypothesis that large dynamic stress changes induced by rupture of the adjacent fault segments are necessary to overcome static friction at the northernmost faults (Bouchon \& Campillo, 1998). In contrast, the lack of aftershocks and large fault offsets in conjunction with relatively shallow slip (Wald \& Heaton, 1994), suggests that the Camp Rock fault was rather statically triggered shortly after the event (Sieh, 1996; Kaneda \& Rockwell, 2009).

Physics-based dynamic rupture simulations allow investigating the full complexity of the earthquake source dynamics by numerically modeling a spontaneously propagating rupture on a prescribed fault surface. The space-time evolution of the rupture is thereby governed by initial stresses on the fault, a frictional constitutive law, and the bulk properties of the medium. Olsen (1997) presents the first dynamic rupture model 
of the Landers event using a single planar fault and initial stresses derived from the slip distribution of Wald and Heaton (1994). Consequently, their model features very heterogeneous on-fault stress conditions. This model is then subsequently refined in an iterative dynamic rupture inversion approach (Peyrat et al., 2001) and well reproduces recorded seismograms at selected sites for frequencies below $0.5 \mathrm{~Hz}$.

However, simulations on single planar faults provide no insight on rupture transfer between fault segments. Also, rupture nucleation, propagation and arrest are highly sensitive to variations in fault geometry. Dynamically, rupture is able to overcome fault bends, branch into or jump to adjacent fault segments only for specific fault pre-stresses, limited distances between adjacent fault segments and limited branching angles of connected faults (e.g., R. Harris \& Day, 1993; Bhat et al., 2007; D. Oglesby, 2008; Lozos et al., 2011; DeDontney et al., 2012; D. D. Oglesby \& Mai, 2012).

Modeling complex fault geometries is challenging for numerical solvers, since the detailed geometry must be honored explicitly by the spatial discretization. Numerical schemes such as the Boundary Integral Equation Method (BIEM) (e.g., Aochi \& Fukuyama, 2002; Ando et al., 2017), Finite Element Methods (FEM) based on tetrahedral elements (e.g., Barall, 2009) - including the Discontinuous Galerkin (DG) Method (e.g., Pelties et al., 2012; Tago et al., 2012) - or numerical methods using curvilinear elements (e.g., Duru \& Dunham, 2016) are able to accurately represent non-planar fault geometries. We point out that the accurate representation of fault branches is restricted to methods that do not use a traction-at-split nodes approach (Andrews, 1999; Day et al., 2005; Dalguer \& Day, 2007), like BIEM and DG methods.

Only a few dynamic rupture scenarios considered the complex fault geometry on which the Landers event occurred. A multi-segment geometry of the Landers fault zone is first integrated into a dynamic rupture model by Aochi and Fukuyama (2002) and Aochi et al. (2003). By analyzing the effects of varying principal stress directions and frictional parameters they conclude that rupture cannot propagate across all of the differently oriented fault segments assuming a single principal stress orientation. That is, the local tectonic setting and non-planar fault structure play the most significant role in this earthquakes generation and rupture process. However, the use of the BIEM restricted this study to fully elastic, homogeneous material properties. Additionally, the Landers earthquake serves as valuable validation and testing scenario, for example for demonstrating the geometrical flexibility of DG methods (Tago et al., 2012; Pelties et al., 2012; Breuer et al., 2014). However, these studies are not able to fully reproduce observations, as e.g. slip on all fault segments or regional seismogram recordings. While these studies incorporate realistic fault geometries and topography, realistic material properties, such as 3D subsurface structure and the possibility of plastic deformation, are missing.

In addition, significant fault-zone damage was observed for the Landers earthquake (e.g., Li, Aki, Adams, et al., 1994; Li, Aki, Vidale, et al., 1994), motivating us to account for inelastic processes off the fault. Recent advances in processing high-resolution aerial photographs of near-fault deformation patterns reveal that off-fault deformation primarily correlates with fault complexity (Milliner et al., 2015). A significant slip reduction towards the shallow part of the faults is inferred, known as shallow slip deficit (SSD), which is often attributed to plastic deformation (Fialko et al., 2005; Kaneko \& Fialko, 2011; Milliner et al., 2015; Gombert et al., 2018). Simulations on a single, planar fault plane reveal that purely elastic simulations underpredict the SSD (Roten et al., 2017) as well as ground motions (Roten et al., 2014, 2015). Wollherr et al. (2018) includes the full geometrical complexity of the fault system in scenario calculations demonstrating that spatio-temporal rupture transfers are significantly altered by off-fault plasticity.

In this study, we develop a suite of dynamic source models for the the multi-segment Landers earthquake based on physics-based and high-performance-computing-enabled rupture simulations. Our dynamic source model incorporates a comprehensive set of ge- 
ological and geophysical information such as high-resolution topography, rotating tectonic stresses, 3D velocity structure, depth-dependent bulk cohesion, and a complex intersecting fault geometry. Unifying aforementioned complexities is enabled by using SeisSol (www.seissol.org, Dumbser and Käser (2006); Pelties et al. (2014)), a software package specifically suited for handling complex geometries and for the efficient use on modern high-performance computing infrastructure (e.g., Heinecke et al., 2014; Uphoff et al., 2017). This work extends recent models presented in (Heinecke et al., 2014; Wollherr et al., 2018) which included complex fault geometries and off-fault plasticity but were restricted to $1 \mathrm{D}$ velocity structure, constantly oriented tectonic background stress and neglecting viscoelastic attenuation of the seismic wave field.

We find that the interplay of dynamic rupture transfers, geometric fault complexity, spatially smoothly varying pre-stress, 3D velocity structure, topography, viscoelastic attenuation and off-fault plasticity constitute a broad but challenging set of conditions for a mechanically self-consistent dynamic source model. Our simulations match a broad range of regional and local observations, including fault slip, seismic moment release and ground motions. The presented model also contributes to the understanding of the shallow slip deficit, directivity effects and rupture branching and "jumping" under realistic conditions.

In the following, we first describe our modeling approach and the observational constraints considered in Sec. 2. We then investigate the rupture characteristics of our preferred model in terms of rupture branching, dynamic triggering, moment rate release, and final slip distribution in Sec. 3. We compare the ratio of shallow near-surface slip and deep slip (within the seismogenic zone) to recent inversion results based on a Bayesian approach (Gombert et al., 2018), as well as the modeled off-fault plastic strain distribution with near-field observations of fault zone width (Milliner et al., 2015). Analyzing ground motions in terms of spatial distribution and shaking levels (e.g. peak ground motions) with respect to the observations proves a good quality of the synthetics produced by the dynamic rupture model. Finally, we discuss the effects of variations in modeling parameterization, e.g. purely elastic setups or models neglecting viscoelastic attenuation, in comparison to our preferred model, as well as implications for understanding earthquake dynamics on segmented fault systems in Sec. 4. 


\section{Model}

In the following, we describe our modeling approach and the observational constraints to construct a self-consistent dynamic rupture model of the 1992 Landers earthquake. Dynamic rupture evolves spontaneously according to the parameterization of frictional behavior, initial fault stress state, and nucleation conditions on prescribed fault surfaces. The nonlinear interaction of rupture propagation and the emanated seismic wave field is further affected by the structural characteristics, such as material properties and topography of the modeling domain.

To construct our preferred model, we follow the sequence of steps described below to define the model parametrization in terms of stress-to-fault angles, stress amplitudes, and frictional parameters for the given fault geometry, velocity structure, off-fault plasticity parametrization and vertical stress amplitudes. The model refinement steps allow us to create a dynamic rupture model that reproduces a broad range of independent observations.

1. Sustained rupture along all fault segments: The assumption of sustained rupture along all fault segments assuming a regional stress state without small scale heterogeneities governing across complex fault geometries introduces strong constraints on the choice of modeling parameters. By testing a range of horizontal stress orientations (i.e. the angle of the regional maximum compressive stress orientation with respect to the fault system) based on inferences from the geological setting and previous seismicity (more details in Sec. 2.2), we constrain the stress orientations in the range of a few degrees variance to the preferred model.

2. Seismic moment: We aim to find a model parametrization that leads to a scenario with a seismic moment comparable to the observationally inferred seismic moment. Criterion 2 constraints the stress amplitudes and the frictional parameters to narrow range given the described assumptions including the fault geometry.

3. Peak seismic moment release: In this step, we simultaneously vary the stress orientations within the few degree variance identified in step 1 together with the frictional parameters of the friction law. We try to match the peak amplitudes of the synthetic seismic moment rate with observationally estimated source time functions taking into account their uncertainties. The misfit in terms of amplitudes is measured by an envelope goodness-of-fit (EG) criteria based on the frequencytime (TF) representation of the signal following Kristeková et al. (2009)).

4. Timing of the peak seismic moment release: Lastly, we improve the phase alignment and timing of the synthetic moment rate (quantified by the phase goodnessof-fit (PG) criteria defined by Kristeková et al. (2009) and determine the final frictional parameters, in particular the critical slip distance of the friction law.

To constrain the model in step 3 and 4, we choose the source time functions (STFs) of the SCARDEC database (Vallée \& Douet, 2016) (see Sec. 4.6 for a discussion of the uncertainties associated with these solutions). Examples of the time-frequency goodnessof-fit criteria for selected models are shown in the supporting information (Text S1 and Fig. S1, calculated using ObsPy (Krischer et al., 2015)). Our preferred model parameters are presented in this Section including a summary of all model parameters in Table 1. Our model captures the interplay of dynamic rupture transfers, geometric fault complexity, spatially smoothly varying pre-stress, 3D velocity structure, topography, viscoelastic attenuation, and off-fault plasticity.

\subsection{Structural Model and Numerical Discretization}

The Landers fault system consists of curved, branched, and segmented faults. We construct the geometry of the main fault segments from photometric images of fault sur- 


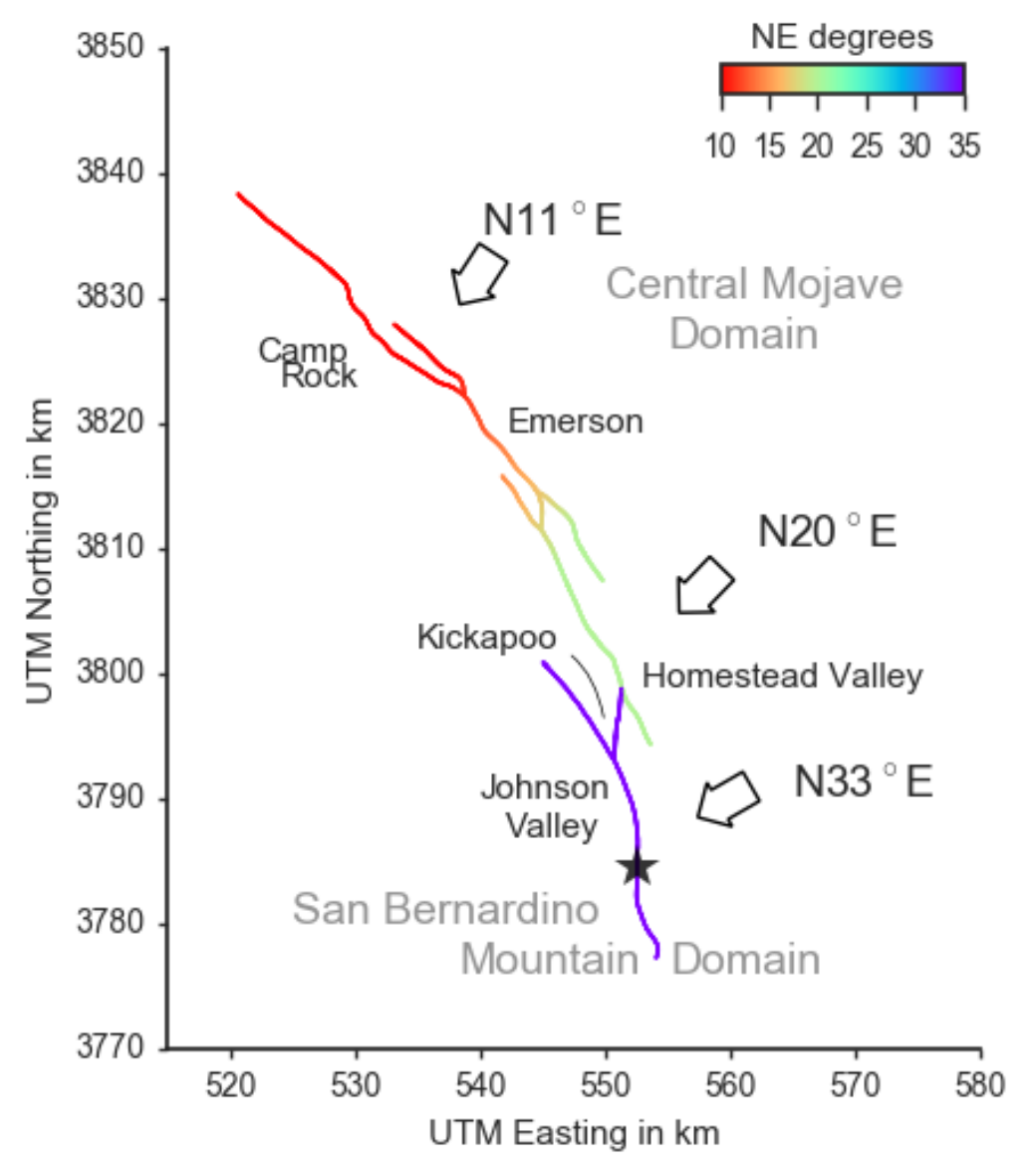

Figure 1. Mapped fault traces (Fleming et al., 1998) that are used in all our simulations and assumed orientation of maximum compressional principal stress $\sigma_{1}$ of our preferred model. The star marks the epicenter of the $1992 M_{w} 7.3$ Landers earthquake. 


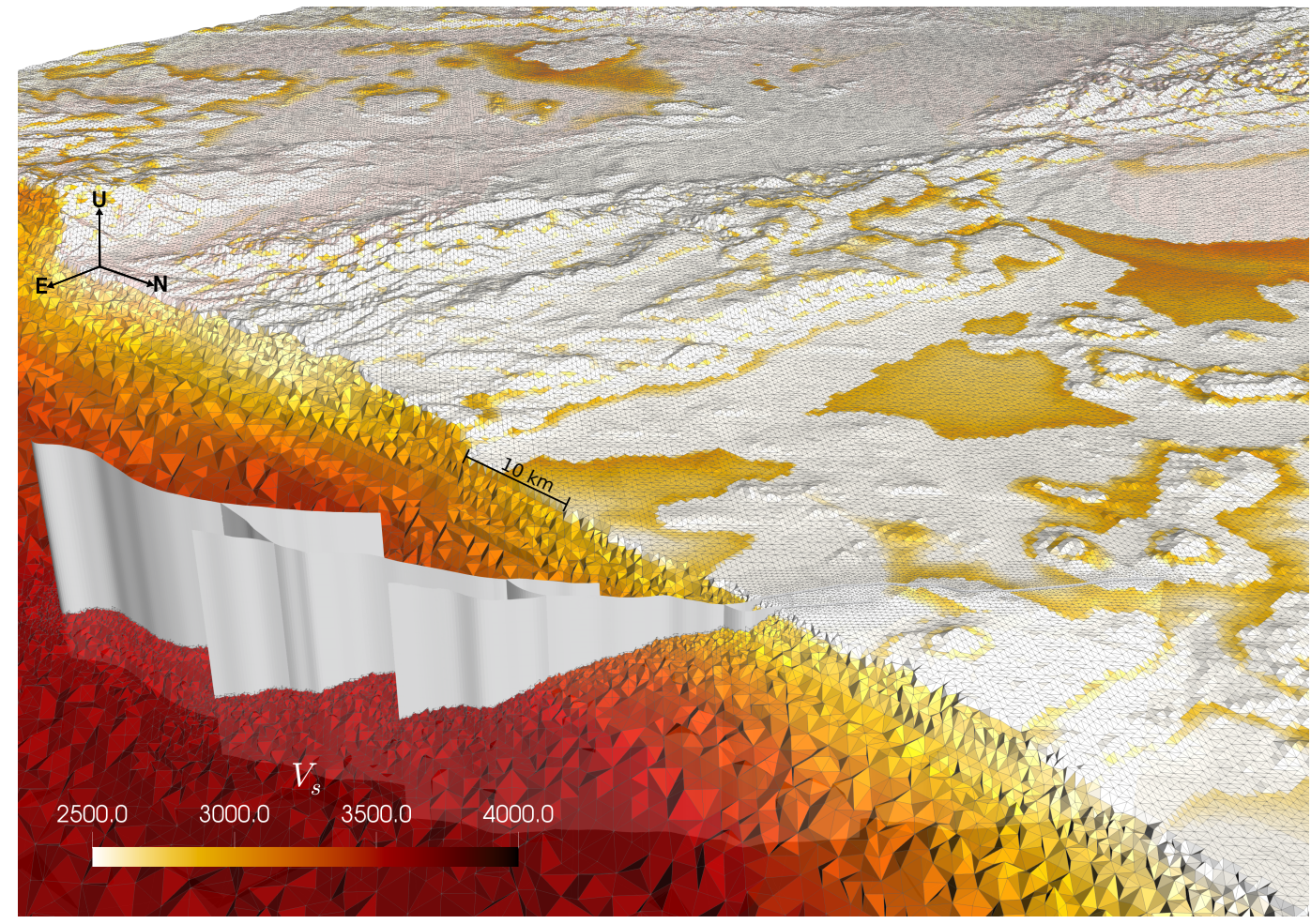

Figure 2. Structural model spatially discretized by tetrahedral computational elements. Colors represent the shear wave velocities $V_{s}$ of the $3 \mathrm{D}$ velocity structure given by the Community Velocity Model-Harvard (CVM-H) (Shaw et al., 2015). Fault surface segments are visualized in white. Local refinement is applied in the vicinity of the faults $(200 \mathrm{~m})$ (Fleming et al., 1998) and the Earth's topography (500 m) (Farr et al., 2007). The fault surfaces intersect the local topography. 


\begin{tabular}{lll} 
symbol & parameter & value with units \\
\hline$\mu_{s}$ & static friction & $0.55(0.44$ at the EF and CRF $)$ \\
$\mu_{d}$ & dynamic friction & 0.22 \\
$D_{c}$ & critical slip distance & $0.62 \mathrm{~m}$ \\
$c$ & bulk cohesion & depth-dependent, good quality \\
& & rock model of Roten et al. (2017) \\
& & ranging between 2.5-50.0 MPa \\
$\phi$ & friction angle & 0.55 \\
$v_{s}, v_{p}$ & shear and p-wave velocity & $3 \mathrm{D} \mathrm{CVM-H} \mathrm{(Shaw} \mathrm{et} \mathrm{al.,} \mathrm{2015)}$ \\
$\rho$ & density & $3 \mathrm{D} \mathrm{CVM-H} \mathrm{(Shaw} \mathrm{et} \mathrm{al.,} \mathrm{2015)}$ \\
$Q_{s}, Q_{p}$ & viscoelastic damping parameters & $50 v_{s}, 2 Q_{s}$ \\
$r$ & nucleation patch radius & $1.5 \mathrm{~km}$ \\
& forced nucleation time & $0.6 \mathrm{~s}$ \\
$R$ & relative pre-stress ratio & 0.65 \\
$\sigma_{2}$ & principal vertical stress & $(2700-1000) \mathrm{kg} / \mathrm{m} 9.8$ abs $(\mathrm{depth} \mathrm{m})$ \\
$\sigma_{1}, \sigma_{3}$ & principal horizontal stresses & orientation visualized in Fig. 1, amplitudes \\
& & determined by $R$ and eq. (2) and (3) \\
$d x$ & smallest element edge & $200 \mathrm{~m}$ \\
$p$ & polynomial order of accuracy & 4 \\
\hline
\end{tabular}

Table 1. Summary of the model parameters of our preferred model described in Secs. $2.1-$ 2.5 .

face traces (Fleming et al., 1998) that we extend to $15 \mathrm{~km}$ depth assuming purely vertical dip. The model includes five distinct non-planar fault segments connected over a total length of $80 \mathrm{~km}$ (see Fig. 1): the Johnson Valley fault (JVF) in the most southern part of the fault system, the Kickapoo fault (KF) connecting to the Homestead Valley fault (HVF), the Emerson fault (EF) including the connecting branch between the HVF and EF, and the Camp Rock fault (CRF) in the northernmost part. The fault surface intersects the local topography, leading to fault elevation differences of up to $1000 \mathrm{~m}$. Our model incorporates DEM data of NASA's Shuttle Radar Topography Mission (SRTM) with 3-arc-seconds sampling (available from the U.S. Geological Survey https://dds.cr .usgs.gov/srtm/version2_1/SRTM3/,((Farr et al., 2007))), re-sampled to match a here chosen spatial topography discretization of $500 \mathrm{~m}$. A view of the resultant structural model is visualized in Fig. 2.

Wollherr et al. (2018) found that the cohesive zone width may vary considerably across geometrically complex fault systems, implying that a minimum intrinsic scale length needs to be resolved instead of some average. For our preferred scenario, we measure a minimum cohesive zone width of $155 \mathrm{~m}$, located at the HVF at a depth of $8 \mathrm{~km}$. Following the convergence tests conducted in Wollherr et al. (2018), a fault discretization of $200 \mathrm{~m}$ using polynomial basis functions of degree $p=4$ or $\mathcal{O} 5$ (corresponding to a minimum cohesive zone resolution of 0.78 mesh elements or 3.88 subelemental points due to the high-order approach) sufficiently resolves the cohesive zone width to ensure convergence (Day et al., 2005). Due to the use of sub-elemental Gaussian integration points, the fault is efficiently discretized by a maximum distance of $33.3 \mathrm{~m}$ (effective minimum cohesive zone width resolution of 4.65 points). More details on the determination of the cohesive zone width and the required resolution are provided in the Appendix A.

We define a high-resolution model area surrounding the fault traces over a width and length of $270 \mathrm{~km}$ (east-west and north-south, respectively). Within this area, topography is represented by tetrahedral elements with $500 \mathrm{~m}$ edge length (Fig. 2). Based on the locally refined and high-order spatio-temporal discretization, the maximum resolved 
frequency is $1.0 \mathrm{~Hz}$ within $105 \mathrm{~km}$ distance to the fault. High frequencies up to $4.0 \mathrm{~Hz}$ are resolved within $10 \mathrm{~km}$ distance to the fault trace. Fig. B1 in Appendix B illustrates the model's resolution exemplary for several stations with varying distances to the fault trace ranging from $0.47 \mathrm{~km}$ (station LUC) to $102.8 \mathrm{~km}$ (station SAL located on the Salton Sea Basin).

To avoid undesired reflections from the domain boundaries, while simultaneously saving computational costs, we gradually increase the element size by a factor of $6 \%$ from element to element up to an edge length of $10 \mathrm{~km}$ outside the high-resolution model area. Equivalent mesh-coarsening is applied in the volume at depth.

\subsection{On-fault Initial Stresses}

To constrain the initial stress conditions, we combine information on the regional tectonic setting, findings of previous dynamic rupture studies, and additional numerical experiments constraining the principal stress directions.

Principal stresses are assumed to vary linearly with depth, in accordance with rock mechanics and field observations. Our prescribed intermediate principal stress component, $\sigma_{2}$, is purely vertical and set to the average confining pressure of the overlying rock reduced by a constant hydrostatic pore fluid pressure (e.g., Suppe, 1985), i.e.

$$
\sigma_{2}=(2700-1000) \mathrm{kg} / \mathrm{m}^{3} g z
$$

with gravity $g=9.8 \mathrm{~m} / \mathrm{s}^{2}$, average rock density of $2700 \mathrm{~kg} / \mathrm{m}^{3}$, and depth $z$ in $\mathrm{m}$. We further follow (Aochi \& Madariaga, 2003) and assume $\sigma_{2}=\left(\sigma_{1}+\sigma_{3}\right) / 2$ and $\Delta \sigma=$ $\left(\sigma_{1}-\sigma_{3}\right) / 2$ where $\Delta \sigma$ defines the radius of the corresponding Mohr-Coulomb stress circle. While the magnitude of $\sigma_{2}$ with respect to $\sigma_{1}$ and $\sigma_{3}$ is a fixed assumption of our model setup and in agreement with Hauksson (1994), Abers and Gephart (2001) infer variable magnitudes for $\sigma_{2}$ ranging from 0 to 0.3 to 1.0 across the fault system. As a consequence of our assumption, the horizontal stresses can be represented as $\sigma_{1}=\sigma_{2}+$ $\Delta \sigma$ and $\sigma_{3}=\sigma_{2}-\Delta \sigma$. Using these definitions we derive the initial shear and normal stress in dependence of $\Delta \sigma$ for a fault plane with orientation $\phi$ :

$$
\begin{aligned}
\tau^{0} & =\Delta \sigma \sin (2 \phi) \\
\sigma_{n}^{0} & =\sigma_{2}-\Delta \sigma \cos (2 \phi) .
\end{aligned}
$$

For given static and dynamic friction coefficient $\mu_{s}$ and $\mu_{d}$, and given frictional cohesion $c$, the relative pre-stress $R$-ratio (Aochi \& Madariaga, 2003) is defined as the fault stress drop $\Delta \tau$ over breakdown strength drop $\Delta \tau_{b}$ :

$$
R=\frac{\Delta \tau}{\Delta \tau_{b}}=\frac{\tau^{0}-\mu_{d} \sigma_{n}^{0}}{c+\mu_{s} \sigma_{n}^{0}-\mu_{d} \sigma_{n}^{0}} .
$$

By inserting $\tau^{0}$ and $\sigma_{n}^{0}$ from eq. 2 into eq. 3 we obtain $\Delta \sigma$ and hence the magnitude of the horizontal principal stresses $\sigma_{1}$ and $\sigma_{3}$. Note that it is particularly important to determine the horizontal principal stress amplitudes such that the stress field is most favorably oriented at the hypocenter (Ulrich et al., 2019), ensuring that the thus optimally oriented fault plane reaches failure before any other fault with different orientation.

The relative level of initial stress has been found to determine rupture style and rupture properties (e.g., Dunham, 2007; Gabriel et al., 2012, 2013). The described $R$ ratio is related to the commonly used $S$ value (e.g., Das \& Aki, 1977) as $S=1 / R-1$. In our simulations, we assume $R=0.65$ which leads to a potential stress drop of $65 \%$ of the breakdown strength drop across the entire fault. Numerical experiments, testing $R$-ratios in the range of $0.5<R<0.9$ and different horizontal stress orientations as 
described below, reveal that $R=0.65$ optimally balances reasonable values of rupture speed and final slip while sustaining rupture across all fault segments by facilitating rupture transfers.

The chosen $R$ value corresponds to a low $S$ value of 0.54 value indicating a rather weak fault. We note, that geometric complexity, the 3D Earth model and partially viscoelasto-plasticity prevent the occurrence of sustained supershear rupture in our preferred scenario. Conditions of apparent fault weakness were recently found to promote rupture cascading in dynamic rupture models along complex faults (Ulrich et al., 2019).

In terms of horizontal stress orientations, the state of stress governing the Landers main shock is only incompletely known due to limited direct measurements of crustal stress in the Mojave block of the Eastern California Shear Zone. The region is characterized by north-west trending strike-slip faulting and a principal stress orientation of approximately $\mathrm{N} 20^{\circ} \mathrm{E}$ (Nur et al., 1989; Hauksson, 1994). The Mojave block can be subdivided into several distinct domains based on geometry and faulting style of tectonic activity (e.g., Dokka \& Travis, 1990; Unruh et al., 1994). While the central and northern part of the fault system (i.e. HVF, EF and CRF) belongs to the central Mojave block, Unruh et al. (1994) suggest that the JVF forms the eastern boundary of a distinct domain around the San Bernardino Mountains characterized by more north-striking strike slip faults.

To understand the details of the dynamic rupture process, the principal stress orientations across the Landers fault system are particularly important. Focal-mechanism analysis of the 1975 Galway and the 1979 Homestead Valley earthquakes, as well as of background seismicity prior to the 1992 Landers main shock, yields a maximum principal stress angle of $38^{\circ}$ to $16^{\circ} \mathrm{NE}$ (Hauksson, 1994). That is, the inferred principal stress directions slightly rotate northwards up to the EF.

While background seismicity is mainly observed in the southern part of the fault system, little is known about the stress state prior the Landers earthquake of the northernmost segments (Hauksson et al., 1993). On the northern Landers fault system, an even steeper oriented maximum principal stress might be plausible, given the locally considerable higher maximum shear-strain orientation compared to the southern fault segments (Sauber et al., 1986). Aochi and Fukuyama (2002) hypothesize a northern rotation to steep angles based on the dynamically locked CRF in their simulations assuming a maximum principal stress orientation of $\mathrm{N} 22^{\circ} \mathrm{E}$. A steep angle of $11^{\circ} \mathrm{NE}$ enabled full dynamic rupture also of the northernmost segments under a non-rotating, depth-dependent background stress (Heinecke et al., 2014; Wollherr et al., 2018).

In this study, we allow for smoothly varying directions of maximum principal stress, consistent with regional stress estimates (summarized in Fig. 1), without any small-scale or randomized heterogeneities. The following model parameters are obtained by the model validation steps detailed at the beginning of Sec. 2. We find that in particular sustained rupture along and dynamic transfers in between fault segments provide strong constraints on the horizontal stress field orientation.

We find that it is optimal in our approach to assume that the southern part of the fault system is contained in the San Bernardino Mountains domain (Aochi \& Fukuyama, 2002; Unruh et al., 1994), whereas all other fault segments are considered part of the central Mojave block. Therefore, in the south we prescribe a maximum principal stress orientation of $\mathrm{N} 33^{\circ} \mathrm{E}$ governing the JVF and KF. The maximum principal stress orientation changes to $20^{\circ}$ between the KF and the HVF (Hauksson, 1994). We then smoothly decrease the principal stress direction northwards from $\mathrm{N} 20^{\circ} \mathrm{E}$ at the $\mathrm{HVF}$, consistent with the observed stress rotation postulated by Hauksson (1994).

We perform several numerical experiments varying the principal stress orientation governing the CRF. We find that the CRF is unfavorably orientated under any angle be- 
tween $15^{\circ}$ and $38^{\circ}$. However, this segment ruptured with a substantial amount of slip (Kaneda \& Rockwell, 2009). Sustained rupture across the EF and CRF occurs in our model under a locally low angle of maximum principal stress orientation of $11^{\circ}$, consistent with previous static and dynamic modeling studies of the full or southern-central fault system (Madden et al., 2013; Heinecke et al., 2014; Wollherr et al., 2018).

While the prescribed stress field orientation is laterally smooth, the varying fault strike orientation generates a heterogeneous initial stress state across all fault segments, leading to both favorably and misaligned portions of the fault system. The Kickapoo branch and the northern part of the HVF are the most favorably orientated segments. In contrast, the northernmost part of JVF, as well as the northernmost and southernmost parts of the EF and CRF are not well aligned with respect to the regional principal stress orientation. As a consequence, these fault segments experience only marginal or no slip (see Sec. 3.2).

\subsection{Frictional Properties}

All frictional parameters are chosen constant across the fault system. Exceptions are the nucleation zone and the northernmost part of the fault system, where we account for palaeoseismological evidence.

Based on theoretical and numerical models of shear crack propagation (e.g., Ida, 1972) we use linear slip-weakening friction. We choose a static friction coefficient $\mu_{s}=$ 0.55 close to Byerlee's coefficient consistent with regional stress inversions (Gross \& Kisslinger, 1997). Under linear slip-weakening friction, high stress drop is required to facilitate rupture transition between distinct fault segments. We find that a dynamic coefficient of friction of $\mu_{d}=0.22$ facilitates rupture cascading. Frictional cohesion $c$ is set to $2 \mathrm{MPa}$ for the entire fault system. Note, that we here refer to frictional cohesion as the cohesive forces acting across the two sides of the fault discontinuity. In contrast, bulk cohesion as defined in Sec. 2.4 describes the cohesional material properties of the host rock. The resulting average stress drop over all slip regions is approximately $12.5 \mathrm{MPa}$ with a maximum stress drop of $33 \mathrm{MPa}$ at $8 \mathrm{~km}$ depth. Surprisingly high stress drops were found for the Landers earthquake from energy to moment rate ratios (Kanamori et al. 1992; Sieh et al., 1993), also in agreement with stress-drop estimates based on a kinematic source models (Bouchon \& Campillo, 1998).

We observe a strong trade-off between rupture speed and critical slip distance where $D_{c}$ denotes the amount of slip over which friction drops from $\mu_{s}$ to $\mu_{d}$. The critical slip distance also affects rupture transitions by determining a critical nucleation size required to initiate spontaneous rupture via dynamic triggering. Step 4 of our modeling workflow reveals that $D_{c}=0.62 \mathrm{~m}$ ensures a balance of efficient rupture transfer between adjacent faults (in accordance with the moment rate release) and the prevention of pronounced supershear rupture.

While previous dynamic rupture simulations of the Landers earthquake choose $D_{c}$ in the range of $0.8 \mathrm{~m}$ (Olsen, 1997; Peyrat et al., 2001), we find that lower $D_{c}$ is required to sustain rupture across the geometrically complex fault system. Besides geometric effects, a lower $D_{c}$ can be attributed to the effect of off-fault plasticity (Roten et al., 2017; Wollherr et al., 2018).

Paleoseismological evidences point to a large event occurring at the EF and CRF approximately 2000-3000 years ago, while the southern part of the fault system has not failed for 8000-9000 years (Sieh, 1996). This suggests locally lower fault strengths due to not yet recovered static friction or lower regional stresses due to the more recent stress release. While we choose a constant stress ratio across the entire fault zone, we locally decrease fault strength by choosing $\mu_{s}=0.44$ instead of 0.55 at the EF and the CRF segments. Our simulations reveal that slightly weakening the CRF and EF is important 
to facilitate dynamically triggered rupture initiation on these segments which also helps to match the observationally inferred seismic moment rate (step 4 of our modeling workflow).

Rupture in the numerical simulations is initiated using a circular nucleation patch of $1.5 \mathrm{~km}$ radius. Within this zone, the friction coefficient is gradually reduced from its static to its dynamic value over a specified time of $0.5 \mathrm{~s}$ (Bizzarri, 2010). Outside this zone, forced rupture is smoothly overtaken by spontaneous rupture. The hypocentral depth is set to $7 \mathrm{~km}$ as constrained by source inversion (Wald \& Heaton, 1994; Cotton \& Campillo, 1995; Hernandez et al., 1999).

At depth, we account for the transition from the brittle to ductile regime between $-9 \mathrm{~km}$ to $-15 \mathrm{~km}$. We linearly increase dynamic friction gradually up to static friction values which allows rupture to stop smoothly. By increasing fault strength instead of prestress with depth we ensure off- and on-fault stresses are equal which is necessary when accounting for off-fault plasticity.

\subsection{Bulk Properties and Plasticity}

Our model incorporates the 3D velocity structure of the Community Velocity ModelHarvard (CVM-H, version 15.1.0, Shaw et al. (2015), available at hypocenter.usc.edu/ research/cvmh/15.1.0/cvmh-15.1.0.tar.gz), visualized in Fig. 2. Velocity and density information are efficiently mapped onto the parallelized computational mesh using the geoinformation server ASAGI (Rettenberger et al., 2016). The lowest shear-wave velocities $v_{s}(\mathrm{~m} / \mathrm{s})$ of the domain and across the fault determine the wave field resolution reached in the simulation. Shear-wave velocities range from $320 \mathrm{~m} / \mathrm{s}$ to $4500 \mathrm{~m} / \mathrm{s}$ in the sedimentary basin around the Salton sea. At the fault, shear-wave velocities are $2800 \mathrm{~m} / \mathrm{s}$ at shallow depths, and do not exceed $3500 \mathrm{~m} / \mathrm{s}$ at the bottom of the fault, determining the upper bound for subshear rupture speeds. Besides the low-velocity basins at the Salton sea and at the San Bernardino basin (minimum wave speed of $680 \mathrm{~m} / \mathrm{s}$ ) the lowest wave speeds within the high resolution model domain is $900 \mathrm{~m} / \mathrm{s}$. The simulation employs viscoelastic rheologies to model intrinsic attenuation (Uphoff \& Bader, 2016). We couple $Q$ to the velocity model by using $Q_{s}=50.0 v_{s}$ and $Q_{p}=2 Q_{s}$ following commonly used parametrization (Graves et al., 2008). We discuss the effect of attenuation on dynamically triggered rupture in detail in Sec. 4.4.

Additionally, our model uses a computationally efficient implementation of DruckerPrager off-fault plasticity (Wollherr et al., 2018). To this end, a domain-wide initialization of initial stresses, cohesion and friction of the bulk (underlying rock) is required, which we base on regional observations from the Landers fault zone area. Here, equivalent initial on- and off-fault stresses are assumed, accounting for the smooth principal stress rotation between the San Bernardino Mountain Domain and the Central Mojave block. Cohesion differs for different rock types, and also depends on depth and the respective damage level of the host rock. In the Landers region, the main near-surface rock type is granodiorite (Dibblee, 1967). Correspondingly, we assume a relatively undamaged granitetype rock, described as "good quality rock" in Roten et al. (2017)) who use a Hoek-Brown model to constrain cohesion values for a given rock type and damage level. We therefore define a depth-dependent parametrization of cohesion, ranging from $c=2.5 \mathrm{MPa}$ at the surface to $c=30 \mathrm{MPa}$ at $6 \mathrm{~km}$ depth and $c=50 \mathrm{MPa}$ at $14 \mathrm{~km}$ depth. While cohesion depends on depth, bulk friction is assumed constant in the entire model domain. We set bulk friction everywhere as equal to 0.55 , resembling static friction of most fault segments. While the static friction coefficient of the northern segments is reduced (see previous section), we assume that off-fault rock properties are not considerably altered by paleoseismological events. 
In case of plastic yielding, plastic strain at time $t$ can be mapped into the scalar quantity $\eta(t)$ (Fig. 10) following Ma (2008):

$$
\eta(t)=\int_{0}^{t} d \eta=\int_{0}^{t} \sqrt{\frac{1}{2} \dot{\epsilon}_{i j}^{p} \dot{\epsilon}_{i j}^{p}} .
$$

with $\epsilon_{i j}^{p}$ being the inelastic strain rate.

\subsection{Numerical Method}

We use the open-source software package SeisSol (www.seissol.org; freely available at github.com/SeisSol/SeisSol) to conduct large-scale dynamic rupture simulations of the 1992 Landers earthquake. SeisSol is based on an Arbitrary high order DERivativeDiscontinuous Galerkin (ADER-DG) approach of high-order accuracy in space and time (Käser \& Dumbser, 2006; Dumbser \& Käser, 2006). SeisSol solves the non-linear problem of spontaneous frictional failure on prescribed fault surfaces coupled to seismic wave propagation (De la Puente et al., 2009; Pelties et al., 2012). It allows to precisely model seismic waves traveling over large distances in terms of propagated wavelengths with minimal dispersion errors (Käser et al., 2008) and features fully adaptive, unstructured tetrahedral grids that allow for complicated geometries and for rapid mesh generation (Wenk et al., 2013).

SeisSol is verified in community benchmarks addressing a wide range of dynamic rupture problems including: branched and curved faults, dipping faults, laboratory derived friction laws, and on-fault heterogeneities. (Pelties et al., 2014; R. A. Harris et al., 2018). End-to-end optimization (Breuer et al., 2014; Heinecke et al., 2014; Breuer et al., 2015, 2016; Rettenberger \& Bader, 2015; Rettenberger et al., 2016; Uphoff \& Bader, 2019) targeting high efficiency on high-performance computing infrastructure includes a tenfold speedup by an efficient local time-stepping algorithm (Uphoff et al., 2017). Viscoelastic rheologies are incorporated using an offline code-generator to compute matrix products in a computationally highly efficient way. This poses an increase in computational cost of a factor of only 1.8 in comparison to a purely elastic model (of $\mathcal{O} 6$ ) while resolving the full memory variables (Uphoff \& Bader, 2016). Similarly, the off-line code generator is used for incorporating off-fault plasticity within a nodal basis approach (Wollherr et al., 2018). The computational overhead of off-fault plasticity falls in the range of $4.5 \%$ - $13.1 \%$ dependent on the number of elements that yield plastically and the polynomial degree of the basis functions. This relatively minor increase of costs enables the use of realistic material properties for large-scale scenarios - and we demonstrate the considerable affects of both, viscoelastic attenuation and off-fault plastic yielding on rupture dynamics and ground motion synthetics in Sec. 4.

The structural model in Universal Transverse Mercator (UTM) coordinates is created with GoCad (Emerson Paradigm Holding, 2018) and discretized using the meshing software Simmodeler (Simmetrix Inc., 2017) to generate a mesh consisting of 20 million elements. For all presented simulations we use a spatio-temporal discretization of polynomial degree $p=4(\mathcal{O} 5)$. The models accounting for off-fault plasticity and attenuation run for $6: 53 \mathrm{~h}$ on 525 nodes on supermuc phase 1 . Note, that the computational costs are higher in comparison to previously presented scenarios (Wollherr et al., 2018) for a similar mesh size due to the additional costs of viscoelastic damping and a higher order of accuracy. 


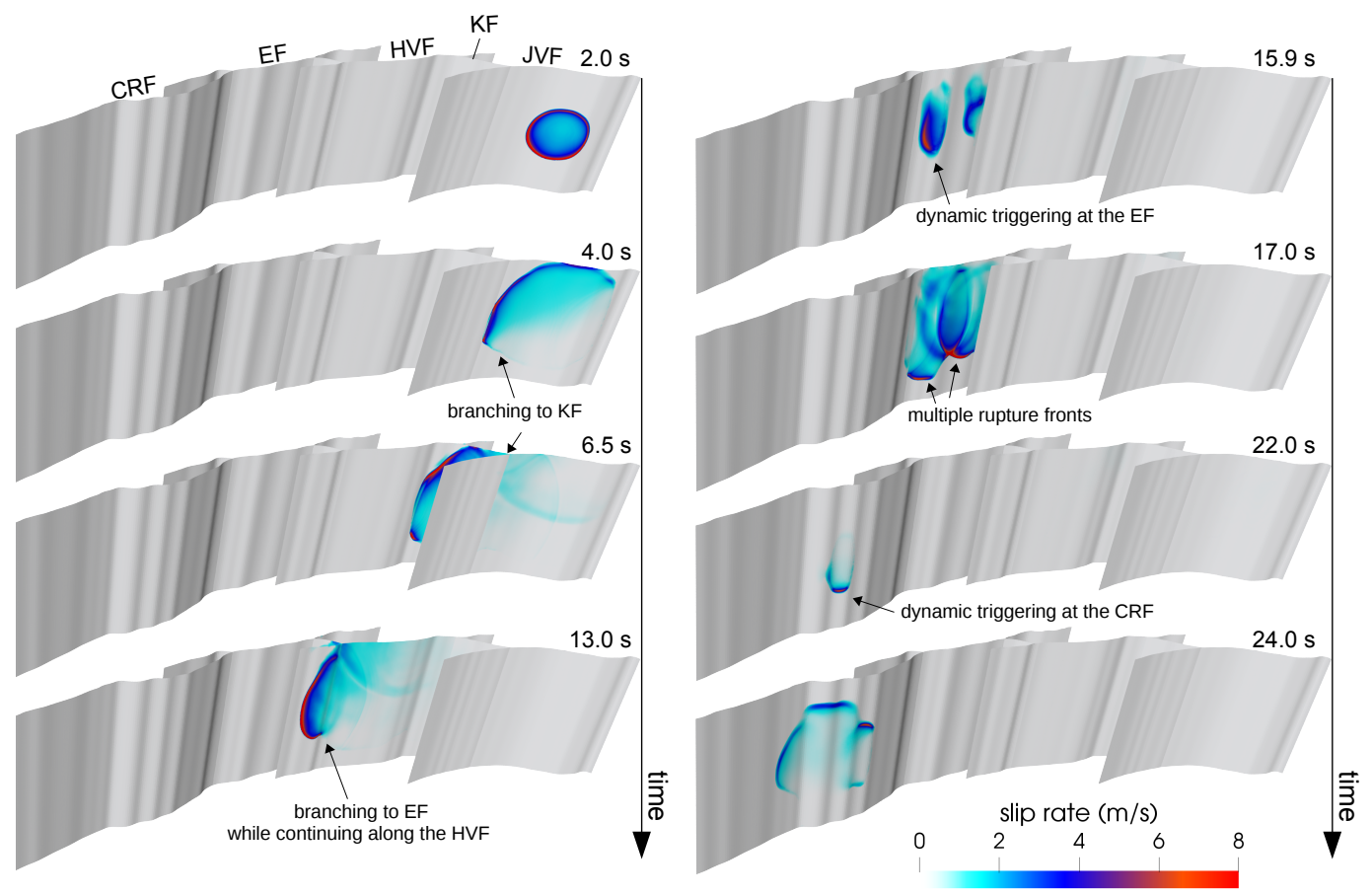

Figure 3. Slip rate across the fault system at selected rupture times illustrating dynamic rupture evolution and complexity. Rupture successively cascades by direct branching and dynamic triggering.

\section{Results}

In the following, we present a fully $3 \mathrm{D}$ dynamic rupture model combining complex fault geometries and off-fault plastic yielding with realistic rheology, viscoelastic attenuation and 3D subsurface structure. Our preferred model reproduces regional (moment release, waveforms and peak ground velocities) and near-fault (slip distribution, shallow slip deficit, fault zone damage) observations. The model captures dynamic rupture transfers between fault segments and helps our understanding of the activation of fault branches and the potential for dynamic triggering of adjacent fault segments.

\subsection{Rupture Dynamics}

In our dynamic model rupture propagates spontaneously across five fault segments and successively cascades by direct branching and dynamic triggering. The evolution of slip-rate across the fault segments at selected time steps is visualized in Fig. 3. Two additional views focusing on the KF and the branch between the HVF and the EF and a high-resolution animation are provided in the supporting information (Figs. S2 and S3, Movie S1).

Our simulation features very complex rupture propagation patterns. In particular: i) we observe a variety of rupture transfer mechanisms between fault segments: direct branching, jumping by dynamic triggering, or combination of both, in forward and reverse direction; ii) we find that dynamically triggered rupture transfer is crucial to en- 
able sustained rupture across the entire fault system; iii) multiple rupture fronts exist at certain times that may propagate in opposite directions, and iv) rupture speed is highly variable in correlation with the fault geometry, its orientation with respect to the prestress and rupture transfers.

In the following we describe in detail the source dynamics in terms of rupture propagation through the complex fault system. Rupture smoothly nucleates within the first $0.6 \mathrm{~s}$ and then spontaneously propagates across the southern part of the Johnson Valley fault segment (JVF). At the fault intersection with the Kickapoo fault (KF), we observe complete rupture transfer by direct branching at high rupture speed at $4 \mathrm{~s}$.

After completely rupturing the KF, slip on the Homestead Valley Fault (HVF) is initiated. However, the pronounced fault bend at the fault intersection nearly stops rupture after approximately $6.5 \mathrm{~s}$ rupture time creating localized small slip patches at shallow depths at its northern part. After a delay of almost $1 \mathrm{~s}$, rupture re-initiates at a depth of $7-8 \mathrm{~km}$ and continues breaking across the full northern extend of the HVF.

At around $11.9 \mathrm{~s}$, rupture is delayed upon branching into the small fault segment connecting the HVF and the Emerson fault (EF). In distinction to the Kickapoo branching, rupture here also continues along its original branch until it is stopped by the boundary of the HVF segment. The EF is first activated at shallow depth by dynamic triggering from waves originating directly from the HVF which eventually dies out. Rupture is activated for a second time just a few seconds later at depth of $6 \mathrm{~km}$, while a slower propagating rupture front arrives after direct branching via the connecting segment. As a consequence, we observe multiple rupture fronts and reversely (towards the south) propagating rupture, as well as repeated slip of the KF. Parts of the HVF and the KF are dynamically re-activated due to the backward propagating rupture when multiple rupture fronts at the EF meet.

After $22.3 \mathrm{~s}$ rupture time, the CRF is dynamically activated at a depth of $8 \mathrm{~km}$ by the superimposed wave field of the preceding failure of the northern part of the HVF $(16 \mathrm{~km}$ from the triggered part of the CRF) and the EF ( $9 \mathrm{~km}$ from the triggered part at the CRF). Note that rupture along the EF and HVF already arrested at that time. Rupture propagates with a strong up-dip component across the central part of the CRF, and then dies out shortly after reaching the surface. Fault slip completely arrests after $30 \mathrm{~s}$ of rupture time.

Our model allows to clearly distinguish between rupture branching and rupture (re)nucleation by dynamic triggering. Rupture continues along secondary fault segments (branches) whenever these are more favorably orientated than the main fault segment. We observe rupture branching twice: between the JVF, KF and HVF and between the $\mathrm{HVF}$ and the EF. In the first case, the optimal orientation of KF towards the background stress field favors rupture propagation. Thus, rupture completely stops at the JVF and instead follows the KF branch. For the second branching transfer (between the HVF and $\mathrm{EF}$ ), the connecting branch is less favorably oriented. Rupture only partially follows the branch while also continuing along the originating fault segment (HVF).

Dynamic stresses propagate like seismic waves from rupturing fault segments towards locked parts of the fault system, eventually nucleating rupture without requiring the direct arrival of a rupture front. Note that the main rupture front is unable to overcome the geometrical barrier between the EF and the CRF. However, unlike previous dynamic rupture scenarios, our model succeeds in rupturing the CRF by dynamic triggering. This is facilitated by a steep angle of principal stress direction governing the northern fault system, a reduced fault strength, and in particular the emitted seismic waves from the almost simultaneous failure of the northern part of the HVF and the EF. The stress changes due to failure of both fault segments are high enough to trigger fault slip over a distance of $9 \mathrm{~km}$ (from the EF) and $15 \mathrm{~km}$ (from the HVF). The abrupt decel- 
eration of rupture between the KF and HVF additionally triggers small patches of shallow slip at the HVF, but also at the most southern part of the EF, which eventually die out (at around 7.9-9.5s).

Rupture speed $v_{r}$ is highly variable across the fault system. On average, we find $v_{r} \approx 2300 \mathrm{~m} / \mathrm{s}$ consistent with earlier studies (Wald \& Heaton, 1994; Hernandez et al., 1999). Rupture accelerates and decelerates in relation to changes of fault orientation and rupture transfers to adjacent segments. We observe very slow local rupture speeds at geometrical barriers, such as $v_{r}=1200 \mathrm{~m} / \mathrm{s}$ at the transition from the KF to the HVF, and again when rupture reaches the EF.

Supershear transitions are rarely observed in nature, but due to the low resolution of the data it remains still unclear if small supershear patches may occur locally. Small patches of supershear rupture are locally induced in our model at shallow depths. Specifically, we observe supershear due to the interaction of the rupture front with the free surface at the KF and at the HVF, as in previous dynamic rupture models (Olsen, 1997; Peyrat et al., 2001). Additionally, branching triggers local supershear episodes (cf. the JVF-KF branching at approximately $5.6 \mathrm{~s}$ rupture time). While localized supershear rupture propagation is not directly enabling rupture transfers, we find that high rupture speeds along the KF facilitate rupture overcoming the fault bend of the HVF.

Rupture termination, and the potential resultant generation of stopping phases, is of specific interest when analyzing rupture in complex, multi-segment fault systems (D. Oglesby, 2008). From a geological point of view, it was a surprising observation to find that the northern part of the JVF did not slip (e.g. Rockwell et al., 2000). Our dynamic rupture model provides a consistent explanation for spontaneous rupture termination on most of the principal fault segments, although fault structures in reality continue.

Rupture termination in our model is overall independent of the prescribed geometric fault endings, except for the northernmost section of the HVF where rupture is stopped at the fault-segment edge. The resulting increase in plastic strain correlates well with the observed increase in damage at this location, as described in Sec. 3.6. In all other cases, rupture is spontaneously stopped due to local fault geometry in conjuncture with the local principal stress orientation: First, rupture is smoothly stopped at the first fault segment in backward direction by the change of fault orientation at the most southern part of the JVF. Second, rupture completely follows the Kickapoo branch, not rupturing the northern part of the JVF. Additionally, rupture only initiates in the central part of the CRF and smoothly dies out towards the southern and northern part of the fault. These results are consistent with the rupture termination analysis by Sieh (1996) (their Fig. 8 ).

\subsection{Slip Distribution}

Numerous studies estimated the on-fault slip distribution of the Landers earthquake (e.g., Campillo \& Archuleta, 1993; Wald \& Heaton, 1994; Cohee \& Beroza, 1994; Cotton \& Campillo, 1995; Fialko, 2004b; Milliner et al., 2015; Gombert et al., 2018). While theses studies are based on different source inversion approaches and datasets, they overall agree that the largest slip is encountered on the HVF. However, the inferred slip distributions also reveal a large degree of non-uniqueness owing to inherent difficulties in finite-fault slip inversion and the resulting variations in slip models (Mai et al., 2016).

The accumulated slip of our simulation is visualized in Fig. 4. Additional views, in particular to the fault branches and the northern and southern part of the EF, are included in Fig. S4 of the supporting information. Fault slip is distributed over the southern part of the JVF, the KF, the central and northern part of the HVF, the central EF, and the central part of the CRF. Slip below 1-2 $\mathrm{m}$ is observed at the southern HVF, and 


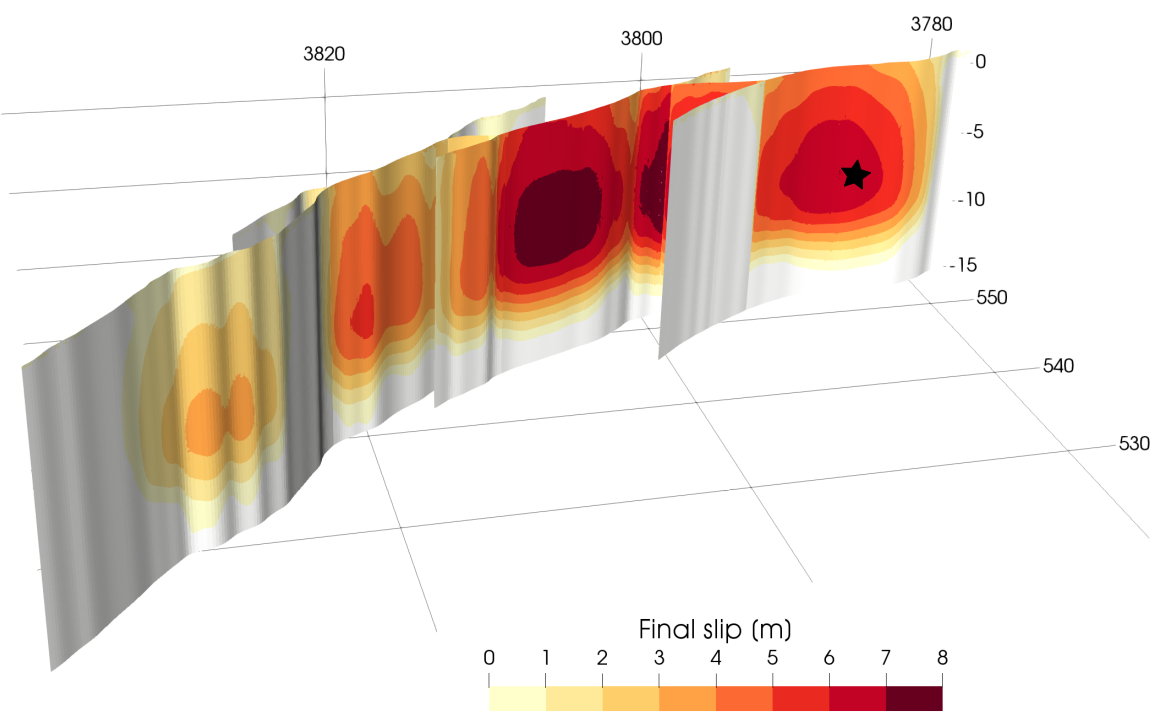

Figure 4. Distribution of total accumulated slip for the preferred dynamic rupture scenario after $100 \mathrm{~s}$ simulation time. Coordinate axis are in UTM coordinates $(\mathrm{km})$. The star marks the hypocenter at depth of $-7 \mathrm{~km}$.

also at the most southern and northern part of the EF where rupture is triggered dynamically. The northern part of the JVF is not ruptured in our simulation.

For all fault segments, slip at depth $(5-10 \mathrm{~km})$ is always larger than at depths less than $5 \mathrm{~km}$. Slip peaks at $7 \mathrm{~m}$ located at $5.5 \mathrm{~km}$ depth of the central HVF in the vicinity to the KF branching point. At this location, the fault abruptly changes its orientation, forming a geometrical barrier that decelerates the rupture while simultaneously accumulating slip.

In the northern part of the fault system the modeled co-seismic slip is at odds with observations. Near-surface slip on the CRF does not exceed $0.5 \mathrm{~m}$ in our simulation, while slip at depth reaches up to $4 \mathrm{~m}$. In contrast, the imaged CRF slip values are high at shallow depth (Sieh et al., 1993; Wald \& Heaton, 1994). However, Sieh (1996) and Kaneda and Rockwell (2009) suggest that the CRF might have slipped as a consequence of static stress changes shortly after the main event. We discuss this hypothesis with respect to our simulation results in Sec. 4.5.

\subsection{Seismic Moment Rate}

The Landers earthquake was the largest earthquake in the contiguous United States in 40 years. The total seismic moment has been inferred between $6.0 \mathrm{e}+19-16.0 \mathrm{e}+19 \mathrm{Nm}$ (moment magnitude $M_{w}$ 7.15-7.4) (Kanamori et al., 1992; Campillo \& Archuleta, 1993; Sieh et al., 1993; Wald \& Heaton, 1994; Dreger, 1994; Cohee \& Beroza, 1994; Vallée \& Douet, 2016). The seismic moment of our dynamic rupture scenario equals $M_{0}=11.2 \mathrm{e}+19$ $\mathrm{Nm}\left(M_{w} 7.29\right)$, in excellent agreement with previous estimates from kinematic models and geological studies.

The multi-segment character of the event reflects on the moment release over time. Most previous studies divide it into two major subevents (Campillo \& Archuleta, 1993; Dreger, 1994; Cohee \& Beroza, 1994), postulating that slip on the JVF and KF released 


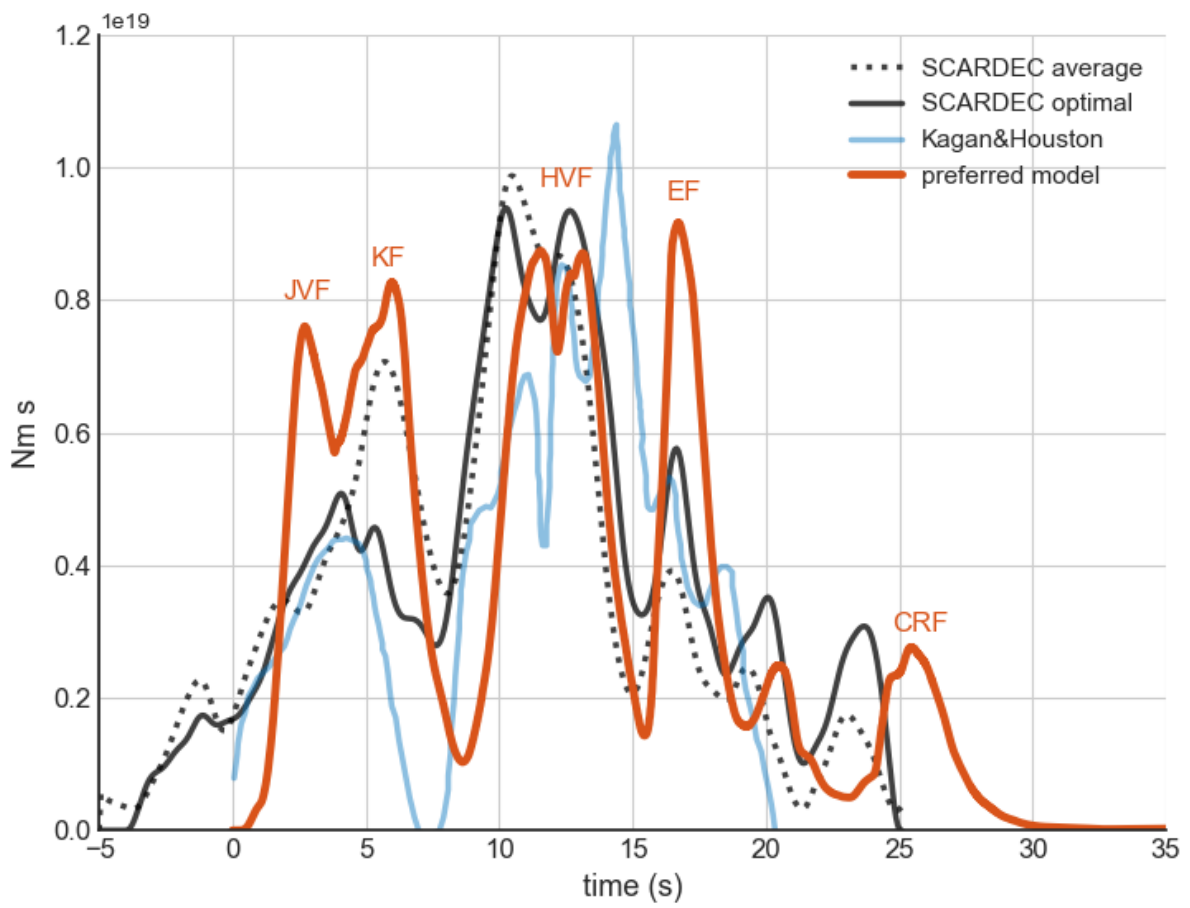

Figure 5. Seismic moment release over time. Our preferred dynamic rupture model (orange) compared to the optimal and average moment rate of the SCARDEC database (in black and dotted light gray, Vallée and Douet (2016)) and moment rate based on the surface slip (in light blue,Kagan and Houston (2005)). The time line is taken from our simulation, the SCARDEC solutions are shifted by $-5 \mathrm{~s}$ accordingly to match the main moment rate peaks as described in the main text. 
approximately $20-25 \%$ of the total seismic moment, while the northern part of the fault system, including the JVF, the EF and CRF, released approximately $75-80 \%$.

Fig. 5 compares the moment release over time from our dynamic rupture simulation to three observationally inferred moment rate functions. The seismic moment at each time step of our simulation is determined by spatial summation of the element-local seismic moment $\left(M_{0}=\mu \times\right.$ slip $\times$ area $)$ calculated for each triangular element interface discretizing the fault surfaces. The optimal and average seismic moment rate provided by the SCARDEC database (last accessed May 2018) are retrieved from teleseismic body waves (Vallée and Douet (2016), gray dotted and black solid lines in Fig. 5). The duration of these source time functions (STFs) exceeds the measured rupture duration of the Landers earthquake (e.g., Dreger, 1994; Wald \& Heaton, 1994). The extended apparent duration of the SCARDEC dataset might be explained by the inclusion of P-wave coda signals (Vallée \& Douet, 2016). Correspondingly, we truncate the duration of the seismic moment rate function such that it matches with other independent studies (Kanamori et al. (1992) or (Campillo \& Archuleta, 1993)), i.e. the average moment rate is cut after $32.9 \mathrm{~s}$ and the optimal moment rate after $27.5 \mathrm{~s}$. We discuss the uncertainties associated with STFs in Sec. 4.6. The source time function published by Kagan and Houston (2005) (blue line in Fig. 5) is based on the surface slip distribution derived by Dreger (1994). Assuming a constant rupture velocity of $2.9 \mathrm{~km} / \mathrm{s}$ as determined by Dreger (1994) and that the seismic moment along strike is the same at all depths, the estimated peak moment amplitudes and the surface slip distribution along strike of Dreger (1994) were translated into a moment-rate function over time in Kagan and Houston (2005). Since it is based on the surface slip, the inferred moment rate might fail to capture the full variability of the seismic moment over time but complements the STFs retrieved from teleseismic data.

Note that we use the onset of dynamic rupture in our simulation as reference point in time, and shift the moment rate of the SCARDEC solution by $5 \mathrm{~s}$ to match the main moment rate peaks. All moment rate functions of Fig. 5 are available in the supporting material. The seismic moment rate of our simulation reproduces the major momentrate peaks of the SCARDEC solution. The first is associated with rupture of the JVF and KF within the first $7 \mathrm{~s}$. The next peak between $7 \mathrm{~s}$ and $15 \mathrm{~s}$ corresponds to the failure of the HVF releasing the largest individual contribution to overall seismic moment. Subsequently, we reproduce several distinct local peaks after $15 \mathrm{~s}$ that we associate with the cascading rupture of the individual northernmost fault segments (e.g. the EF and $\mathrm{CRF}$ ).

Pronounced delays of moment release in observations as well as our simulation may be correlated with rupture transferring between fault segments. Specifically, dynamic triggering (rupture jumping) has been associated with the observed segmentation of moment release. However, our dynamic rupture model reveals that dynamic triggering is not the only factor reducing the moment release significantly. Specifically, rupture deceleration due to fault geometry strongly affects the moment release, thus complicating the inference of rupture transfers from observations.

Rupture propagation along the HVF (at $\approx 7 \mathrm{~s}$ ) is delayed by $\approx 0.5-1.0 \mathrm{~s}$, in the SCARDEC solutions as well as our simulation result. The moment rate provided by Kagan and Houston (2005) even accounts for a delay of 2.0-2.5 s and a complete stop of moment release, which may correspond to the observed slip gap near the surface (Spotila \& Sieh, 1995). Previous studies interpret this delay of rupture propagation as an indication of rupture jumping from the KF to the HVF(e.g., Campillo \& Archuleta, 1993). However, our simulation suggests that this delay rather corresponds to a slow rupture propagation after the branching between the KF and the HVF. Rupture encounters a pronounced fault bend at the center of the HVF and is dynamically slowed down. Rupture re-initiating is then potentially facilitated by arriving seismic waves from the failure of previous segments as discussed in Sec. 4.4. 


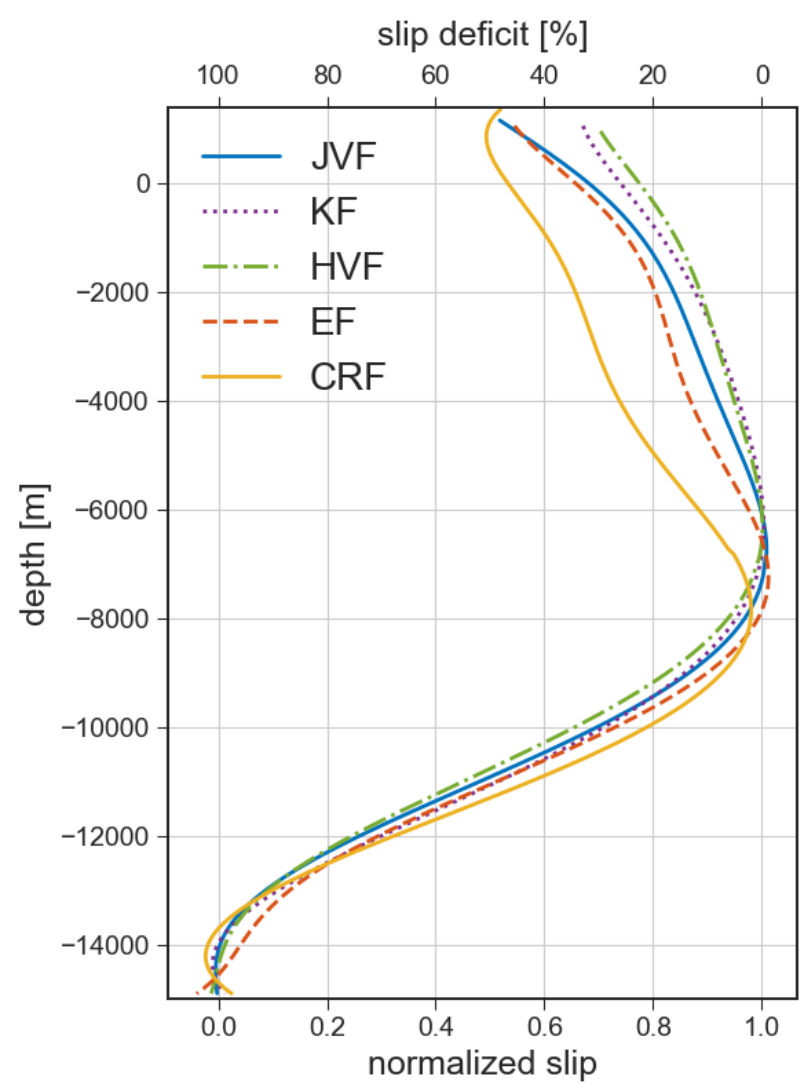

Figure 6. Slip, normalized by each segment's maximum (bottom axis) and corresponding shallow slip deficit (top axis) for each fault segment in dependence of fault depth for our preferred Landers simulation. Each line represents the average over the corresponding fault segment.

The most prominent differences in the moment rate functions are found in the early rupture stage. In addition, our scenario overestimates the moment release at $17 \mathrm{~s}$ (rupture of the EF) with respect to the SCARDEC solution. However, this high moment rate release at the EF could be related to the highest peak of the moment rate of Kagan and Houston (2005) at $14 \mathrm{~s}$. On the other hand, peak moment rates are underestimated around 10 and $15 \mathrm{~s}$ (rupture of the HVF and the connecting branch between the HVF and EF). We further discuss these discrepancies in dependence of the model assumptions and artificial nucleation procedure in Sec. 4.1.

\subsection{The Shallow Slip Deficit and Stress Drop}

In this section we investigate the shallow slip deficit (SSD) - the reduction of shallow slip relative to slip at depth - in our simulation. The SSD is frequently observed in geodetic slip inversions for major strike-slip earthquakes, including the 1992 Landers event (e.g., Fialko, 2004b; Milliner et al., 2015). We show that an along-strike variability of the SSD is possible, even for laterally constant rock cohesion and bulk friction.

The SSD of the Landers earthquake is estimated to be $30-60 \%$ (e.g., Cohee \& Beroza, 1994; Fialko, 2004b; Milliner et al., 2015). Recent coseismic slip models derived by a Bayesian approach suggest that the overall SSD for the Landers event is about $40 \%$, but might vary between fault segments (Gombert et al., 2018). 
The origin of the SSD is still under debate. While Xu et al. (2016) argue that the majority of inferred SSD is a result of poor resolution of near-fault surface data in slip inversions, it is often attributed to coseismically occurring plastic deformation at shallow depths (e.g., Kaneko \& Fialko, 2011; Milliner et al., 2015). Numerical models show that shallow slip is already reduced by $18.6 \%$ in simulations with purely elastic material properties (supplemental material of Roten et al., 2017). The SSD in their simulations is further increased when accounting for off-fault plasticity, but depends on the underlying bulk cohesion model (higher SSD with lower rock quality). The modeled SSD on a non-planar yet single fault plane model of the Landers system ranges between $42.9 \%$ (good quality rock) and 28.0\% (high quality rock) (Roten et al., 2017), consistent with slip inversion results.

Let us compare the resulting slip distribution of our dynamic rupture model (on a segmented fault system and including off-fault plasticity) to inversion results of Gombert et al. (2018) and to numerical simulations on a single planar fault plane (Roten et al., 2017). Recall from Sec. 2.4 that all material properties that influence off-fault plasticity, such as bulk cohesion and bulk friction, are constant along strike.

Fig. 6 shows normalized slip (bottom axis) and corresponding SSD (top axis) of our simulation. The corresponding SSD quantifies the slip reduction within the first $100 \mathrm{~m}$ from the surface with respect to the maximum slip, similar to the definition of Roten et al. (2017). We therefore calculate the mean slip across each fault segment within intervals of $100 \mathrm{~m}$ depth, considering only slip higher than $0.1 \mathrm{~m}$, and then normalize it by the segment's maximum mean slip. The maximum mean slip is $5.62 \mathrm{~m}, 6.65 \mathrm{~m}, 5.46 \mathrm{~m}$, $4.13 \mathrm{~m}$, and $2.34 \mathrm{~m}$ for the JVF, KF, HVF and for the CRF, respectively. Note that the SSD functions for different fault segments start at slightly different depths since the fault surfaces intersect with the changing topography.

Our derived SSDs vary between $29.6 \%$ and $48.2 \%$, with an average SSD of $40.8 \%$. The highest SSD is found at the JVF $(48.2 \%)$ and at the CRF (48.0\%). An SSD of around $30 \%$ is found at the HVF while the KF depict a SSD of $32.9 \%$. Surface slip on the EF is reduced by around $45 \%$. Our results indicate that variations of the SSDs within $\approx 20 \%$ are possible without any lateral heterogeneity of bulk cohesion. The analysis of the SSD of the corresponding elastic simulation reveals that an even higher variability is present without plasticity (see discussion in Sec. 4.5.) Hence, spatial variations in SSD can be attributed to different fault orientations and the resulting variations in dynamic rupture behavior. While our results agree well with the observational range of 30-60\% Gombert et al. (2018)'s Bayesian slip-inversion suggests that the maximum SSD of $50 \%$ occurred at the HVF, which is underestimated in our model. In contrast, our SSD-values at the JVF and EF are overestimated in comparison to the probabilistic approach of Gombert et al. (2018). Additionally, their shallow slip at CRF is reduced by only $20 \%$, while we observe a SSD of $48.0 \%$.

We infer a relatively high SSD of $50 \%$ across the first rupture segments, which may be related to the inferred principal stress orientation. We assume that the hypocentral region is well oriented with respect to the principal stress orientation leading to a large amount of slip at depth. Subsequently, rupture propagates mostly along the Kickapoo branch, preventing larger surface slip at the JVF. The results are independent of the nucleation procedure initiating spontaneous rupture, as discussed in Sec. 4.1.

We now compare our findings to single fault-plane simulations that include frictional heterogeneity to approximate along-strike variations in fault strength (Roten et al., 2017). Their reported average SSD of $42.9 \%$ is almost identical to the inferred $40.8 \%$ using a similar cohesion model but more complex fault structures.

In our model, relatively high stress drops facilitate rupture transfers across geometrical complexities. The scenario features a maximum stress drop of $33 \mathrm{MPa}$ at a depth 
of $10 \mathrm{~km}$, which is slightly higher than the maximum stress drop of $25 \mathrm{MPa}$ used in Landerstype simulations by Roten et al. (2017). The average stress drop over all positive slip regions is $12.5 \mathrm{MPa}$. Such overall high stress drops are consistent with expectations for events with long recurrence time and the inferred global averages from far-field waveforms (Sieh et al., 1993; Kanamori et al., 1992). However, stress drop estimates contain substantial uncertainty: Sieh et al. (1993) and Kanamori et al. (1992) report for instance 20-28 MPa inferred from the ratio of radiated energy to seismic moment. An analysis of on-fault static stress-drop estimates from kinematic source models for the Landers earthquake, using the method of Ripperger and Mai (2004), reveals stress drop averages over all positive slip regions of 6-12 $\mathrm{MPa}$, and maximum stress changes of over $30 \mathrm{MPa}$ within the largest asperities, consistent with our model. However, high stress drops also increase the effect of plasticity, and as a consequence the reduction of shallow slip due to plastic yielding along single fault planes (Roten et al., 2016). Our model indicates that similar SSD values are possible, even for scenarios with higher stress drop but more complex fault geometries.

Finally, we compute the radiated seismic energy, using the approach of Ma and Archuleta (2006) (their Eq. 5) by subtracting the total frictional work (including fracture energy and heat energy) from the potential energy change due to fault slip. For our preferred model, we find a radiated energy of $11.8 e+15 \mathrm{~J}$, which is about $30 \%$ higher than the largest value of $8.6 e+15 \mathrm{~J}$ reported in Venkataraman and Kanamori (2004). However, Kanamori et al. (1992) report a value of $4.3 e+15$ J. Obviously, there are large uncertainties (on the order of a factor of 2-3) in published estimates of radiated seismic energy (see also Kaneko and Shearer (2015)), likely associated with directivity effects, attenuation models, and data-processing intricacies.

\subsection{Ground Motions}

In the following, we compare synthetic seismograms of our preferred dynamic rupture scenario to observed waveforms and their peak ground velocities (PGVs). The stations used for comparison are shown in Fig. 7. Site names, $V s_{30}$-values the average shearwave velocity between the surface and 30-meters depth, Joyner-Boore distances $R_{J B}$ (the shortest distance from a site to the surface projection of the rupture surface, and hypocenterstation azimuths are summarized in Table 2. Velocity time series for the station LUC are downloaded from the PEER Ground Motion database (https://ngawest2.berkeley .edu/). For all other stations, recorded accelerograms are downloaded from the Center of Engineering Strong Motion Data (http://www.strongmotioncenter.org/) and integrated for velocities. Note that the scope of our study is not to fine-tune the model towards detailed waveform fitting. We rather use ground-motion comparisons as an independent, additional source of information after constraining our preferred model to inform us how well (or badly) complex, fully physics-based simulations can reproduce observations.

\subsubsection{Peak Ground Velocities}

The Landers event is a prominent example for a strike-slip earthquake with strong directivity effects, i.e. exhibiting large PGV variability with respect to the azimuth (e.g., Vyas et al., 2016). Correspondingly, we analyze the PGVs not only in dependence of $R_{J B^{-}}$ distance, but also with respect to azimuth to the hypocenter.

We calculate PGVs using the sensor orientation independent measure GMRotD50 which represents the median of the horizontal motions rotated over all possible rotation angles (Boore et al., 2006). Fig. 7 is an overview map of our high-resolution model region depicting synthetic PGVs exceeding $5 \mathrm{~cm} / \mathrm{s}$. The maximum synthetic PGVs exceed $200 \mathrm{~cm} / \mathrm{s}$, and are found in the vicinity of the HVF. We observe a clear directivity effect to the north, north-north-west, while we find strong amplification of ground motions 


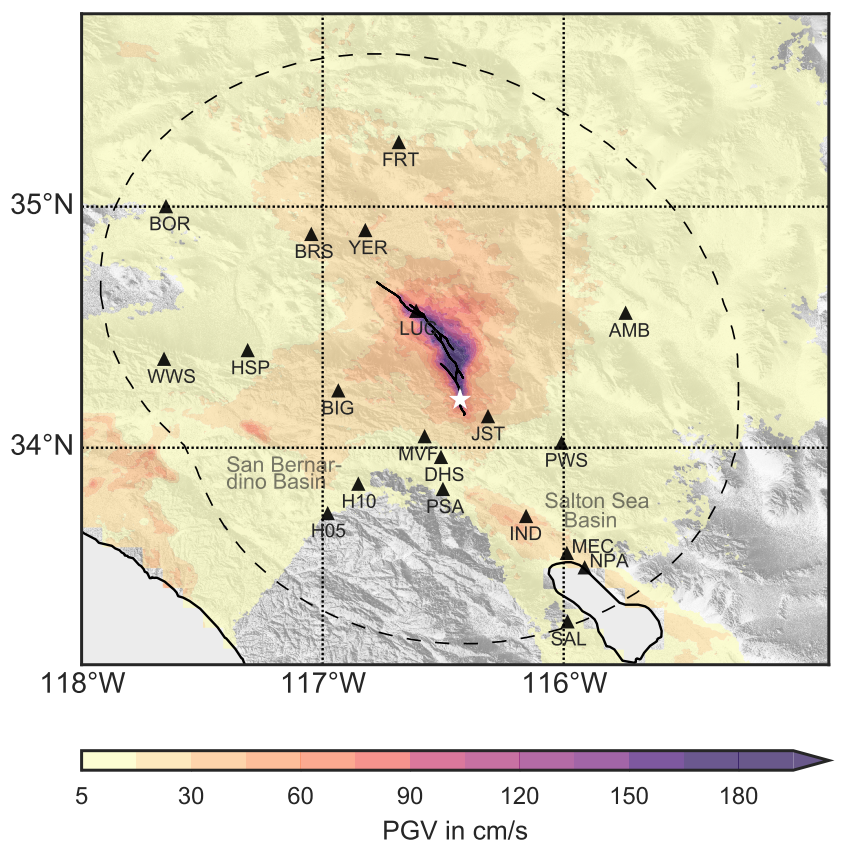

Figure 7. Overview map of the model domain, colored by the simulation's peak ground motions above $5 \mathrm{~cm} / \mathrm{s}$ based on GMRotD50 (Boore et al., 2006). The white star marks the epicenter of the 1992 Landers mainshock. Black triangles mark the seismic stations used for comparisons (for details see Table 2). The dashed line denotes the area of $R_{J B}$-distance of $105 \mathrm{~km}$.

\begin{tabular}{l|lccccc} 
station & name & Lat & Lon & $V s_{30}(\mathrm{~m} / \mathrm{s})$ & $R_{J B}(\mathrm{~km})$ & azimuth $\left(^{\circ}\right)$ \\
\hline LUC & Lucern & 34.57 & -116.61 & 685 & 0.47 & -22.57 \\
JST & Joshua Tree & 34.13 & -116.31 & 379 & 9.04 & 125.23 \\
MVF & Morongo Valley & 34.05 & -116.58 & 345 & 17.93 & -141.47 \\
DHS & Desert Hot Springs & 33.96 & -116.51 & 345 & 21.12 & -164.86 \\
YER & Yermo & 34.90 & -116.82 & 354 & 24.37 & -25.03 \\
BRS & Barstow & 34.89 & -117.05 & 371 & 33.37 & -36.77 \\
PSA & Palm Springs Airport & 33.83 & -116.50 & 207 & 34.88 & -171.24 \\
PWS & Twentynine Palms & 34.02 & -116.01 & 685 & 39.37 & 116.64 \\
BIG & Big Bear & 34.22 & -116.94 & 415 & 40.98 & -85.00 \\
H10 & Silent Valley & 33.85 & -116.85 & 685 & 51.32 & -135.01 \\
IND & Indio & 33.72 & -116.16 & 345.0 & 52.09 & 154.30 \\
HSP & Hesperia & 34.41 & -117.31 & 371 & 58.31 & -74.41 \\
FRT & Fort Irwin & 35.27 & -116.68 & 345 & 64.97 & -11.36 \\
AMB & Amboy & 34.56 & -115.74 & 270 & 67.78 & 57.19 \\
H05 & Hemet & 33.73 & -116.98 & 339 & 69.00 & -136.00 \\
MEC & Mecca & 33.56 & -115.99 & 318 & 74.58 & 149.40 \\
NPA & North Shore Salton Sea & 33.50 & -115.91 & 265 & 83.89 & 147.75 \\
BOR & Boron & 35.00 & -117.65 & 291 & 87.33 & -51.49 \\
WWS & Wrightwood & 34.37 & -117.66 & 506 & 88.41 & -80.56 \\
SAL & Salton City & 33.28 & -115.98 & 325 & 102.80 & 157.51 \\
\hline
\end{tabular}

Table 2. Stations used in this study, including site name, latitude and longitude, $V s_{30}$-value (used to calculate the corresponding GMPE values), Joyner-Boore distance $R_{J B}$, and hypocenterstation azimuth from north. Stations are ordered with respect to $R_{J B}$-distance. 
a)

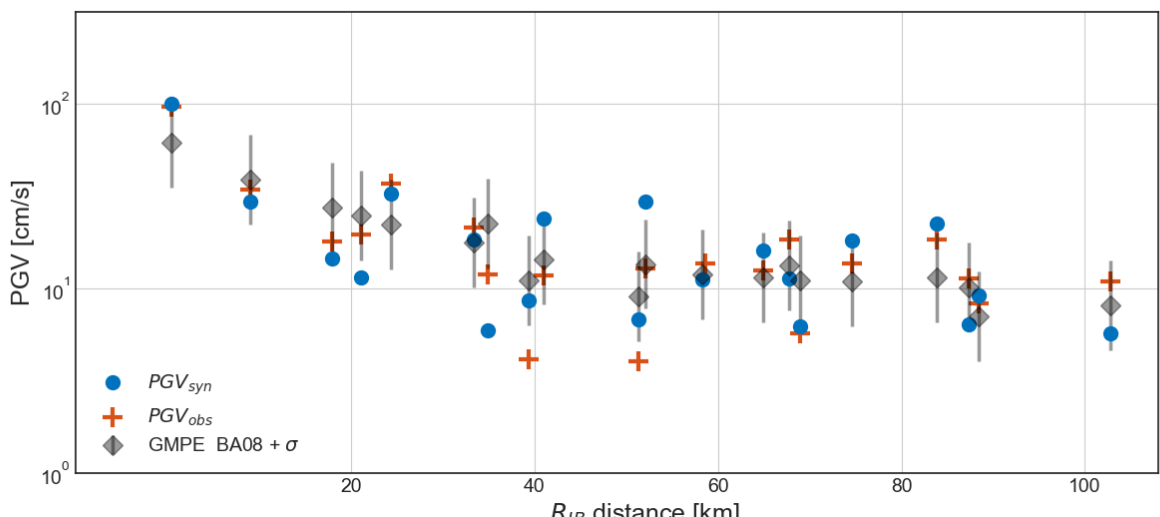

b)

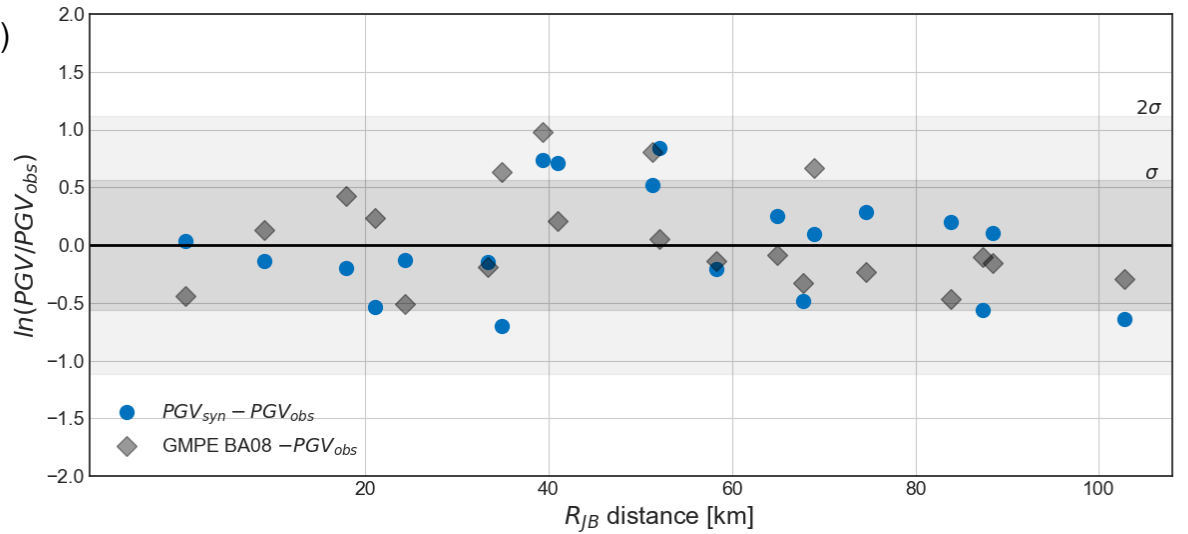

c)

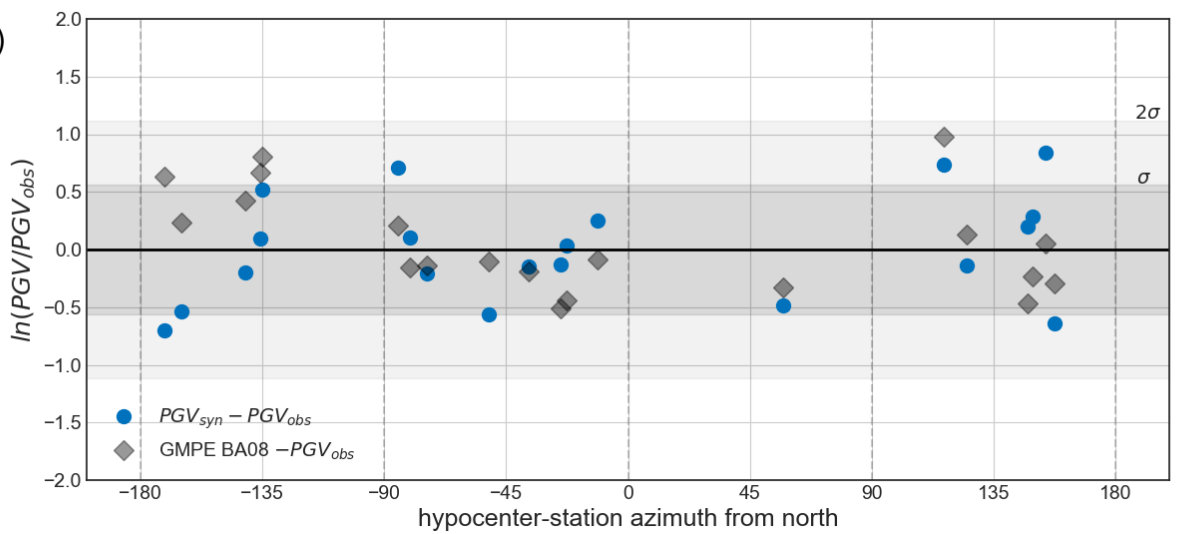

Figure 8. a) PGVs synthetic $\left(\mathrm{PGV}_{\mathrm{syn}}\right.$, blue) and observed $\left(\mathrm{PGV}_{\text {obs }}\right.$, orange) in dependence of Joyner-Boore distance $R_{J B}$ for all stations in Fig. 7. Gray diamonds represent corresponding GMPE values (Boore \& Atkinson, 2008) (including its standard deviation shown as gray bars). b) PGV-residuals, calculated as $\ln \left(\mathrm{PGV}_{\mathrm{syn}} / \mathrm{PGV}_{\mathrm{obs}}\right)$ for synthetic and observed PGVs (blue dots) and $\ln \left(\mathrm{GMPE} / \mathrm{PGV}_{\mathrm{obs}}\right.$ ) for GMPE values and observed PGVs (gray diamonds) in dependence of $R_{J B}$. c) Corresponding PGV-residuals, in dependence of hypocenter-station azimuth. The dark and light gray shaded areas show the $\sigma$ and $2 \sigma$ standard deviation interval, respectively. 
close to the Salton Sea Basin and the San Bernardino Basin due to low S-wave speeds in the subsurface model (see ground motions in Fig. 7).

Fig. 8 a) compares the synthetic $\left(\mathrm{PGV}_{\mathrm{syn}}\right)$ and the observed PGVs $\left(\mathrm{PGV}_{\mathrm{obs}}\right)$ with respect to $R_{J B}$-distance. We include the standard deviation $\sigma$-interval (gray error bars) of the ground-motion prediction equations (GMPEs, gray diamond, Boore and Atkinson (2008)) for each station. The corresponding residuals $\left(\ln \left(\mathrm{PGV}_{\mathrm{syn}} / \mathrm{PGV}_{\mathrm{obs}}\right)\right)$ between the synthetic and observed PGVs, as well as between GMPEs and observed PGVs $(\ln (\mathrm{GMPE} / \mathrm{PGV}$ obs $)$ ) are depicted in Fig. 8 b).

In general, our simulation results agree well with the observed PGVs, as all residuals are within two standard deviations. Particular close to the fault, our simulation results agree better with the observations than the values inferred from GMPEs. The largest residuals are found for stations within $39-51 \mathrm{~km} R_{J B}$-distance (stations PWS, BIG, H10, IND) for which the simulations over-predict PGV-values. These four stations are all somewhat in the backward rupture directivity direction, in particular IND and PWS. The backpropagating rupture on the HVF in our scenario may contribute to the locally larger synthetic PGVs.

To analyze a potential azimuthal trend, we plot the residuals with respect to the hypocenter-station azimuth (Fig. 8 c)), defined as the azimuth between the North and the line between the hypocenter and the station. First, we observe an underestimation of the GMPEs with respect to the observations in forward direction $\left(\approx 10-39^{\circ}\right)$, as also reported by Vyas et al. (2016). In that case, our simulation results reproduce the observations much better than the generic GMPEs do for these stations. Synthetic PGVs in forward direction show very good agreement with the recorded PGVs within one standard deviation. Synthetic PGVs overestimate several stations in backward direction (> $110^{\circ}$ ), as mentioned above.

In summary, the peak ground velocities from our simulation results agree well with observations, without any significant error trend with respect to $R_{J B}$-distance and hypocenterstation azimuth. The specific effects of off-fault plasticity on the synthetic peak ground motions with respect to the directivity effect is described in the Discussion part ( Sec. $4.2)$.

\subsubsection{Waveforms}

Next, we examine the seismic waveform characteristics of our simulations, and compare them against observations. Fig. 9 shows three-component seismograms for a selection of stations in forward and backward direction, as well as perpendicular to the fault, ordered by $R_{J B}$-distance. All seismograms show velocities in $\mathrm{cm} / \mathrm{s}$, are bandpass filtered between $0.05 \mathrm{~Hz}$ and $1.0 \mathrm{~Hz}$, and are normalized by the maximum value of each component of the recorded seismogram, similar to Graves and Pitarka (2010). The maximum values of each component is annotated above the time series. Some of the observational strong motion recordings lack exact timing information, hence, we cross-correlate them with our synthetics for temporal alignment. The synthetic velocities of all other stations listed in Table 2 are provided in the supporting information (Figs. S6-S15).

The waveform comparisons show very good agreement between simulations and observations, although not all details of the recordings are reproduced. However, this does not come as a surprise, because our study does not attempt to find an optimized source parameterization to fit waveforms (like in a source inversion study). Still, our synthetic waveforms capture the main S-wave pulses, amplitudes, and shaking duration, indicating the quality of dynamic rupture model.

To quantitatively compare the fit between synthetic and observed waveforms, we use a misfit criteria that evaluates the phase and envelope misfit based on a time-frequency 


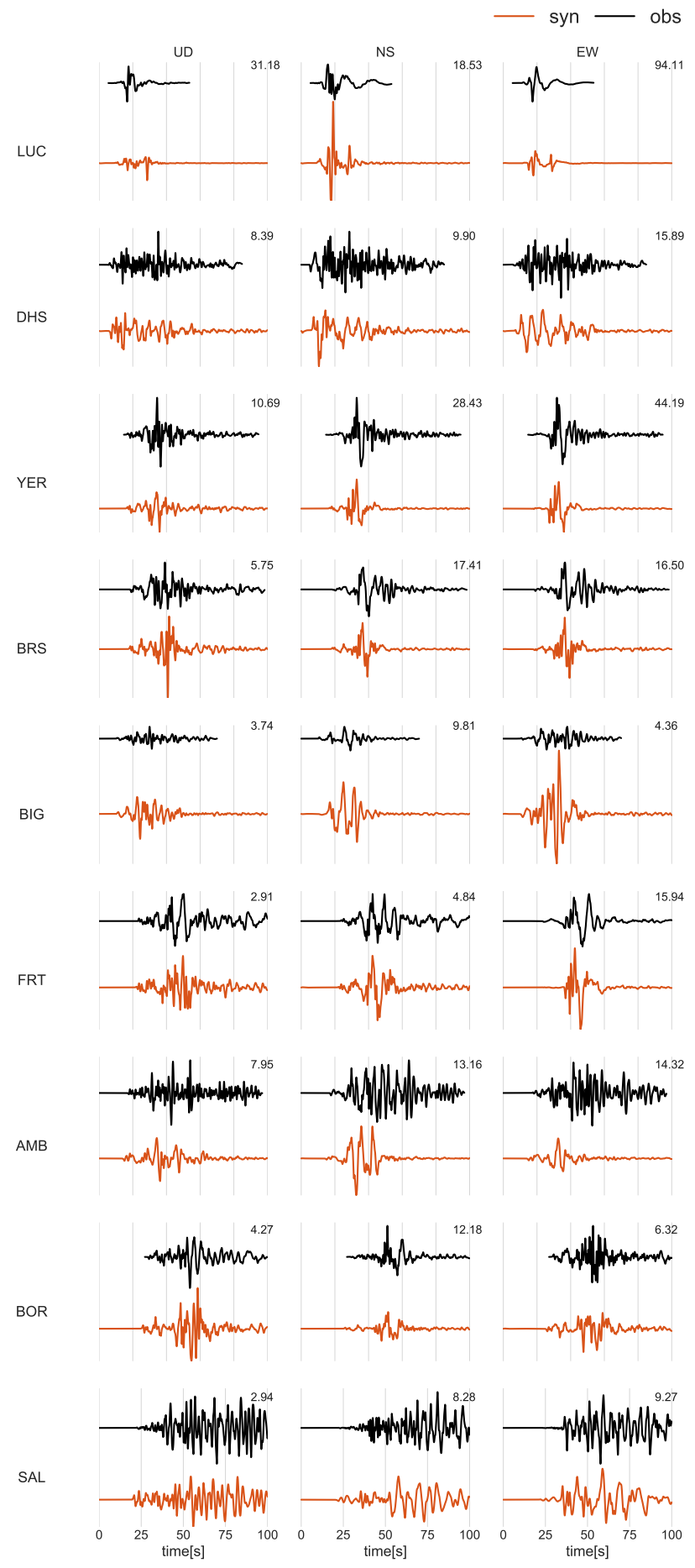

Figure 9. Observed (black) and synthetic (orange) seismic velocities in $\mathrm{cm} / \mathrm{s}$ for a selection of stations (Fig. 7). All seismograms are bandpass filtered between 0.05 and $1 \mathrm{~Hz}$. The waveforms are normalized by the maximum value of each component of the observation (stated above each trace) and ordered by their $R_{J B}$-distance. 
representation of the signals, following the goodness-of-fit measurement (GoF) of Kristeková et al. (2009) (their equations 15 and 16). The GoF evaluates the level of agreement and is suitable for comparing observed and synthetic waveforms. The detailed analysis of the waveform misfit can be found in the supporting information, including visualizations of the time-frequency envelope- and phase-GoFs (Text S2 and Figures S6-S15). The GoF determines a number between 0 (poor) and 10 (identical) to quantify the phase (PG) and amplitude (EG) fit between two signals. The PG and EG for each station and each component are summarized in Table S1 and S2 of the supporting information. In average, we find an EG of 4.64 and a PG of 5.25 which confirms the good agreement between synthetics and observations. The poorest fit is found for the EG of station PSA (1.94), while the maximum GoF values reach close to 8 for the PG of some components of stations BOR, YER and BRS.

In the forward direction, the main velocity pulses at stations YER and BRS are well reproduced with an average EG of around 5 and average PG of 7 over all components. At YER, waveform characteristics and amplitudes agree very well on all three components. For BRS, both horizontal components are very consistent, while for the vertical component the synthetic waveform is substantially larger. For these two stations we also notice that our simulations are not quite able to reproduce the coda-wave behavior following the main pulses, possibly due to the influence of unmodeled small-scale heterogeneity that leads to seismic scattering. This changes, to some extend, for the fartheraway stations BOR and FRT. Both are located north of the fault but not exactly in the expected forward-directivity cone. In both cases, the synthetics well reproduce not only the dominant source-related S-wave pulses (of about $5 \mathrm{sec}$ duration), but also the later part of the waveforms (at least in a statistical sense). On all three components, the amplitudes are well matched at stations BOR and FRT as indicated by an EG value in average above 5 .

In backward direction (i.e. to the south of the fault system), we obtain good agreement at station DHS for an $\approx 10 \mathrm{sec}$ long source-dominated shear-wave that arrives in two distinct wave packages (spaced about 6-7 sec apart). Amplitudes match reasonable well, but coda-waves (due to scattering) are not well reproduced. A similar pattern evolves for stations to the east of the fault (e.g., AMB) and to the west (e.g., BIG). The sourcedominated shear-waves are in excellent agreement (though the amplitudes of the synthetics at BIG are higher by a factor 2-5), while the coda behavior is not well reproduced.

For the frequency range considered here, scattering due to topography and a rather smooth 3D Earth model is too weak to generate realistically scattered waves (Imperatori \& Mai, 2015), thereby affecting the waveform misfit. Note, however, that the farthest recording (at SAL) demonstrates a very consistent overall waveform character, including the coda waves, as regional wave-propagation effects dominate (e.g. the sedimentary basin of the Salton Sea). To reduce the path and side effects and to focus on the source characteristics, we further present the corresponding displacements in the supporting information (Fig. S16).

The closest station to the fault trace, Lucerne station (LUC), recorded strong motions in only $470 \mathrm{~m}$ distance from our modeled fault trace of the EF. We note, that the waveforms in the synthetic seismogram show lower agreement with observations in terms of amplitudes and phases, in contrast to the synthetics for other stations in forward direction (such as YER and BRS). Additionally, the amplitude on the north-south (NS) component of LUC is over-predicted by our simulations, while the east-west (EW) component is underpredicted (in each case about a factor 2).

\subsection{Off-fault Deformation}

During earthquake rupture, the released energy is not only accommodated by frictional sliding on the fault and radiated seismic waves, but is also absorbed by inelastic 
processes such as plastic deformation in the vicinity of the fault. Off-fault deformation thus poses a key component in the energy budget of earthquakes (e.g., Rice et al., 2005; Kanamori \& Rivera, 2006). Relationships between the width of the damage zone and fault displacement provide helpful insight into the associated fault growth and rupture processes (e.g., Faulkner et al., 2011).

Milliner et al. (2015) correlate pairs of aerial photographs before and after the 1992 Landers earthquake to map co-seismic off-fault deformation. The corresponding fault zone width is defined as the perpendicular extend of surface shear to either side of the fault. They find that the magnitude and width of the mapped off-fault deformation correlates with geometrical complexity of fault surface traces.

Fig. 10 compares the accumulated plastic strain distribution at the surface in our simulation with fault zone width (FZW) measurements (Milliner et al., 2015). Here, we focus on the qualitative characteristics of the synthetic plastic strain distribution and its relation to fault geometry, as the numerical resolution does not allow for quantitatively translating the dynamically induced plastic strain fields into mapped fault damage zones. Our simulation reproduces key features of the mapped fault zone width, in particular the drastic increase of off-fault damage in geometrically complex fault regions. Note, that all simulation results are linked to the here prescribed fault geometry, which cannot account for co-seismic creation of new rupture branches or a new linkage of existing ones.

Following the fault trace from south to north, an increase of FZW for both the mapped and modeled damage zones can be observed, particularly at the southernmost part of the JVF. Close to the branching point to the KF, at around $3795 \mathrm{~km}$ UTM Northing and $550 \mathrm{~km}$ UTM Easting, our model predicts an increase in plastic deformation on the extensional side of the fault which agrees with the FZW of Milliner et al. (2015). The region with highest plastic strain between $3800-3810 \mathrm{~km}$ UTM Northing is clearly correlated with the observed increase of the FZW. Although the southernmost part of the EF did not fully rupture in the simulation, shallow fault slip still triggers plastic deformation very narrowly around the fault trace. Both models show an increase in fault zone complexity at the transition of the HVF and EF (see inset to Fig. 10). In particular, the dynamic rupture scenario reveals how the accumulated plastic strain connects the ends of the HVF and the EF. The northernmost part of the fault system lacks off-fault plastic deformation, owing to the lack of shallow slip at the CRF.

Due to the lack of observational constraints, our models include laterally homogeneous plasticity parameters (bulk cohesion and bulk friction). While major features of the modeled off-fault deformation pattern are related to the changing fault orientation, the existing discrepancies might be related to missing heterogeneous structure along the fault segments. Off-fault deformation correlates with the near-surface lithology that either promote or prevent off-fault damage (Zinke et al., 2014; Milliner et al., 2016).

An observed increase of the FZW close to the hypocenter suggests that the fault zone structure may be locally more complex than our modeled fault-surface representation. Accounting for a more complex geometry would potentially slow down rupture and/or reduce the energy release at the JVF (Zielke et al., 2017) (see also Sec. 4.1). Smallscale fault roughness, as observed for natural faults (e.g., Candela et al., 2012), is not included in our model, but potentially may lead to a strong signature in the simulated plastic deformation (Dunham et al., 2011b; Shi \& Day, 2013).

At the transition between the HVF and EF, our model geometry accounts only for one branch, while fault trace mappings shows two subsequent branches to the EF (Sieh et al., 1993; Milliner et al., 2015).. Interestingly, the simulated plastic strain, resulting from the abrupt stopping of the rupture at the prescribed end of the HVF surface, exactly connects the HVF and EF where the second branch is observed. Hence, this con- 

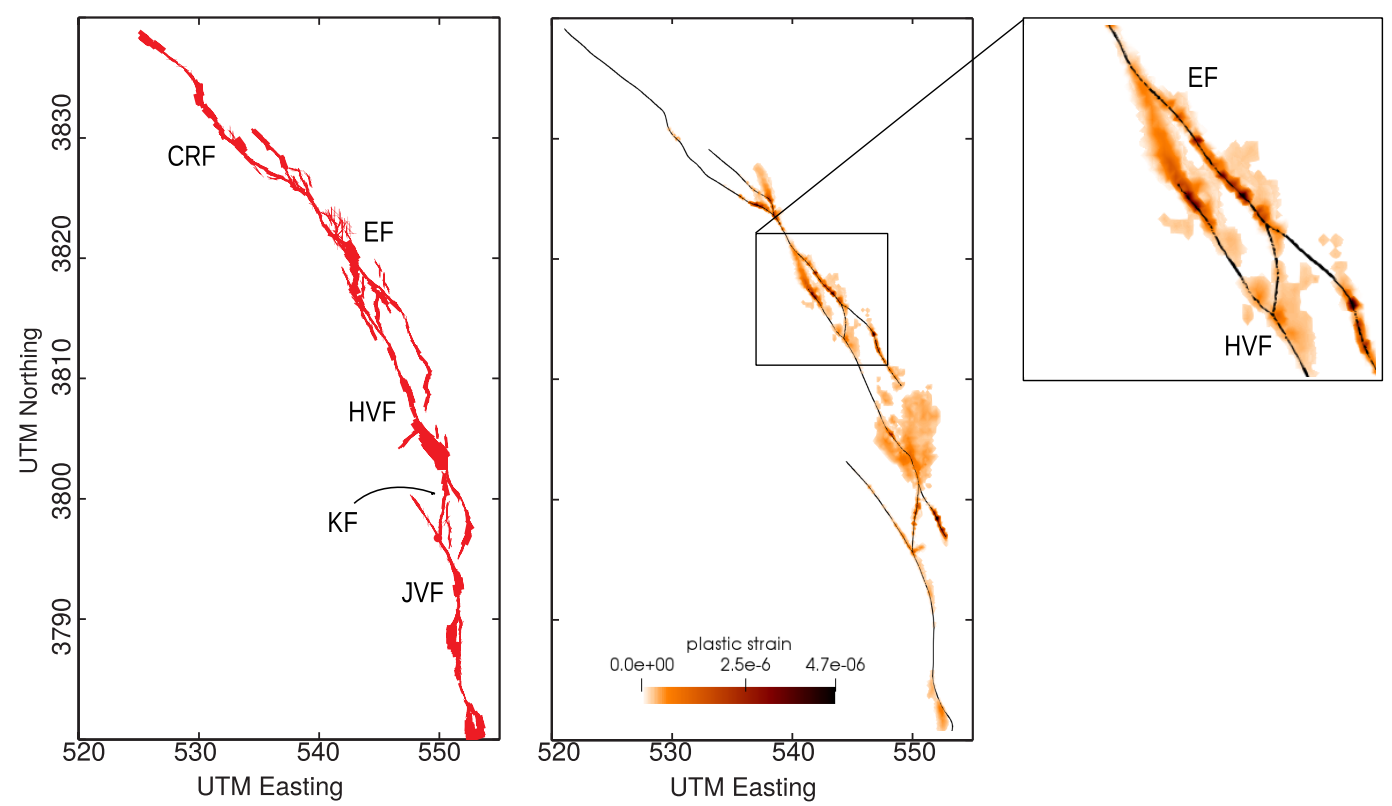

Figure 10. Fault zone width (FZW) compiled by Milliner et al. (2015) from aerial photograph correlations (left) in comparison to the accumulated plastic strain from the presented dynamic rupture simulation (middle). The right figure shows an inset at the transition from the HVF to EF.

nection may have been created or enhanced during the 1992 Landers event. In order to investigate whether a connecting branch slipped co-seismically, future simulations would need to explicitly include such segment into the prescribed fault network geometry. 


\begin{tabular}{l|cccccc} 
model name & $\begin{array}{c}\text { visco- } \\
\text { elasticity }\end{array}$ & plasticity & $\begin{array}{c}\text { stress along } \\
\text { the KF }\end{array}$ & $\begin{array}{c}\text { critical slip } \\
\text { distance } D_{c}\end{array}$ & $\begin{array}{c}\text { EG } \\
\text { avg/opt }\end{array}$ & $\begin{array}{c}\text { PG } \\
\text { avg/opt }\end{array}$ \\
\hline $\begin{array}{l}\text { VP-KF0-062 } \\
\text { (preferred) }\end{array}$ & yes & yes & KF0 & $0.62 \mathrm{~m}$ & $7.85 / 8.03$ & $8.24 / 8.39$ \\
\hline VP-KF1-062 & yes & yes & KF1 & $0.62 \mathrm{~m}$ & $3.68 / 3.6$ & $5.23 / 4.56$ \\
VP-KF2-062 & yes & yes & $\mathbf{K F 2}$ & $0.62 \mathrm{~m}$ & $5.79 / 5.89$ & $4.15 / 4.43$ \\
VE-KF0-062 & yes & no & KF0 & $0.62 \mathrm{~m}$ & $8.42 / 8.33$ & $8.96 / 8.61$ \\
VE-KF0-072 & yes & no & KF0 & $\mathbf{0 . 7 2} \mathbf{~ m}$ & $8.59 / 8.39$ & $8.79 / 8.52$ \\
P-KF0-062 & no & yes & KF0 & $0.62 \mathrm{~m}$ & $8.37 / 8.52$ & $8.65 / 8.69$ \\
\hline
\end{tabular}

Table 3. Summary of the model variations discussed in Sec. 4, their abbreviated names and the corresponding envelope goodness-of-fit (EG) and phase goodness-of-fit (PG) of the moment release rate with respect to the average (avg) and optimal (opt) SCARDEC moment rate. The details of the varying rotation of stresses governing the Kickapoo fault in models VP-KF0/KF2062 are explained in Sec. 4.1. The elastic models VE-KF0-062 and VE-KF0-072 are compared to our preferred model in Sec. 4.2, while the influence of attenuation (comparison between model VP-KF0-062 and P-KF0-062) is discussed in Sec. 4.4.

\section{Discussion}

Sustained rupture along the geometrical complex fault of the 1992 Landers earthquake provides strong constraints on the model parameters such as stress orientation, stress amplitudes and friction. Our source model shows good agreement with estimated moment-release rate, recorded PGV's, and key features of the observed off-fault deformation patterns. We discuss in the following further implications, potential improvements, but also the sensitivity to variations in prior assumptions of the preferred dynamic rupture model. The variations of the discussed models, their abbreviated names and their corresponding envelope and phase goodness-of-fit, quantifying the agreement between the modeled moment rate and the average and optimal SCARDEC moment rate, are summarized in Table 3. Lastely, we discuss uncertainties associated with observationally inferred source time functions and implications for our modeling approach in Sec. 4.6.

\subsection{Early moment release and earthquake initiation}

Our preferred Landers earthquake scenario slightly overestimates seismic moment release within the first $10 \mathrm{~s}$ (Fig. 5) compared to the SCARDEC solutions (Vallée \& Douet, 2016). The higher moment release occurs during nucleation, rupture across the JVF and branching into the KF. It has been shown that rupture initiation of spontaneous rupture simulations is highly sensitive to the choice of numerical nucleation procedure (Galis et al., 2014) and initial stress and strength on- and off-fault (Gabriel et al., 2012, 2013) in the hypocentral region. We here discuss potential reasons and improvements specifically with respect to earthquake nucleation and the parametrization of the first segments of the fault system.

Dynamic rupture simulations are initiated by an artificial nucleation procedure on a pre-defined nucleation patch (Sec. 2.3). This leads to a rapid start of rupture, which is further enhanced by the favorable orientation of the hypocentral fault region with respect to the regional stress field. However, observations indicate that rupture started gradually during the first 3 seconds, likely due to a small foreshock in the vicinity of the epicenter (e.g., Campillo \& Archuleta, 1993; Abercrombie \& Mori, 1994). 


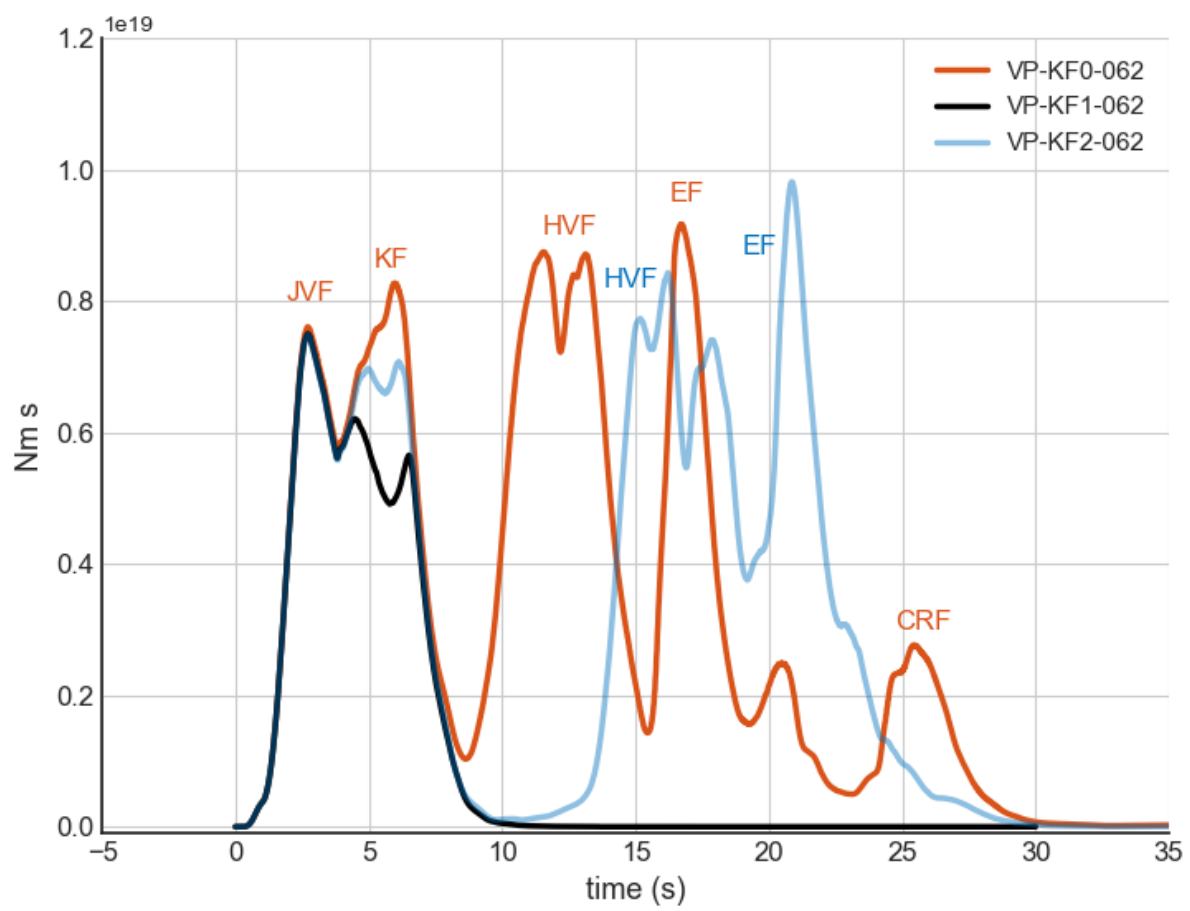

Figure 11. Seismic moment rate of our preferred model (orange) in comparison to two models with changed principal stress orientation governing the KF: Model VP-KF1-062 (black) assumes a linear transition of the stress regime of the JVF to the HVF $\left(33^{\circ}\right.$ to $\left.20^{\circ}\right)$ starting at the beginning of the KF and ending at the intersection with the HVF. Model VP-KF2-062 (light blue) features the same transition to $20^{\circ}$ at the HVF but starting in the center of the KF.

We find that rupture dynamics and associated moment release remain robust across the first fault segment when varying nucleation patch size, forced rupture time or forced rupture speed within the nucleation patch. This allows to also examine if the prescribed nucleation procedure affects spontaneous rupture behavior at the JVF. Spontaneous rupture is delayed, but still initiates for radii as small as $0.5 \mathrm{~km}$. For larger radii (up to $4.5 \mathrm{~km}$ ), rupture initiates faster, however, the moment-release rate remains unchanged. Similar behavior is found for varying the time of the forced nucleation $t_{n u c}$ : for shorter nucleation times $(0.2 \mathrm{~s})$ rupture initiates faster, but spontaneous rupture outside the nucleation patch is identical. We find that rupture speed and moment-release rate outside the nucleation patch are not changed by varying the forced rupture speed within the nucleation patch $v_{n u c}$ in the range of $2000 \mathrm{~m} / \mathrm{s}$ to $3300 \mathrm{~m} / \mathrm{s}$.

Mapped surface traces and distributed off-fault deformation indicate that structural complexity is enhanced close to the hypocenter (Liu et al., 2003; Milliner et al., 2015). The rapid rupture initiation could potentially be delayed by considering fault structures more complex than the curved, yet purely strike-slip fault geometry used in our simulation. Including small-scale geometrical roughness may additionally slow down rupture and limit the stress drop (Dunham et al., 2011a; Shi \& Day, 2013; Zielke et al., 2017; Mai et al., 2017), while simultaneously increasing off-fault damage. 
The $5 \mathrm{~km}$ short connecting Kickapoo fault (KF) plays a crucial role for early moment release by linking the Johnson Valley (JVF) and Homestead Valley (HVF) faults. Despite its short length, it slipped with a maximum of nearly 3 meters (Hill et al., 1980; Sowers et al., 1994). However, local principal stress orientation are not well constrained, since it is not clear whether this fault branch is part of the San Bernardino or the Central Mojave domain (Unruh et al., 1994).

We observe a second relatively high peak of moment-release rate at $6 \mathrm{~s}$ (Fig. 11) related to slip at the KF. Decreasing the angle of principal stress orientation acting on this fault step-over branch reduces this peak. In our preferred model, the KF experiences an equivalent angle of maximum compressive stress $\left(33^{\circ}\right)$ as the JVF (hereafter referred to as KF0) (Sec. 2.2). However, if the KF already constitutes the transition between the San Bernardino and the Central Mojave domains, its local stress orientation might be steeper.

Correspondingly, we test two variations in stress orientations across the KF, which respectively vary its strength while rupture in all three models is initiated by the same nucleation procedure. First, background stresses smoothly rotate from $33^{\circ}$, starting at the beginning of the KF and reaching $20^{\circ}$ at the intersection with the HVF (model VPKF1-062 with rotation KF1). The black line in Fig. 11 demonstrates the reduced momentrelease rate between 4-7 s, related to rupture on the KF, for this case. However, subsequently rupture completely arrests at the JVF, and thus is unable to propagate across the remaining fault segments. As a consequence, the agreement between the modeled moment rate and the SCARDEC moment rates is reduced in comparison to our preferred model, as indicated by the lower EG and PG values (see Table 3). This illustrates the sensitivity of our modeling approach to the dynamics of rupture transfers.

Second, we test the hypothesis that the initial part of the KF is favorably oriented $\left(33^{\circ}\right.$, to promote branching), while stresses start to rotate to $20^{\circ}$ only in the center of the KF (model VP-KF2-062 with rotation KF2, light blue line in Fig. 11). In this case, the moment-release rate between $4-7 \mathrm{~s}$ is still decreased with respect to our preferred model, but not as pronounced as for model variation 1. Rupture initiation at the HVF is drastically delayed by $5.5 \mathrm{~s}$ in comparison to our preferred model. After re-initiation, rupture overcomes the fault-bend barrier and breaks the entire fault system. The rupture path is very similar to the preferred model, highlighting the robustness of the source dynamics described in Sec. 3.1.

Our numerical experiments therefore suggest a locally steeper angle of principal stress orientation in order to better match the estimated moment-release rate within the first $10 \mathrm{~s}$ of rupture. However,due to the resulting rupture delay at the HVF, the agreement is reduced after $10 \mathrm{~s}$, as also shown by the lower EG and PG values with respect to the preferred model (see Table 3). Such steeper principal stress orientation along the KF may therefore require other mechanisms facilitating rupture transfers, such as: i) more complex fault geometries, including additional connecting fault segments as seen in fault traces by Liu et al. (2003), ii) fault weakening mechanisms, such as strong velocity-weakening friction or the effect of thermal pressurization, since there is evidence of a fluid-saturated upper crust, (Fialko, 2004a), iii) compliant fault zones with reduced rigidity promoting rupture propagation (Finzi \& Langer, 2012a). Investigating the effects of these physical mechanisms on the dynamic rupture process of the Landers earthquake will be hopefully addressed in future work, but is beyond the scope of this study.

\subsection{The Effect of Off-fault Plasticity on the SSD, Rupture Transfer and Moment Rate}

In nature, high stresses during earthquake rupture are accommodated by inelastic processes near the crack tip, but also in the bulk, such as plastic deformation of the host rock. Off-fault plastic response is an important physical process that needs to be 


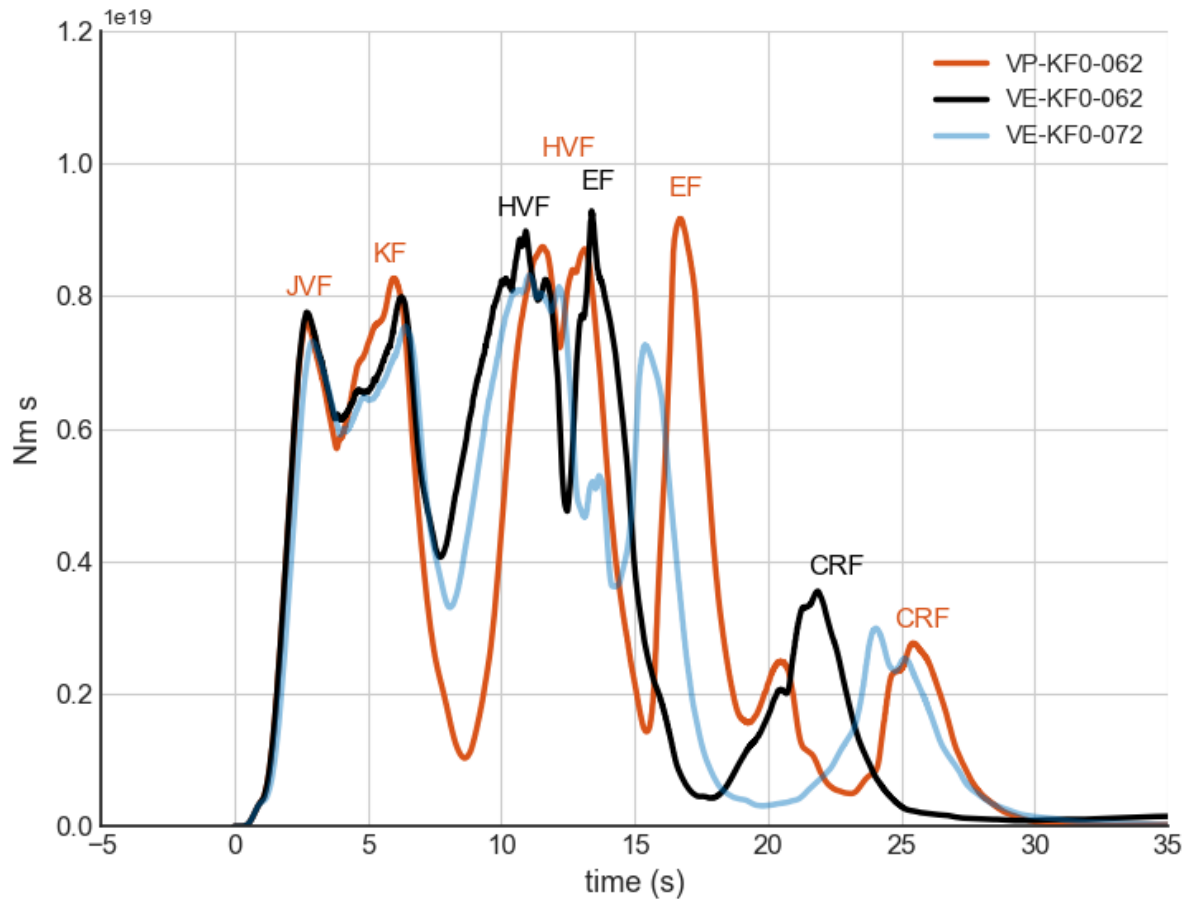

Figure 12. Seismic moment-release rate of our preferred model including off-fault plasticity (VP-KF0-062, orange), compared to an identically parametrized but purely elastic simulation (VE-KF0-062, black), and an elastic simulation with a higher critical slip distance $D_{c}$ (VE-KF0072 , light blue). 
considered in realistic models of rupture dynamics, for example to limit on-fault stresses and slip rates as well as peak ground shaking levels (Andrews, 2005; Roten et al., 2017) and to enable comparisons with mapped off-fault deformation patterns (Milliner et al., 2015). Plastic strain accumulates when the rupture path deviates from planarity, e.g., at changes of fault strike orientation, branching, or segment endings. Wollherr et al. (2018) demonstrate the influence of non-elastic material behavior on the spatio-temporal rupture transfer processes across the geometrical complexities of the Landers fault system. Off-fault plasticity also delays rupture arrivals across the entire fault, even to a larger extend than reported for scenarios on planar faults (Roten et al., 2015; Wollherr et al., 2018). In direct comparison of purely elastic scenarios and those including plasticity, slip is found to be locally higher but more concentrated. As a result, moment magnitudes are comparable with and without plasticity, even though the rupture path differs dynamically.

We now compare the results of our preferred model that includes off-fault plasticity to simulations with purely elastic material properties (model VE-KT0-062), and discuss the effect of off-fault deformation on the corresponding SSD, moment-release rate and rupture transfer on this complex-fault system. The normalized slip and the corresponding SSD of the purely elastic simulation is visualized in the supporting information (Fig. S5, similar to Fig. 6). The inferred SSD falls in between $11.7 \%$ and $44.2 \%$. The highest SSD is found at the JVF (44.2\%). An SSD of $32.2 \%$ and $35.8 \%$ is found at the KF and the EF, respectively. Slip in the shallow part is reduced by $20.5 \%$ at the HVF and by $11.7 \%$ at the CRF.

In contrast to our preferred model with plasticity, the purely elastic simulation depicts lower SSDs along all fault segments. The SSD is increased between $0.7 \%(\mathrm{KF})$ and $36 \%$ (CRF) by plasticity. Interestingly, along-strike spatial variations of the SSD of up to $33 \%$ become apparent also in the elastic simulation (with plasticity: $20 \%$ ). As a consequence, the spatial variations can be attributed to the fault geometry and velocity structure and their influence on the resulting rupture dynamics, rather than to the influence of the heterogeneous occurrence of off-fault plasticity.

While the estimated SSDs of the Bayesian approach by Gombert et al. (2018) along some segments show better agreement with our preferred model including plasticity (i.e. at the HVF), their SSDs along other segments is better represented by the purely elastic results (i.e. at the CRF). In addition to the influence of fault geometry and rupture dynamics on the spatial variation of the SSD, these results suggest that off-fault deformation might be more pronounced on some segments than on others. However, our preferred model accounting for off-fault plastic deformation is characterized by laterally homogeneous plasticity characteristics (cohesion and friction of the host rock). Further information of lateral varying plastic material properties such as bulk cohesion and bulk friction that control the amount of plasticity along each fault segment might therefore be taken into account in future simulations.

Fig. 12 depicts the corresponding moment-release rate of our preferred simulation (model VP-KT0-062, orange) to an equivalent scenario assuming purely elastic material response (model VE-KT0-062, black). The model parameterization is otherwise exactly the same. The resulting seismic moment is $M_{0}^{\text {ela }}=11.102 \mathrm{e}+19 \mathrm{Nm}\left(M_{w}^{\text {ela }} 7.292\right)$, compared to $M_{0}=11.106 \mathrm{e}+19 \mathrm{Nm}\left(M_{w} 7.293\right)$ of preferred model with off-fault plasticity.

While the overall seismic moment is almost identical for both cases, the moment release is distributed slightly differently during the intermediate rupture stage: We find that rupture transfers across geometrical barriers are generally enhanced if off-fault plasticity is neglected. The rupture transfer between the KF and the HVF is facilitated by the purely elastic material response (at $11 \mathrm{~s}$ in Fig. 12), and rupture also transfers faster between the HVF and EF, leading to a smaller gap in moment rate release (at $12 \mathrm{~s}$ ). Con- 
sequently, rupture at the CRF is initiated $\approx 5 \mathrm{~s}$ earlier than in the simulation with offfault plasticity (compare the last moment rate peak for both scenarios).

Facilitated rupture transfers within the elastic model (VE-KF0-062) nominally increase the agreement between the corresponding moment rate and the SCARDEC moment rates (higher EG and $\mathrm{PG}$ values in comparison to the preferred model, see Table 3). However, our preferred model accounting for off-fault plastic deformation is not only capturing the crucial physics of off-fault deforming rocks that accommodate the unphysically high stresses and high slip rates typical for purely elastic dynamic rupture simulations (Andrews, 2005); it also allows comparison to newly available optical correlation data of fault zone width which cannot be captured in purely elastic models. Our preferred model results suggest that off-fault plastic deformation may vary along-strike and specifically may be less pronounced across the CRF, similar to our findings with respect to the SSD. Future models may explore the interaction of rupture transfers, plastic deformation and spatially varying bulk cohesion and friction models in dependence of each fault-segment or even smaller scales.

Interestingly, our numerical tests reveal that fully elastic simulations can partially emulate our preferred model when increasing the critical slip distance $D_{c}$. In this case, moment-release rate and rupture transfer dynamics are preserved, but exhibit slower rupture speeds and longer delays when transferring to adjacent segments due to an increased critical size (e.g., Ampuero et al., 2002; Bizzarri, 2010; Galis et al., 2014) to initiate selfsustained rupture by dynamic triggering.

For simulations based on linear slip weakening friction including off-fault plasticity (i.e. the reference case), we find that both, relatively high stress drops and a relatively low critical slip distance of $D_{c}=0.62 \mathrm{~m}$, are required to sustain rupture along the segmented faults. In particular, the geometrical barrier at the center of the HVF, as well as the transition between the HVF and the EF, pose strong boundary conditions for sustained rupture. When increasing $D_{c}$ only to $D_{c}=0.64 \mathrm{~m}$, we observe rupture delays of more than $5 \mathrm{~s}$ between the KF and the HVF. For values of $D_{c}>0.64 \mathrm{~m}$ we observe a complete stop of rupture before breaking all segments.

In the corresponding elastic simulations, rupture transfers are facilitated by the lack of plastic deformation in the vicinity of geometrical barriers (e.g., Wollherr et al., 2018). For example, by increasing $D_{c}$ to $0.72 \mathrm{~m}$ in the elastic simulation (i.e. increasing the fracture energy by 16\%), rupture and the transition between distinct fault segments are distinctly slowed down (model VE-KT0-072, light blue line in Fig. 12). The resulting seismic moment of $M_{0}^{\text {ela }}=10.057 \mathrm{e}+19 \mathrm{Nm}\left(M_{w}^{\text {ela }} 7.279\right)$ is very similar to the seismic moment of our preferred model.

\subsection{The Effect of Off-fault Plasticity on Peak Ground Motions}

Let us examine the effects on peak ground motions for these three scenarios. Ground motions in seismic hazard assessment are typically described by Ground Motion Prediction Equations (GMPEs) that depend mainly on event magnitude, source-to-site distance, and site-effects (e.g. the $V s_{30}$-value), but other source-related and path-related effects may be important, too. However, standard GMPEs fail to describe ground motions of earthquakes with strong directivity effects, varying rupture speed or 3D velocity structures including low-velocity basins (e.g., Graves et al., 2008; Spudich \& Chiou, 2008; RamirezGuzman et al., 2015). Therefore, dynamic rupture simulations like ours are useful to possibly complement GMPEs by exploring physically possible parameter spaces.

Ground motions in dynamic rupture simulations on single faults are reduced by offfault plastic yielding (Roten et al., 2014, 2015), however, the combined effects of plastic deformation, physics-based dynamic rupture transfers, and directivity on the ground motion properties for complex-geometry faults has not yet been analyzed. For this pur- 


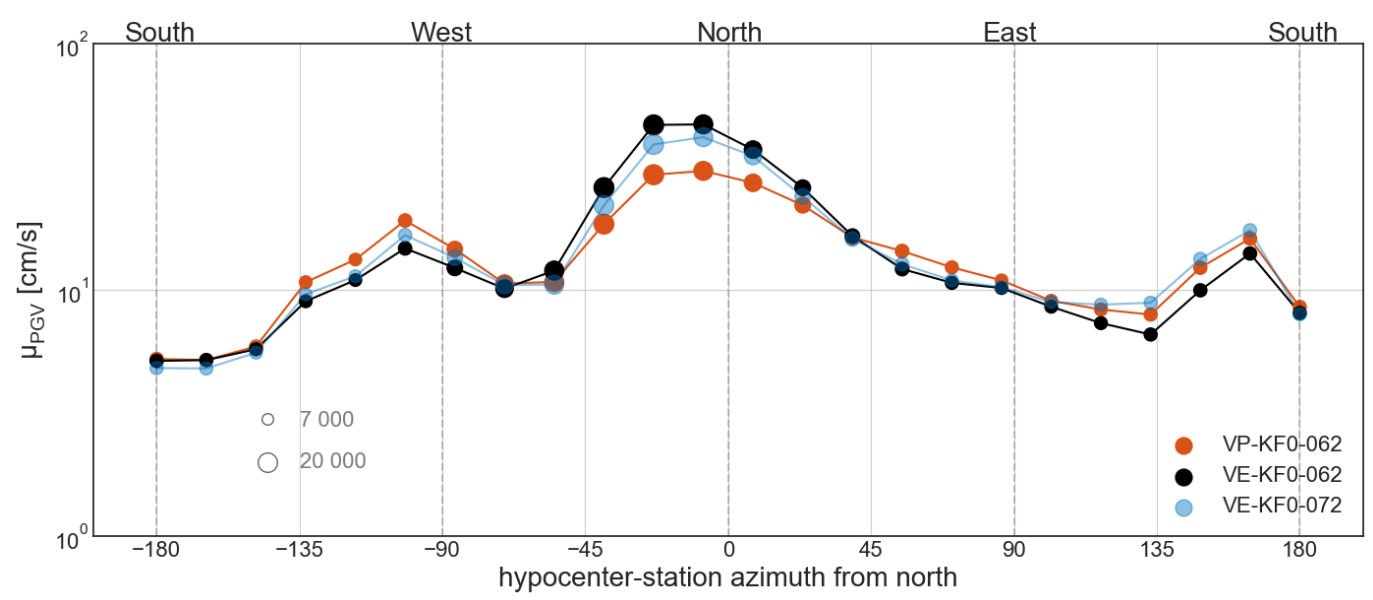

Figure 13. Azimuthal dependence of a) mean PGV denoted as $\mu_{\mathrm{PGV}}$ for our preferred model (orange), the corresponding elastic simulation (black) and the elastic simulation with increased $D_{c}$ (light blue) for all stations between $1 \mathrm{~km}$ and $105 \mathrm{~km} R_{J B}$-distance (bin width $=20 \mathrm{~km}$ ). The circle radii represent the number of stations in each bin.

pose, we examine the mean peak ground motions and their variability for the three scenarios discussed above. The corresponding PGV maps can be found in Appendix Appendix C.

\subsubsection{Azimuthal Dependence of PGVs}

First, we analyze the dependence of peak ground velocities (PGVs) on receiver-epicenter azimuth to help understand directivity effects in our simulations under different material responses. Interestingly, this effect has not yet been analyzed systematically for dynamic rupture simulations with and without off-plasticity. Our results show that off-fault plasticity reduces the mean PGVs mainly in forward direction, while they are increased in backward direction. This effect can be only partially mitigated by decreasing the rupture speed (e.g., by increasing $D_{c}$ ) in purely elastic simulations.

We calculate the PGVs of 250000 synthetic stations distributed within $1 \mathrm{~km}$ and $105 \mathrm{~km} R_{J B^{-}}$distance of the fault trace using GMRotD50 (Boore et al., 2006). These stations are binned with respect to their azimuth to the epicenter with a bin width of $15^{\circ}$, resulting in at least 7000 stations per bin.

Fig. 13 shows the azimuthal dependence of the mean value of PGVs $\mu_{\mathrm{PGV}}$ calculated for each bin and for all three scenarios. We observe differences in absolute PGVs between our scenarios, especially in the forward and backward directions. The purely elastic simulation model VE-KT0-062 (black) exhibits the highest $\mu_{\mathrm{PGV}}$ reaching up to $47.1 \mathrm{~cm} / \mathrm{s}$ in forward direction (between $-30^{\circ}$ and $-15^{\circ}$ ). The increase of $D_{c}$ from $0.62 \mathrm{~m}$ to $0.72 \mathrm{~m}$ (model VE-KT0-072) decreases $\mu_{\mathrm{PGV}}$ by up to $11 \%$ in forward direction. Plasticity reduces $\mu_{\mathrm{PGV}}$ by up to $35 \%$ compared to an identical elastic simulation with $D_{c}=$ $0.62 \mathrm{~m}$. However, the directions between $-90^{\circ}$ and $-45^{\circ}$ and $45^{\circ}$ and $-135^{\circ}$ experience very similar $\mu_{\mathrm{PGV}}$ for all three scenarios. In backward direction (between $150^{\circ}$ and $165^{\circ}$ ), $\mu_{\mathrm{PGV}}$ is elevated and peaks for the simulation with off-fault plasticity and the elastic simulation with increased $D_{c}$.

While some of the increase of $\mu_{\mathrm{PGV}}$ in backward directivity is attributed to the low velocity basin around the Salton Sea that generates basin-amplification effects (see Fig. 7 ), we can also attribute our results to the geometrical complexity of the fault system. 

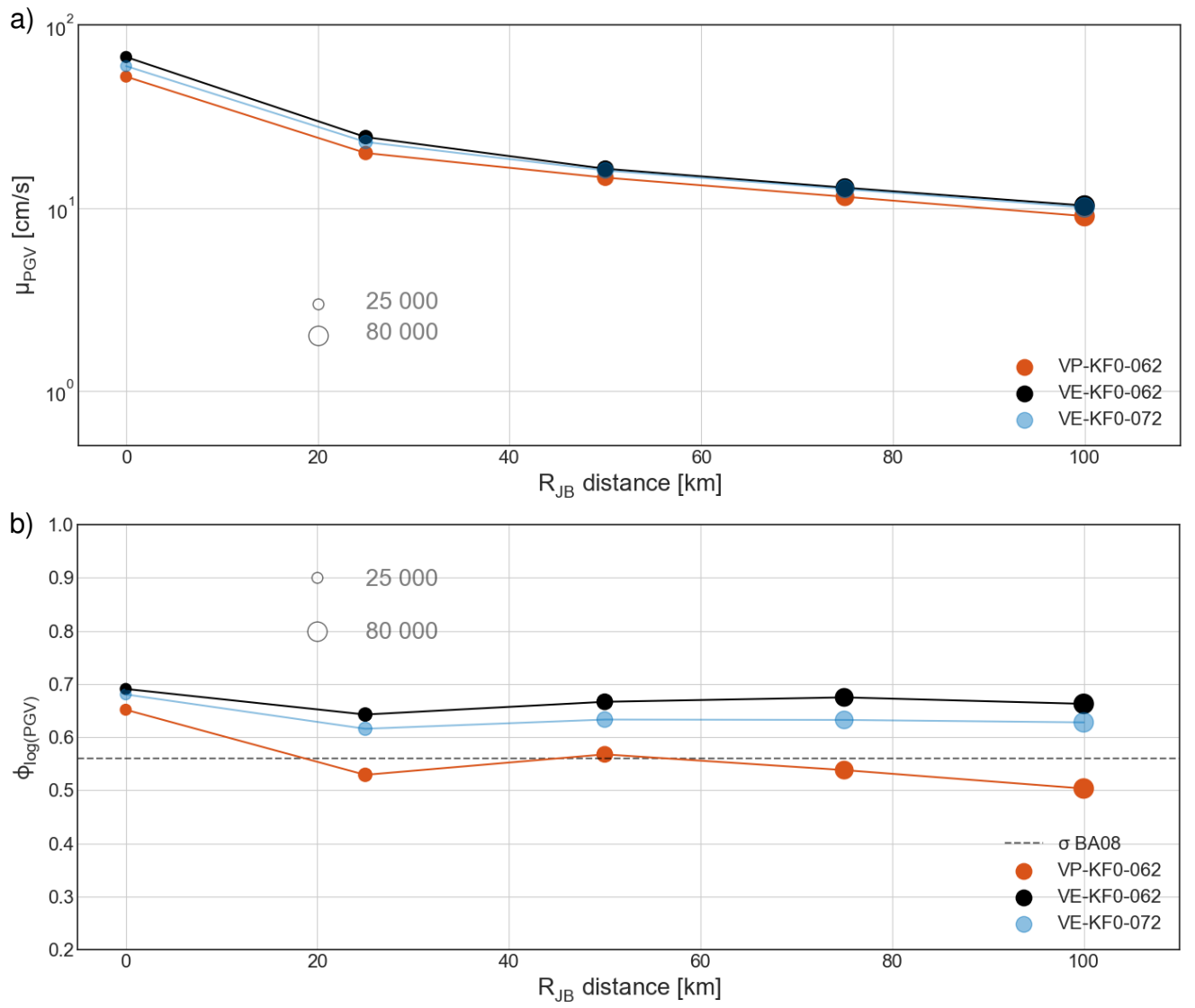

Figure 14. Distance dependence of a) the mean PGV $\mu_{\mathrm{PGV}}$ and b) standard deviation $\phi_{\log (\mathrm{PGV})}$ for our preferred model with plasticity (orange), the corresponding elastic simulation (model VE-KT0-062, black) and the elastic simulation with increased $D_{c}$ (model VE-KT0-072, light blue) for all stations between $1 \mathrm{~km}$ and $105 \mathrm{~km} R_{J B}$-distance (bin width $=20 \mathrm{~km}$ ). The circle size represents the number of stations in each bin. The dashed line in b) represents the constant standard deviation of the GMPE of (Boore \& Atkinson, 2008).

Rupture propagation is slowed down at geometrical barriers or fault branches by the occurrence of plastic yielding which leads to an increase of reversely propagating rupture. We observe that lower rupture speeds and longer delays at geometrical barriers lead to more backward traveling seismic waves which further increase PGVs in backward direction.

We conclude that the effect of plasticity can only be partially emulated by a rupture speed decrease (e.g. increasing $D_{c}$ ) in purely elastic simulations: the simulation with plasticity and the elastic simulation with increased $D_{c}$ show similar $\mu_{\mathrm{PGV}}$ between $-180^{\circ}$ and $-45^{\circ}$ and $45^{\circ}$ and $180^{\circ}$, but the purely elastic simulation still overestimates the directivity effect between $-45^{\circ}$ and $45^{\circ}$.

\subsubsection{Distance Dependence of PGVs}

Let us now investigate the distance dependence of the mean PGVs $\mu_{\mathrm{PGV}}$ for the three simulations. Plastic yielding primarily appears in the vicinity of the fault, but corresponding PGV maps show reductions (beyond the standard geometrical spreading) over 
large distances (Roten et al., 2014). To investigate this effect systematically, all stations are binned with respect to their $R_{J B}$-distances using a bin widths of $20 \mathrm{~km}$ (at least 25 000 stations per bin). Fig. 14 a) shows the mean PGV $\mu_{\mathrm{PGV}}$ for each of these bins.

In general, the elastic simulations show higher $\mu_{\mathrm{PGV}}$ over all distances in comparison to our preferred model with plasticity. Larger differences are visible close to the fault where plasticity reduces $\mu_{\mathrm{PGV}}$ by $21.9 \%$ within the first $20 \mathrm{~km}$, while $\mu_{\mathrm{PGV}}$ is reduced by on average $12.4 \%$ between $85 \mathrm{~km}$ and $105 \mathrm{~km} R_{J B}$-distance. By increasing $D_{c}$ in the purely elastic simulations, $\mu_{\mathrm{PGV}}$ is reduced by $10.8 \%$ within the first $50 \mathrm{~km}$ (still $12.4 \%$ difference to the simulation with plasticity), but shows almost identical behavior for larger distances compared to the elastic simulation with $D_{c}=0.62 \mathrm{~m}$.

GMPEs commonly assume a constant ground motion variability (Boore \& Atkinson, 2008), independent of the distance to the fault. However, a distance dependent variability is found for kinematic simulations of the Landers earthquake assuming purely elastic material properties (Vyas et al., 2016). Different ground motion variability values might have a significant impact on the results of seismic hazard analysis (e.g., Restrepo-Velez \& Bommer, 2003; Bommer \& Abrahamson, 2006; Strasser et al., 2009). Here, we additionally investigate the distance dependence of ground motion variability in dynamic rupture simulations on complex faults including off-fault plasticity.

Fig. $14 \mathrm{~b}$ ) shows the standard deviation of the logarithmic PGVs $\phi_{\log (\mathrm{PGV})}$ for each bin in comparison to the constant value of 0.56 used by the GMPE of Boore and Atkinson (2008). The variability is in general higher than 0.56 for the purely elastic simulations although $\phi_{\log (\mathrm{PGV})}$ is already reduced by $4.4 \%$ in average when we increase $D_{c}$. The simulation with plasticity shows the smallest ground motion variability, ranging from 0.65 (0-20 km bin) to 0.50 (85-105 km bin), very close to what is used in GMPEs by Boore and Atkinson (2008). In the simulation with plasticity, high stresses are limited by plastic yielding, which results in a reduction and smoothing of on-fault slip rates (e.g., Wollherr et al., 2018). As a consequence of the smoother peak slip rates, the resulting ground motions have lower variability.

Overall, we observe only a small distance dependence of ground motion variability for the simulations using purely elastic rock properties, in contrast to what is reported by Vyas et al. (2016). However, they employ kinematic source models of the 1992 Landers earthquakes using a second order accurate generalized finite-difference code (Ely et al., 2008). They find that the variability is much higher close to the fault (in average 0.79), and reduces to a constant value of 0.6 only at $100 \mathrm{~km}$ distance (Fig. 5 in Vyas et al. (2016)).

We argue that the smoother final slip distribution of our dynamic rupture source models is responsible for the lower variability of simulated ground motions. In our model, the highest slip is always located at depth, and it is very smoothly distributed across the fault segments (Fig. 4). In contrast, Vyas et al. (2016) use kinematic source models of Cotton and Campillo (1995); Hernandez et al. (1999); Zeng and Anderson (2000); Wald and Heaton (1994) and Cohee and Beroza (1994) which all feature very heterogeneous slip distributions, that is, slip occurs in isolated patches. Also, four out of their five models contain zones of large near-surface slip that may lead to an increased variability of ground motions in the vicinity of the fault. Vyas et al. (2016) observe the lowest distance dependence of variability for the kinematic source model of Zeng and Anderson (2000) that has its highest slip at depth, similar to our simulations.

In contrast to the purely elastic simulation, ground motion variability close to the fault for our preferred model with plasticity is increased by $29.4 \%$ with respect to variability between $85 \mathrm{~km}$ and $105 \mathrm{~km} R_{J B}$-distance. Localized plastic deformation (see Fig. 10) additionally alters PGVs very heterogeneously in the vicinity of the fault, therefore further increasing the variability within the first $20 \mathrm{~km}$. 


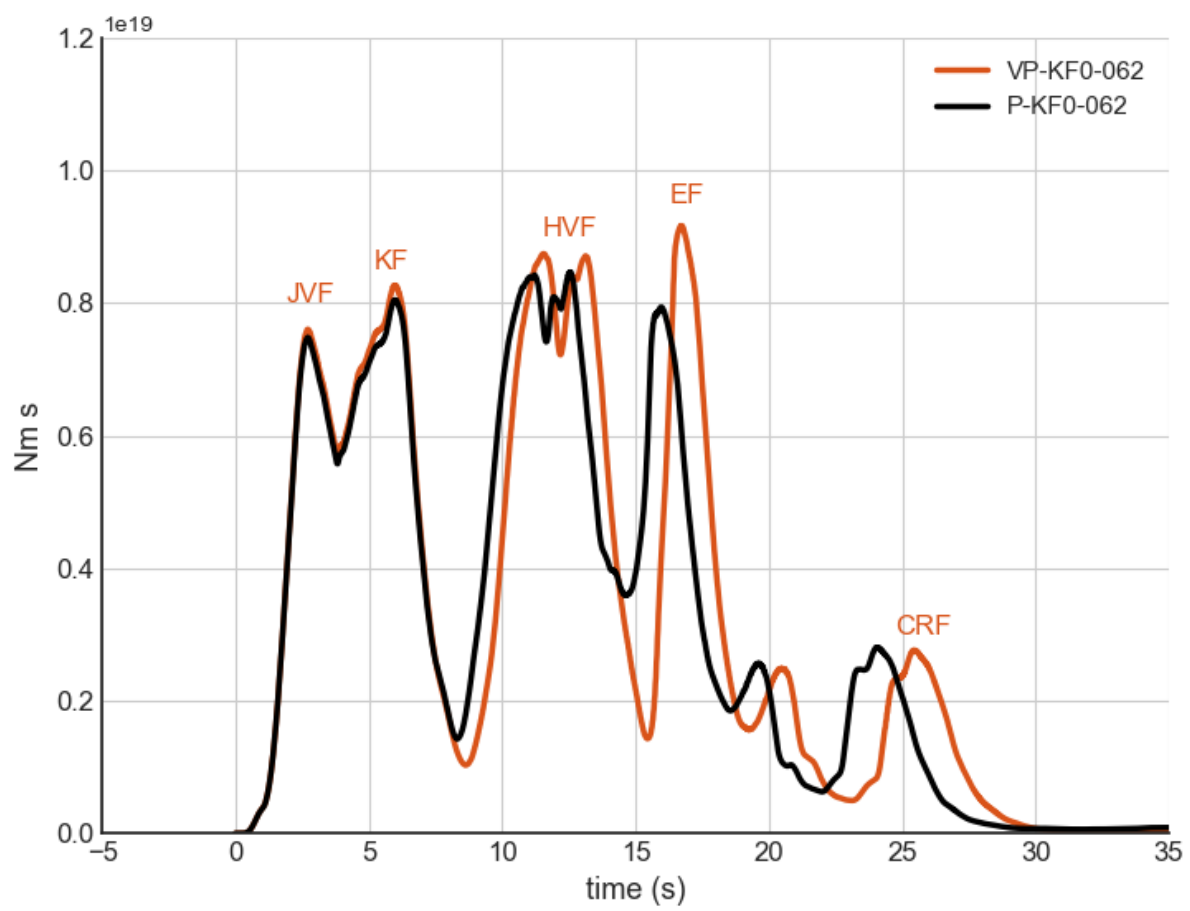

Figure 15. Seismic moment-release rate of our preferred model including off-fault plasticity and viscoelastic attenuation (VP-KF0-062, orange) in comparison to the corresponding simulation accounting for off-fault plasticity but not for viscoelastic attenuation (P-KF0-062, black).

We conclude that mean peak ground motions are stronger reduced in the vicinity of the fault when accounting for off-fault plastic yielding, but the reduction is still visible at $100 \mathrm{~km} R_{J B}$-distance. Additionally, ground motion variability for our preferred model using off-fault plasticity is close to what is commonly used in GMPEs (Boore \& Atkinson, 2008), and in general lower than in the elastic simulations. Due to the heterogeneous distribution of near-fault plastic yielding, ground motion variability in the simulation with off-fault plasticity are slightly increased within $20 \mathrm{~km}$ to the fault.

\subsection{The Effect of Attenuation on Dynamic Triggering}

Viscoelastic attenuation is an important physical mechanism that describes the gradual damping of high frequency seismic waves with propagation distance. Our preferred scenario accounts for viscoelastic-plastic rheology (model VP-KF0-062). We clearly observe decreasing peak velocities with increasing travel distances in comparison to a setup without attenuation (model P-KF0-062, see Fig. D1 in Appendix Appendix D for synthetic PGVs of all seismic stations without and with accounting for seismic attenuation). However, as a consequence of the damping of high frequency seismic waves, seismic attenuation also affects rupture dynamics, specifically the dynamically triggered rupture transfers and re-initiation.

We find that all rupture transfer processes of our extended fault system are affected by the energy the seismic waves carry - no attenuation meaning more seismic energy and thus facilitation of dynamic triggering. Fig. 15 shows the moment rate over time of our 
preferred simulation (model VP-KF0-062, orange) compared to the same simulation but without accounting for seismic attenuation (model P-KF0-062, black). Within the first $8 \mathrm{~s}$ rupture propagation and moment rate release are identical. At $8.1 \mathrm{~s}$, after the rupture delay at the HVF central fault bend, we observe faster rupture re-initiation in the simulation without attenuation. Additionally, rupture is dynamically triggered at the EF at an earlier time (at $15 \mathrm{~s}$ ). With attenuation, rupture jumping to the CRF is additionally delayed (from 17.9 to $22 \mathrm{~s}$ ).

The faster rupture initiation after the bend at the center of the HVF in the simulation without attenuation suggests that rupture transfer is facilitated by the non-damped arriving seismic waves. We note, that dynamic triggering in a segmented fault system is highly non-linear and may bridge distances larger than expected from simplified setups (R. Harris \& Day, 1993; D. Oglesby, 2008; Finzi \& Langer, 2012b). For instance, at the northernmost segments which are affected by seismic waves traveling more than $50 \mathrm{~km}$ from the hypocenter remote triggering is delayed with attenuation. Curiously, the modeled moment rate not accounting for attenuation yields a nominal better fit to the SCARDEC moment rate as indicated by the higher EG and PG values with respect to our preferred model (Table 3) but are within the uncertainties associated with the observationally constrained moment rate. Still, the resulting slip distribution and moment magnitude is in both cases identical $\left(M_{w} 7.29\right)$. A detailed analysis of the frequency bands responsible for remote triggering of rupture at adjacent fault segments will be considered in future work.

For simulations without off-fault plasticity, rupture dynamics are less altered by ignoring attenuation. This suggests that near fault plastic deformation places strong constraints on the conditions allowing sustained rupture. As a consequence dynamic triggering, and an exact modeling of the emanated seismic wave field and its interaction with the fault system is crucial. The spatial extend of the Landers fault system leads to dynamic triggering effects over distances large enough such that seismic attenuation matters.

\subsection{Shallow Slip at the Camp Rock Fault}

It is debated whether the shallow part of the CRF slipped co-seismically or if it was triggered by static stress changes shortly after the event (Sieh, 1996; Kaneda \& Rockwell, 2009). A lack of aftershock recordings (Hauksson et al., 1993; Sieh et al., 1993) as well as the asymmetric right-lateral slip pattern indicate that slip may have been induced by static stress changes due to the failure of the EF (Sieh, 1996; Kaneda \& Rockwell, 2009). Interestingly, slip inversion results based on GPS data (Wald \& Heaton, 1994; Hernandez et al., 1999; Gombert et al., 2018) show higher shallow slip in the northernmost part of the fault system than inversions based on seismic recordings (Cohee \& Beroza, 1994; Cotton \& Campillo, 1995). However, due to the restriction of most inversion methods to simplified fault surfaces it is difficult to assign the shallow slip non-ambiguously to either the EF and CRF.

Our dynamic rupture model of the Landers earthquake with plasticity does not create large shallow slip at the northernmost fault segment. The central part of the CRF is dynamically triggered at a depth of $\approx 8 \mathrm{~km}$. Rupture dies out quickly towards the surface, without inducing large surface slip (average surface slip along the CRF of $0.8 \mathrm{~m}$ ). Similar values are obtained for the corresponding elastic simulation (although the elastic SSD is lower due to a lower maximum slip at depth).

The here assumed regional stress field at the CRF in conjuncture with the given fault geometry, inhibits large surface slip. Dynamic rupture experiments varying stress orientations and stress amplitudes reveal that considerably higher surface slip cannot be generated while breaking the full fault system and generating reasonable amount of slip 
at the the southernmost fault segments. Thus, our dynamic rupture model aligns with the hypothesis of statically triggered shallow rupture at the CRF.

Kaneda and Rockwell (2009) investigate the CRF in detail by analyzing tectonicgeomorphic features along this fault segment. The 1992 rupture at the CRF differs distinctly from the characteristics of the penultimate and long-term ruptures. In particular, the vertical motion is almost opposite to previous ruptures. They conclude that the fault geometry might include a small dipping component at the center of the fault segment which shows a reverse-slip motion induced by static stress changes. In contrast, our dynamic rupture model uses a vertical fault geometry for the entire fault system. Future work could investigate whether a dipping fault geometry at the center of the CRF facilitates dynamic rupture activation and propagation at shallow depth or if shallow slip can only be induced by static stress changes.

\subsection{Uncertainties associated with source time functions}

Observationally constrained source time functions (STFs) are associated with substantial uncertainties, owing to data distribution, near-receiver wave-propagation effects, and aspects of the radiation pattern, in particular in case of complex faulting geometry. Despite these uncertainties, STFs provide first-order estimates of the moment release over time but should not be considered as measured ̈̈ata. Instead, STFs represent an inferred/ estimated quantity that helps to map and understand the kinematic rupture process. It is important to state that in addition to the overall uncertainties associated with STFs, specifically if solely based on teleseismic data, the 1992 Landers earthquake introduces additional complications: First, STFs are in general less reliable for pure strike-slip events, as the P-wave radiation pattern is especially unfavorable for far-field source-process estimation. Second, the change in strike makes it even more difficult to resolve the moment release due to the hypothesis of a constant mechanism. Availability and quality of observational data of this relatively old earthquake further complicates the problem of estimating an accurate and reliable far-field moment-rate function for such earthquakes.

We developed our preferred model by comparing to the SCARDEC source time functions (Vallée \& Douet, 2016). Alternative dynamic rupture model parametrizations might have been obtained if using different STFs, for example, from near-field finite-fault inversions. However, given that finite fault inversions are inherently non-unique and thus the inferred rupture models may be highly variable for a given earthquake (e.g., Mai et al., 2016), their corresponding STFs also show substantial differences. Thus, we focus here on a set of STFs derived from the same database to ensure internal consistency. 


\section{Conclusions}

We present a mechanically viable dynamic rupture scenario of the 1992 Landers earthquake, that helps our understanding of the physical mechanisms of rupture transferring between adjacent fault segments while simultaneously reproducing a wide range of observations.

The model accounts for high-resolution topography, complex fault system geometries, 3D subsurface structure, viscoelastic attenuation, off-fault plasticity and depth-dependent cohesion. Earthquake rupture is able to break all geometrically complex segments of the fault system under the assumption of smoothly varying fault stress and strength conditions. The simulation reproduces far-field and near-field observations, such as the total moment rate, final fault slip, seismic waveforms and respective peak ground motions, as well as off-fault deformation patterns. Our dynamic rupture earthquake scenario allows detailed analysis of the mechanical sustainability of dynamic rupture transfer with respect to the interplay of tectonic stress and local fault strength conditions.

Sustained dynamic rupture of all Landers fault segments poses a strong constraint on model parametrization. Specifically, the facilitation and timing of rupture transfers between the principal fault segments determine the amplitude and orientation of initial fault stresses and friction. Scenarios succeeding in rupture across the entire fault system feature very robust slip distribution under variation of nucleation patch sizes and frictional parameters that alter the stress drop- however timing of rupture transfers are highly sensitive.

Importantly, the resulting source dynamics depict a variety of rupture transfer mechanisms, including dynamic triggering and direct rupture branching and combination of both; both mechanisms are crucial to drive rupture across the entire fault system given the fault geometry used in this study. Large stress changes due to the subsequent, or almost simultaneous, failure of the $\mathrm{HVF}$ and $\mathrm{EF}$ enables dynamic triggering of the CRF over distances much larger than previously suggested.

Our dynamic rupture model reveals that dynamic triggering - often associated with the observed segmentation of moment release - is not the only feature reducing the moment release. In particular, rupture deceleration due to complex fault geometry strongly affects the moment-release rate, thus complicating the inference of rupture transfer mechanisms from observations.

In contrast to previous models (Aochi \& Fukuyama, 2002; Aochi et al., 2003), we find that a steeply oriented regional stress field (maximum principal stress close to north) is crucial to allow the northernmost part (CRF) to rupture. Interestingly, large shallow slip of the CRF is dynamically inhibited in our scenario, supporting the hypothesis of statically triggered shallow rupture at the CRF shortly after the main event (Sieh, 1996; Kaneda \& Rockwell, 2009). We are unable to generate considerably higher surface slip by variations in stress orientations and stress amplitudes while simultaneously breaking the entire fault system and creating reasonable amount of slip at the southernmost fault segments for the given fault geometry and under the assumption of frictional parameters being constant at all depths.

Rupture termination in our model is overall independent of the geometrically prescribed fault endings, with exception of the northernmost section of the HVF. Rupture is stopped smoothly corresponding to fault orientation towards the principal stress orientation. Our dynamic rupture model therefore provides a consistent explanation for spontaneous rupture termination on most of the principal fault segments, although fault structures in reality continue.

We show that an along-strike variability of the SSD of up to $20 \%$ is possible, even for laterally constant rock cohesion and bulk friction. Since these variations also exists 
for the purely elastic simulation, they can be attributed to different principal stress directions and the complex fault geometry. Shallow plastic deformation increases the SSD between $0.7 \%$ and $36 \%$ in dependence of the fault orientation and resulting rupture dynamics. Relatively high SSDs (up to 50\%) are possible for good quality rock without the presence of pre-exising fault-damage zones if stress drop is high. We observe dramatically increased off-fault deformation in the vicinity of fault bends and intersections, in excellent agreement with recent maps of fault-zone width (Milliner et al., 2015). Good agreement of synthetic waveform characteristics and associated peak ground velocities with observations include capturing of the main S-wave pulses, amplitudes, and shaking duration.

In contrast to a purely elastic simulation, our viscoelastic-plastic scenario reduces the mean PGVs in forward direction by up to $35 \%$, while ground motions perpendicular to the fault are very similar. Rupture transfer and moment rate of the simulation with plasticity can be partially emulated by an elastic simulation with increased critical slip distance $D_{c}$ that leads to slower rupture speeds and longer delays for transferring rupture to adjacent segments. However, the elastic simulation with decreased rupture speed still overestimates PGVs in forward rupture direction by $11 \%$.

Ground motion variability with respect to fault distance is in general lower for the simulation with off-fault plasticity, and found to be close to 0.56 (e.g., Boore \& Atkinson, 2008), commonly assumed in GMPEs. However, the simulation accounting for plastic yielding creates higher ground motion variability close to the fault, presumably due to the heterogeneous distribution of near-fault plastic yielding.

We find that the complex source dynamics of the Landers fault system lead to dynamic triggering over large distances, which are large enough to be strongly affected by seismic attenuation. The effect of attenuation on dynamic triggering is pronounced for models including off-fault plastic deformation. 


\section{Appendix}

\section{Appendix A Cohesive Zone Width}

Wollherr et al. (2018) find, that the cohesive zone width can vary considerably across geometrically complex fault systems. The authors suggest that its minimum should pose the inherent length scale to be resolved instead of an average value. Additionally, a measured cohesive zone width may vary with underlying (coarse) fault discretization. Only for sufficiently high resolutions of the fault, one can determine a correct ("numerically converged") cohesive zone width. Higher resolutions need to be considered to determine whether the cohesive zone width reached a stable value (i.e. converged) or if the solution is still changing with mesh refinement.

To calculate the cohesive zone width, we determine the time of the onset of rupture $(R T)$, as well as the time when shear stresses reach their dynamic value $(D S)$. Using the rupture speed $v_{r}$, the cohesive zone is then defined by the formula $(D S-R T) v_{r}$. For our preferred model the minimum cohesive zone width is measured as $155 \mathrm{~m}$ located at the HVF at a depth of $8 \mathrm{~km}$. For a given on-fault resolution of $200 \mathrm{~m}$, the minimum cohesive zone is then resolved by 0.775 mesh elements (or 4.56 sub-elemental Gaussian integration points for polynomial degree $p=4$.). Note, that due to the different principal stress amplitudes and orientations used in this model, the rupture paths varies from the scenarios in Wollherr et al. (2018) and consequently the cohesive zone width is slightly smaller than reported therein.

The convergence rates in Wollherr et al. (2018) help to determine the potential error level with respect to a high resolution reference solution given the minimum cohesive zone width resolution and a polynomial degree $p$. For $p=4$, the $200 \mathrm{~m}$ on-fault resolution corresponds to a mean error of $0.16 \%$ for peak slip rate time, $4.16 \%$ for peak slip rate, $0.15 \%$ for rupture arrival and $0.94 \%$ for final slip. These values are sufficiently small to accurately resolve the source dynamics (Day et al., 2005).

\section{Appendix B Resolved Frequencies}

We analyze the distance dependent frequency content of synthetic velocity recordings to determine the maximum resolved frequency content of the wave field in our simulation. Fig. B1 shows the normalized frequency spectrum of the observed and simulated seismic velocities for a selection of seismic stations. The stations locations are visualized in Fig. 7. Their full name, $R_{J B}$-distance, and corresponding $V s_{30}$-value can be found in Table 2.

The highest resolved frequencies are determined by evaluating the maximum frequency for which the synthetic spectra align with the expected $\omega^{-1}$ frequency decay. In particular close to the faults, our simulation reaches very high frequencies without modeling small-scale roughness or pre-stress heterogeneities. The station LUC, which is the closest station to the fault traces $\left(0.47 R_{J B}\right.$-distance), shows frequencies reaching up to $4.0 \mathrm{~Hz}$. The stations YER (24.37 km $R_{J B}$-distance) in forward direction includes frequencies up to $\approx 3.0 \mathrm{~Hz}$. With increasing distance the resolved frequency content increasingly deviate from an ideal $\omega^{-1}$ decay: Stations FRT $\left(64.97 \mathrm{~km} R_{J B^{-}}\right.$distance) and BOR (87.33 $\mathrm{km} R_{J B}$-distance) reach up to $2.0 \mathrm{~Hz}$ and $1 \mathrm{~Hz}$, respectively. In the low velocity basin of the Salton Sea, station SAL (102.8 $\mathrm{km} R_{J B}$-distance) only resolves a maximum frequency of $1.0 \mathrm{~Hz}$. Therefore, to assure consistent frequency ranges of all synthetics, we bandpass filter all stations in Sec. 3.5.2 in between 0.05 and $1.0 \mathrm{~Hz}$. 


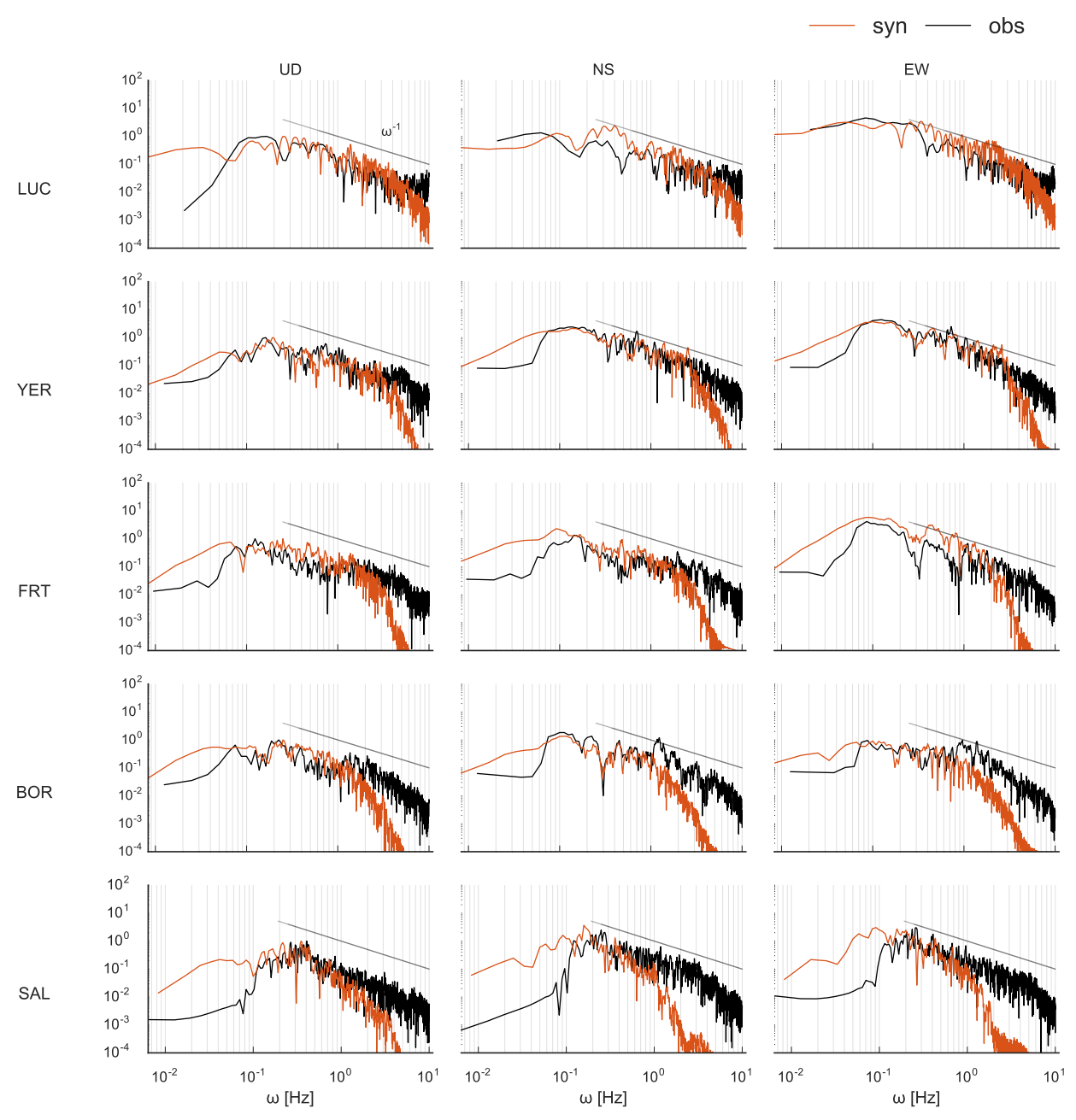

Figure B1. Normalized frequency spectra for observed (orange) and simulated (black) seismic velocities for a selection of stations listed in Table 2 . The stations are ordered by their $R_{J B^{-}}$ distance. The black line indicates the ideally expected frequency decay of $\omega^{-1}$. The frequencies are cut at their respective Nyquist frequency. 

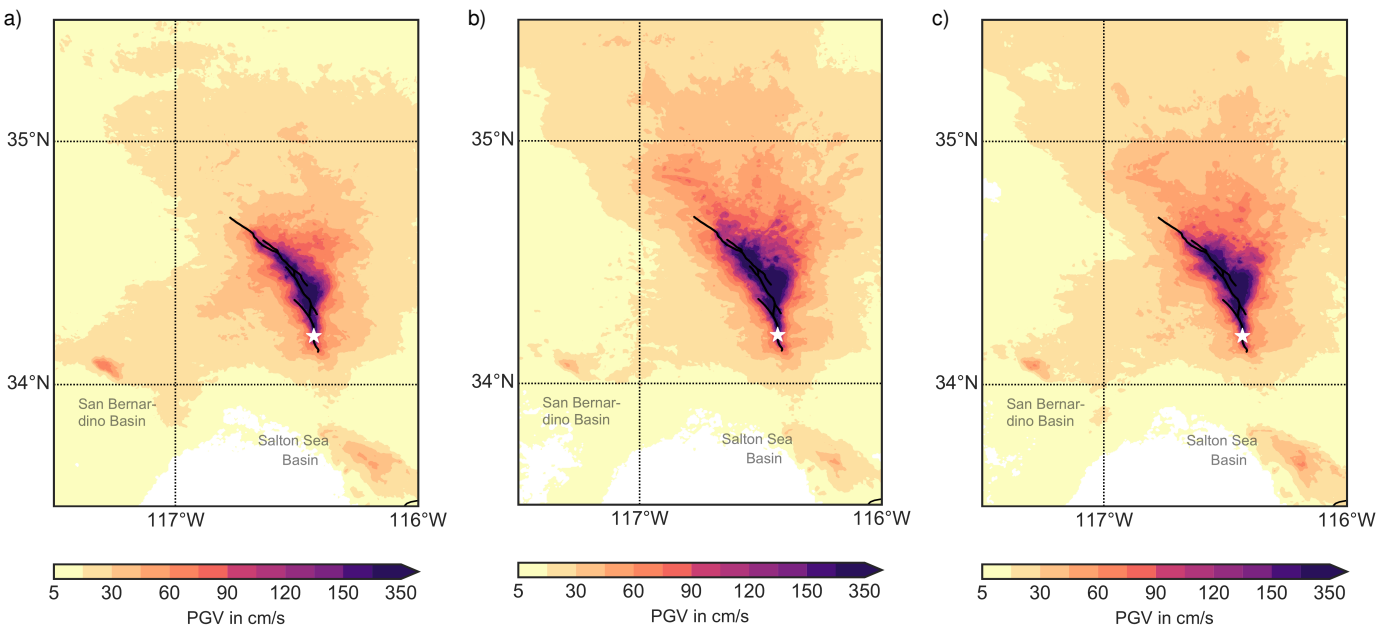

Figure C1. Simulated GMRotD50 (Boore et al., 2006) PGVs above $5 \mathrm{~cm} / \mathrm{s}$ for a) our preferred simulation with plasticity (VP-KF0-062), b) the corresponding purely elastic simulation (VE-KF0-062) and b) for the purely elastic simulation with increased $D_{c}$ (VE-KF0-072). The white star marks the epicenter of the 1992 event.

\section{Appendix C Peak Ground Motions Maps}

We here show a close-up of the PGVs of the three presented simulations in Sec. 4.2: the preferred model with plasticity (Fig. C1 a)), the corresponding elastic simulation (Fig. $\mathrm{C} 1 \mathrm{~b})$ ) and the corresponding elastic simulation with increased $D_{c}$ (Fig. C1 c)). Consistent with the findings for the mean PGVs with respect to the distance or azimuth bins in Sec. 4.2, we find that the directivity effect is much more pronounced in the elastic simulations. However, an increase of $D_{c}$ in the elastic simulation drastically reduces the PGVs in forward direction while the PGV in the Salton Sea Basin are slightly increased due to the slower rupture which results in more backward propagating rupture. Still, ground motions in the plastic simulation differ, in particular in the forward direction.

\section{Appendix D Effect of Attenuation on Peak Ground Motions}

We discuss in Sec. 4.4 the effect of attenuation on source dynamics, in particular on dynamic triggering. Fig. D1 shows how attenuation affects the simulated PGVs for the stations listed in Sec. 3.5 and visualized in Fig. 7. While PGVs are almost identical for near fault stations up to $20 \mathrm{~km} R_{J B}$-distance, we observe a clear decrease in PGVs for greater distances due to the attenuation of seismic waves with propagation distance. 


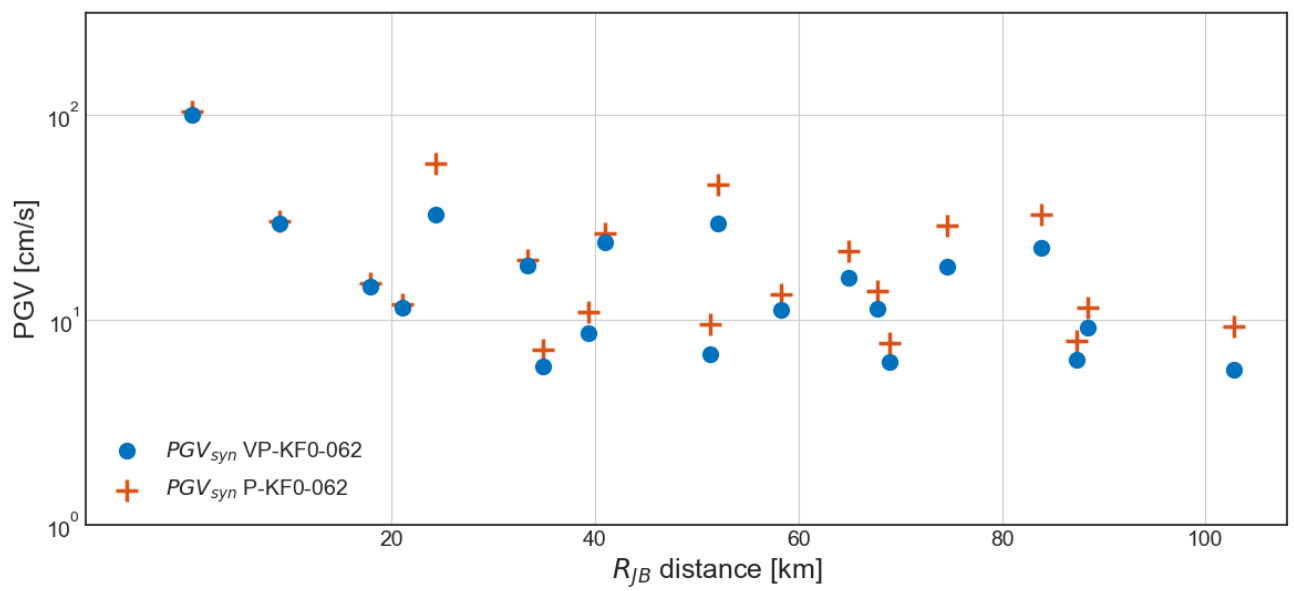

Figure D1. Simulated PGVs with (blue circles) and without attenuation (orange crosses) in dependence of $R_{J B}$-distance of the stations given in Table 2 . 


\section{Acknowledgments}

We thank Christopher Milliner for providing the left part of Fig. 10 which is similar to Fig. 7 in Milliner et al. (2015). All data used are listed in the paper. Simulation results were obtained using the open-source software package SeisSol, freely available at github.com/SeisSol/SeisSol. All initial conditions and results generated by our simulations are available upon request. Computing resources were provided by the Leibniz Supercomputing Centre (LRZ, projects no. pr45fi and pr63qo on SuperMUC). The work presented in this paper was supported by the German Research Foundation (DFG) (projects no. KA 2281/4-1, GA 2465/2-1, BA 3529/6-1), by the Bavarian Competence Network for Technical and Scientific High Performance Computing (KONWIHR), project GeoPF (Geophysics for PetaFlop Computing), by the Volkswagen Foundation (project ASCETE - Advanced Simulation of Coupled Earthquake-Tsunami Events, grant No. 88479), by the European Union's Horizon 2020 research and innovation program under grant agreement No. 671698 and No. 823844 as well as by King Abdullah University of Science and Technology (KAUST) in Thuwal, Saudi Arabia, under grant ORS-2016-CRG5-3027-04 and OSR-CRG2017-3389. P. M. Mai is sponsored through KAUST research fund BAS/1339-01-01.

\section{References}

Abercrombie, R., \& Mori, J. (1994). Local observations of the onset of a large earthquake: 28 June 1992 Landers, California. Bulletin of the Seismological Society of America, $84(3), 725$.

Abers, G. A., \& Gephart, J. W. (2001). Direct inversion of earthquake first motions for both the stress tensor and focal mechanisms and application to southern California. Journal of Geophysical Research: Solid Earth, 106(B11), 2652326540.

Ampuero, J.-P., Vilotte, J.-P., \& Sanchez-Sesma, F. (2002). Nucleation of rupture under slip dependent friction law: simple models of fault zone. Journal of Geophysical Research: Solid Earth, 107(B12).

Ando, R., Imanishi, K., Panayotopoulos, Y., \& Kobayashi, T. (2017). Dynamic rupture propagation on geometrically complex fault with along-strike variation of fault maturity: Insights from the 2014 Northern Nagano earthquake Crustal Dynamics: Unified Understanding of Geodynamics Processes at Different Time and Length Scales Yoshihisa Iio, Richard H. Sibson, Toru Takeshita, Takeshi Sagiya, Bunichiro Shibazaki and Junichi Nakajima. Earth Planets Space, 69(1). doi: 10.1186/s40623-017-0715-2

Andrews, D. J. (1999). Test of two methods for faulting on finite-difference calculations. Bulletin of the Seismological Society of America, 89(4), 931-937.

Andrews, D. J. (2005). Rupture dynamics with energy loss outside the slip zone. Journal of Geophysical Research: Solid Earth, 110(1), 1-14. doi: 10.1029/2004JB003191

Aochi, H., \& Fukuyama, E. (2002). Three-dimensional nonplanar simulation of the 1992 Landers earthquake. Journal of Geophysical Research: Solid Earth, 107(B2), B22035. doi: 10.1029/2000JB000061

Aochi, H., \& Madariaga, R. (2003). The 1999 Izmit, Turkey, earthquake: Nonplanar fault structure, dynamic rupture process, and strong ground motion. Bulletin of the Seismological Society of America, 93(3), 1249-1266. doi: 10.1785/ 0120020167

Aochi, H., Madariaga, R., \& Fukuyama, E. (2003). Constraint of fault parameters inferred from nonplanar fault modeling. Geochemistry, Geophysics and Geosystems , 4 (2), 1-16. doi: 10.1029/2001GC000207

Barall, M. (2009). A grid-doubling finite-element technique for calculating dynamic three-dimensional spontaneous rupture on an earthquake fault. Geophysical Journal International, 178(2), 845-859. doi: 10.1111/j.1365-246X.2009.04190 . $\mathrm{x}$ 
Bhat, H. S., Olives, M., Dmowska, R., \& Rice, J. R. (2007). Role of fault branches in earthquake rupture dynamics. Journal of Geophysical Research: Solid Earth, 112(B11), B11309. doi: 10.1029/2007JB005027

Bizzarri, A. (2010). How to promote earthquake ruptures: Different nucleation strategies in a dynamic model with slip-weakening friction. Bulletin of the Seismological Society of America, 100(3), 923-940.

Bommer, J. J., \& Abrahamson, N. A. (2006). Why do modern probabilistic seismichazard analyses often lead to increased hazard estimates? Bulletin of the Seismological Society of America, 96(6), 1967-1977.

Boore, D. M., \& Atkinson, G. M. (2008). Ground-motion prediction equations for the average horizontal component of pga, pgv, and 5\%-damped psa at spectral periods between $0.01 \mathrm{~s}$ and $10.0 \mathrm{~s}$. Earthquake Spectra, 24(1), 99-138.

Boore, D. M., Watson-Lamprey, J., \& Abrahamson, N. A. (2006). Orientationindependent measures of ground motion. Bulletin of the Seismological Society of America, 96(4A), 1502-1511.

Bouchon, M., \& Campillo, M. (1998). Stress field associated with the rupture of the 1992 Landers, California, earthquake and its implifications concerning the fault strength at the onset of the earthquake. Journal of Geophysical Research: Solid Earth, 103(B9), 21091-21097.

Breuer, A., Heinecke, A., \& Bader, M. (2016). Petascale local time stepping for the ADER-DG finite element method. In 2016 IEEE International Parallel and Distributed Processing Symposium (pp. 854-863). IEEE.

Breuer, A., Heinecke, A., Rannabauer, L., \& Bader, M. (2015). High-Order ADERDG Minimizes Energy-and Time-to-Solution of SeisSol. In Proceedings of the International Conference on High Performance Computing (pp. 340-357). Cham: Springer International Publishing.

Breuer, A., Heinecke, A., Rettenberger, S., Bader, M., Gabriel, A.-A., \& Pelties, C. (2014). Sustained Petascale Performance of Seismic Simulations with SeisSol on SuperMUC. In Proceedings of the international supercomputing conference (pp. 1-18). Cham: Springer International Publishing.

Campbell, K. W., \& Bozorgnia, Y. (1994). Empirical analysis of strong ground motion from the 1992 landers, california, earthquake. Bulletin of the Seismological Society of America, 84(3), 573.

Campillo, M., \& Archuleta, R. J. (1993). A rupture model for the 28 June 1992 Landers, California, earthquake. Geophysical Research Letters, 20(8), 647-650.

Candela, T., Renard, F., Klinger, Y., Mair, K., Schmittbuhl, J., \& Brodsky, E. E. (2012). Roughness of fault surfaces over nine decades of length scales. Journal of Geophysical Research: Solid Earth, 117(B8). doi: 10.1029/2011JB009041

Chen, X. (1995). Near-field ground motion from the Landers earthquake (Unpublished doctoral dissertation). California Institute of Technology.

Cohee, B. P., \& Beroza, G. C. $\quad$ (1994). Slip distribution of the 1992 Landers earthquake and its implications for earthquake source mechanics. Bulletin of the Seismological Society of America, 84(3), 692-712. doi: 10.1016/0148-9062(95)94486-9

Cotton, F., \& Campillo, M. (1995). Frequency domain inversion of strong motions: Application to the 1992 Landers earthquake. Journal of Geophysical Research: Solid Earth, 100(B3), 3961-3975.

Dalguer, L. A., \& Day, S. M. (2007). Staggered-grid split-node method for spontaneous rupture simulation. Journal of Geophysical Research: Solid Earth, 112(2), 1-15. doi: 10.1029/2006JB004467

Das, S., \& Aki, K. (1977). Fault plane with barriers: a versatile earthquake model. Journal of Geophysical Research: Solid Earth, 82(36), 5658-5670.

Day, S. M., Dalguer, L. A., Lapusta, N., \& Liu, Y. (2005). Comparison of finite difference and boundary integral solutions to three-dimensional spontaneous rupture. Journal of Geophysical Research: Solid Earth, 110(B12).

(B12307) 
doi: $10.1029 / 2005 J B 003813$

DeDontney, N., Rice, J. R., \& Dmowska, R. (2012). Finite Element Modeling of Branched Ruptures Including Off-Fault Plasticity. Bulletin of the Seismological Society of America, 102(2), 541-562. doi: 10.1785/0120110134

De la Puente, J., Ampuero, J.-P., \& Käser, M. (2009). Dynamic rupture modeling on unstructured meshes using a discontinuous Galerkin method. Journal of Geophysical Research: Solid Earth, 114(B10). (B10302)

Dibblee, T. W. J. (1967). Geologic Map of the Old Woman Springs Quadrangle San Bernardino County, California (Tech. Rep.). Washington, DC: Department of the Interior United States Gelogical Survey.

Dokka, R. K., \& Travis, C. J. (1990). Late cenozoic strike-slip faulting in the mojave desert, california. Tectonics, 9(2), 311-340.

Dreger, D. S. (1994). Investigation of the Rupture Process of the 28 June 1992 Landers Earthquake Utilizing Terrascope. Bulletin of the Seismological Society of America, 84(3), 713-724.

Dumbser, M., \& Käser, M. (2006). An arbitrary high-order discontinuous Galerkin method for elastic waves on unstructured meshes II. The three-dimensional isotropic case. Geophysical Journal International, 167(1), 319-336. doi: 10.1111/j.1365-246X.2006.03120.x

Dunham, E. M. (2007). Conditions governing the occurrence of supershear ruptures under slip-weakening friction. Journal of Geophysical Research: Solid Earth, 112(7), 1-24. doi: 10.1029/2006JB004717

Dunham, E. M., Belanger, D., Cong, L., \& Kozdon, J. E. (2011a). Earthquake Ruptures with Strongly Rate-Weakening Friction and Off-Fault Plasticity, Part 1: Planar Faults. Bulletin of the Seismological Society of America, 101 (5), 2296-2307. doi: 10.1785/0120100075

Dunham, E. M., Belanger, D., Cong, L., \& Kozdon, J. E. (2011b). Earthquake Ruptures with Strongly Rate-Weakening Friction and Off-Fault Plasticity, Part 2: Nonplanar Faults. Bulletin of the Seismological Society of America, 101 (5), 2308-2322. doi: 10.1785/0120100076

Duru, K., \& Dunham, E. M. (2016). Dynamic earthquake rupture simulations on nonplanar faults embedded in 3D geometrically complex, heterogeneous elastic solids. Journal of Computational Physics, 305, 185-207.

Ely, G. P., Day, S. M., \& Minster, J.-B. (2008). A support-operator method for viscoelastic wave modelling in 3-d heterogeneous media. Geophysical Journal International, 172(1), 331-344.

Emerson Paradigm Holding. (2018). GoCad: A computer aided design program for geological applications.

Farr, T. G., Rosen, P. A., Caro, E., Crippen, R., Duren, R., Hensley, S., ... Alsdorf, D. (2007). The shuttle radar topography mission. Reviews of Geophysics, 45 (2). doi: 10.1029/2005RG000183

Faulkner, D. R., Mitchell, T. M., Jensen, E., \& Cembrano, J. (2011). Scaling of fault damage zones with displacement and the implications for fault growth processes. Journal of Geophysical Research: Solid Earth, 116(B5). doi: 10.1029/2010JB007788

Fialko, Y. (2004a). Evidence of fluid-filled upper crust from observations of postseismic deformation due to the $1992 \mathrm{Mw} 7.3$ Landers earthquake. Journal of Geophysical Research: Solid Earth, 109(8), 1-17. doi: 10.1029/2004JB002985

Fialko, Y. (2004b). Probing the mechanical properties of seismically active crust with space geodesy: Study of the coseismic deformation due to the $1992 \mathrm{Mw}$ 7.3 Landers (southern California) earthquake. Journal of Geophysical Research: Solid Earth, 109(B3), B03307. doi: 10.1029/2003JB002756

Fialko, Y., Sandwell, D., Simons, M., \& Rosen, P. (2005). Three-dimensional deformation caused by the Bam, Iran, earthquake and the origin of shallow slip deficit. Nature, 435(7040), 295-299. doi: 10.1038/nature03425 
Finzi, Y., \& Langer, S. (2012a). Damage in step-overs may enable large cascading earthquakes. Geophysical Research Letters, 39(May), 1-5. doi: 10.1029/ 2012GL052436

Finzi, Y., \& Langer, S. (2012b). Predicting rupture arrests, rupture jumps and cascading earthquakes. Journal of Geophysical Research: Solid Earth, 117(12), 111. doi: 10.1029/2012JB009544

Fleming, R., Messerich, J., \& Cruikshank, K. (1998). Fractures along a portion of the Emerson fault zone related to the 1992 Landers, California, earthquake: Evidence for the rotation of the Galway-Lake-Road block. Geol. Soc. Am., Map and Chart Series. (MCH082)

Fliss, S., Bhat, H. S., Dmowska, R., \& Rice, J. R. $\quad$ (2005). Fault branching and rupture directivity. Journal of Geophysical Research: Solid Earth, 110(B6), B06312. doi: 10.1029/2004JB003368

Freymueller, J., King, N. E., \& Segall, P. (1994). The co-seismic slip distribution of the Landers earthquake. Bulletin of the Seismological Society of America, $84(3), 646-659$.

Gabriel, A.-A., Ampuero, J., Dalguer, L. A., \& Mai, P. M. (2012). The transition of dynamic rupture styles in elastic media under velocity-weakening

friction. Journal of Geophysical Research: Solid Earth, 117(B9). doi: 10.1029/2012JB009468

Gabriel, A.-A., Ampuero, J.-P., Dalguer, L. A., \& Mai, P. M. (2013). Source properties of dynamic rupture pulses with off-fault plasticity. Journal of Geophysical Research: Solid Earth, 118(8), 4117-4126. doi: 10.1002/jgrb.50213

Galis, M., Pelties, C., Kristek, J., Moczo, P., Ampuero, J.-P., \& Mai, P. M. (2014). On the initiation of sustained slip-weakening ruptures by localized stresses. Geophysical Journal International, 200(2), 890-909. doi: 10.1093/gji/ggu436

Gombert, B., Duputel, Z., Jolivet, R., Doubre, C., Rivera, L., \& Simons, M. (2018). Revisiting the 1992 landers earthquake: a bayesian exploration of co-seismic slip and off-fault damage. Geophysical Journal International, 212(2), 839852. Retrieved from thttp://dx.doi.org/10.1093/gji/ggx455 doi: $10.1093 /$ gji/ggx 455

Graves, R. W., Aagaard, B. T., Hudnut, K. W., Star, L. M., Stewart, J. P., \& Jordan, T. H. (2008). Broadband simulations for Mw 7.8 southern San Andreas earthquakes: Ground motion sensitivity to rupture speed. Geophysical Research Letters, 35(22). doi: 10.1029/2008GL035750

Graves, R. W., \& Pitarka, A. (2010). Broadband Ground-Motion Simulation Using a Hybrid Approach. Bulletin of the Seismological Society of America, 100 (5A), 2095-2123. doi: 10.1785/0120100057

Gross, S., \& Kisslinger, C. (1997). Estimating tectonic stress rate and state with Landers aftershocks. Journal of Geophysical Research: Solid Earth, 102(B4), 7603. doi: 10.1029/96JB03741

Harris, R., \& Day, S. M. (1993). Dynamic of fault interaction: parallel strike-slip faults. Journal of Geophysical Research: Solid Earth, 98(No. B3), 4461-4472. doi: 10.1029/92JB02272

Harris, R. A., Barall, M., Aagaard, B., Ma, S., Roten, D., Olsen, K., .. Dalguer, L. (2018). A suite of exercises for verifying dynamic earthquake rupture codes. Seismological Research Letters, 89(3), 1146. Retrieved from +http://dx.doi.org/10.1785/0220170222 doi: 10.1785/0220170222

Hauksson, E. (1994). State of stress from focal mechanisms before and after the 1992 Landers earthquake sequence. Bulletin of the Seismological Society of America, 84(3), 917-934. doi: 10.1016/0148-9062(95)94483-4

Hauksson, E., Jones, L. M., Hutton, K., \& Eberhart-Phillips, D. (1993). The 1992 Landers earthquake sequence: Seismological observations. Journal of Geophysical Research: Solid Earth, 98(B11), 19835-19858.

Heinecke, A., Breuer, A., Rettenberger, S., Bader, M., Gabriel, A.-A., Pelties, C., ... 
Liao, X.-K. (2014). Petascale High Order Dynamic Rupture Earthquake Simulations on Heterogeneous Supercomputers. In Proceedings of the international conference for high performance computing, networking, storage and analysis (pp. 3-15). IEEE. doi: 10.1109/SC.2014.6

Hernandez, B., Cotton, F., \& Campillo, M. (1999). Contribution of radar interferometry to a two-step inversion of the kinematic process of the 1992 Landers earthquake. Journal of Geophysical Research: Solid Earth, 104(B6), 1308313099.

Hill, R., Treiman, J., Given, J., Pechman, J., McMillan, J., \& Ebel, J. (1980). Geologic study of the homestead valley earthquake swarm of march 15, 1979. California Geology, 33(3), 60-67.

Ida, Y. (1972). Cohesive Force across the Tip of a Longitudinal-Shear Crack and Griffith's Specific Surface Energy. Journal of Geophysical Research: Solid Earth, r7(20), 3796-3805.

Imperatori, W., \& Mai, P. M. (2015). The role of topography and lateral velocity heterogeneiteis on near-source scattering and ground-motion variability. Geophysical Journal International, 202, 2163-2181. doi: 10.1093/gji/ggv281

Kagan, Y. Y., \& Houston, H. (2005). Relation between mainshock rupture process and Omori's law for aftershock moment release rate. Geophysical Journal International, 163(September), 1039-1048. doi: 10.1111/j.1365-246X.2005.02772 $\mathrm{x}$

Kanamori, H., \& Rivera, L. (2006). Energy Partitioning During an Earthquake. In Earthquakes: Radiated energy and the physics of faulting geophysical monograph series 170 (pp. 3-13). American Geophysical Union.

Kanamori, H., Thio, H.-K., Dreger, D., Hauksson, E., \& Heaton, T. (1992). Initial investigation of the landers, california, earthquake of 28 june 1992 using terrascope. Geophysical Research Letters, 19(22), 2267-2270.

Kaneda, H., \& Rockwell, T. K. (2009). Triggered and primary surface ruptures along the camp rock fault, eastern California shear zone. Bulletin of the Seismological Society of America, 99(5), 2704-2720. doi: 10.1785/0120080310

Kaneko, Y., \& Fialko, Y. (2011). Shallow slip deficit due to large strike-slip earthquakes in dynamic rupture simulations with elasto-plastic off-fault response. Geophysical Journal International, 186(3), 1389-1403.

Kaneko, Y., \& Shearer, P. (2015). Variability of seismic source spectra, estimated stress drop, and radiated energy, derived from cohesive-zone models of symmetrical and asymmetrical circular and elliptical ruptures. Journal of Geophysical Research: Solid Earth, 120(2), 1053-1079.

Käser, M., \& Dumbser, M. (2006). An Arbitrary High Order Discontinuous Galerkin Method for Elastic Waves on Unstructured Meshes I: The Two-Dimensional Isotropic Case with External Source Terms. Geophysical Journal International, $166(2), 855-877$.

Käser, M., Hermann, V., \& de la Puente, J. (2008). Quantitative accuracy analysis of the discontinuous Galerkin method for seismic wave propagation. Geophysical Journal International, 173(3), 990-999.

Kaven, J. O., \& Pollard, D. D. (2013). Geometry of crustal faults: Identification from seismicity and implications for slip and stress transfer models. Journal of Geophysical Research: Solid Earth, 118(9), 5058-5070. doi: 10.1002/jgrb.50356

Krischer, L., Megies, T., Barsch, R., Beyreuther, M., Lecocq, T., Caudron, C., \& Wassermann, J. (2015). ObsPy: a bridge for seismology into the scientific python ecosystem. Computational Science \& Discovery, 8(1), $014003 . \quad$ doi: 10.1088/1749-4699/8/1/014003

Kristeková, M., Kristek, J., \& Moczo, P. (2009). Time-frequency misfit and goodness-of-fit criteria for quantitative comparison of time signals. Geophysical Journal International, 178(2), 813-825. doi: 10.1111/j.1365-246X.2009.04177 
. $\mathrm{X}$

Li, Y.-G., Aki, K., Adams, D., Hasemi, A., \& Lee, W. H. K. (1994). Seismic guided waves trapped in the fault zone of the Landers, California, earthquake of 1992. Journal of Geophysical Research: Solid Earth, 99(94), 11705-11722. doi: 10.1029/94JB00464

Li, Y.-G., Aki, K., Vidale, J. E., Lee, W. H., \& Marone, C. J. (1994). Fine structure of the Landers fault zone: segmentation and the rupture process. Science, 265(5170), 367-370.

Liu, J., Sieh, K., \& Hauksson, E. (2003). A structural interpretation of the aftershock cloud of the $1992 \mathrm{M} \mathrm{w} 7.3$ Landers earthquake. Bulletin of the Seismological Society of America, 93(3), 1333-1344.

Lozos, J. C., Oglesby, D. D., Duan, B., \& Wesnousky, S. G. (2011). The effects of double fault bends on rupture propagation: A geometrical parameter study. Bulletin of the Seismological Society of America, 101(1), 385-398. doi: $10.1785 / 0120100029$

Ma, S. (2008). A physical model for widespread near-surface and fault zone damage induced by earthquakes. Geochemistry, Geophysics and Geosystems, 9(11), 19. doi: 10.1029/2008GC002231

Ma, S., \& Archuleta, R. J. (2006). Radiated seismic energy based on dynamic rupture models of faulting. Journal of Geophysical Research: Solid Earth, 111 (B5).

Madden, E. H., Maerten, F., \& Pollard, D. D. (2013). Mechanics of nonplanar faults at extensional steps with application to the 1992 M 7.3 Landers, California, earthquake. Journal of Geophysical Research: Solid Earth, 118(1), 3249-3263. doi: $10.1002 /$ jgrb.50237

Madden, E. H., \& Pollard, D. D. (2012). Integration of surface slip and aftershocks to constrain the 3D structure of faults involved in the M 7.3 landers earthquake, Southern California. Bulletin of the Seismological Society of America, 102(1), 321-342. doi: 10.1785/0120110073

Mai, P. M., Galis, M., Thingbaijam, K. K., Vyas, J. C., \& Dunham, E. M. (2017). Accounting for fault roughness in pseudo-dynamic ground-motion simulations. Pure and Applied Geophysics, 174(9), 3419-3450.

Mai, P. M., Schorlemmer, D., Page, M., Ampuero, J.-P., Asano, K., Causse, M., ... others (2016). The earthquake-source inversion validation (siv) project. Seismological Research Letters, 87(3), 690-708.

Milliner, C. W. D., Dolan, J. F., Hollingsworth, J., Leprince, S., \& Ayoub, F. (2016). Comparison of coseismic near-field and off-fault surface deformation patterns of the $1992 \mathrm{Mw} 7.3$ Landers and $1999 \mathrm{Mw} 7.1$ Hector Mine earthquakes: Implications for controls on the distribution of surface strain. Geophysical Research Letters, 43(19), 10,115-10,124. doi: 10.1002/2016GL069841

Milliner, C. W. D., Dolan, J. F., Hollingsworth, J., Leprince, S., Ayoub, F., \& Sammis, C. G. (2015). Quantifying near-field and off-fault deformation patterns of the $1992 M_{w} 7.3$ Landers earthquake. Geochemistry, Geophysics and Geosystems, 16, 1577-1598. doi: 10.1002/2014GC005693

Nur, A., Ron, H., \& Scotti, O. (1989). Kinematics and mechanics of tectonic block rotations. Slow Deformation and Transmission of Stress in the Earth, 31-46.

Oglesby, D. (2008). Rupture Termination and Jump on Parallel Offset Faults. Bulletin of the Seismological Society of America, 98(1), 440-447. doi: 10.1785/0120070163

Oglesby, D. D., \& Mai, P. M. (2012). Fault geometry, rupture dynamics and ground motion from potential earthquakes on the north anatolian fault under the sea of marmara. Geophysical Journal International, 188(3), 1071-1087. doi: 10.1111/j.1365-246X.2011.05289.x

Olsen, K. B. (1997). Three-Dimensional Dynamic Simulation of the 1992 Landers Earthquake. Science, 278(5339), 834-838. doi: 10.1126/science.278.5339.834 
Pelties, C., de la Puente, J., Ampuero, J.-P., Brietzke, G. B., \& Käser, M. (2012). Three-dimensional dynamic rupture simulation with a high-order discontinuous Galerkin method on unstructured tetrahedral meshes. Journal of Geophysical Research: Solid Earth, 117(B2), B02309. doi: 10.1029/2011JB008857

Pelties, C., Gabriel, A.-A., \& Ampuero, J.-P. (2014). Verification of an ADERDG method for complex dynamic rupture problems. Geoscientific Model Development, 7(3), 847-866. doi: 10.5194/gmd-7-847-2014,10.5194/gmdd-6-5981 $-2013$

Peyrat, S., Olsen, K. B., \& Madariaga, R. (2001). Dynamic modeling of the 1992 Landers earthquake. Journal of Geophysical Research: Solid Earth, 106(B11), 26467-26482.

Ramirez-Guzman, L., Graves, R. W., Olsen, K. B., Boyd, O. S., Cramer, C., Hartzell, S., ... Zhong, J. (2015). Ground-motion simulations of 1811-1812 new madrid earthquakes, central united states. Bulletin of the Seismological Society of America, 105(4), 1961-1988.

Restrepo-Velez, L. F., \& Bommer, J. J. (2003). An exploration of the nature of the scatter in ground-motion prediction equations and the implications for seismic hazard assessment. Journal of Earthquake Engineering, 7(spec01), 171-199.

Rettenberger, S., \& Bader, M. (2015). Optimizing Large Scale I/O for Petascale Seismic Simulations on Unstructured Meshes. In Proceedings of the international conference on cluster computing (pp. 314-317). Chicago, IL: IEEE.

Rettenberger, S., Meister, O., Bader, M., \& Gabriel, A.-A. (2016). ASAGI: A Parallel Server for Adaptive Geoinformation. In Proceedings of the exascale applications and software conference 2016 (pp. 2:1-2:9). New York: ACM. doi: 10 $.1145 / 2938615.2938618$

Rice, J. R., Sammis, C. G., \& Parsons, R. (2005). Off-fault secondary failure induced by a dynamic slip pulse. Bulletin of the Seismological Society of America, 95(1), 109-134.

Ripperger, J., \& Mai, P. (2004). Fast computation of static stress changes on 2D faults from final slip distributions. Geophysical Research Letters, 31(18).

Rockwell, T. K., Lindvall, S., Herzberg, M., Murbach, D., Dawson, T., \& Berger, G. (2000). Paleoseismology of the Johnson Valley, Kickapoo, and Homestead Valley faults: Clustering of earthquakes in the eastern California shear zone. Bulletin of the Seismological Society of America, 90(5), 1200-1236.

Roten, D., Cui, Y., Olsen, K. B., Day, S. M., Withers, K., Savran, W. H., .. Mu, D. (2016). High-frequency nonlinear earthquake simulations on petascale heterogeneous supercomputers. In Proceedings of the International Conference for High Performance Computing, Networking, Storage and Analysis (pp. 82:1-82:12). IEEE.

Roten, D., Olsen, K. B., Cui, Y., \& Day, S. M. (2015). Quantification of fault zone plasticity effects with spontaneous rupture simulations. In Best practices in physics-based fault rupture models for seismic hazard assessment of nuclear installations. Vienna, Austria.

Roten, D., Olsen, K. B., \& Day, S. M. (2017). Off-fault Deformations and Shallow Slip Deficit from Dynamic Rupture Simulations with Fault Zone Plas-

ticity. Geophysical Research Letters, n/a-n/a. (2017GL074323) doi: 10.1002/2017GL074323

Roten, D., Olsen, K. B., Day, S. M., Cui, Y., \& Fäh, D. (2014). Expected seismic shaking in Los Angeles reduced by San Andreas fault zone plasticity. Geophysical Research Letters, 41(8), 2769-2777. doi: 10.1002/2014GL059411.

Sauber, J., Thatcher, W., \& Solomon, S. C. (1986). Geodetic measurement of deformation in the central Mojave Desert, California. Journal of Geophysical Research: Solid Earth, 91 (B12), 12683-12693.

Shaw, J. H., Plesch, A., Tape, C., Suess, M. P., Jordan, T. H., Ely, G., .. . Munster, J. (2015). Unified Structural Representation of the southern California 
crust and upper mantle. Earth and Planetary Science Letter, 415, 1-15. doi: 10.1016/j.epsl.2015.01.016

Shi, Z., \& Day, S. M. (2013). Rupture dynamics and ground motion from 3d roughfault simulations. Journal of Geophysical Research: Solid Earth, 118(3), 11221141. doi: 10.1002/jgrb.50094

Sieh, K. (1996). The repetition of large-earthquake ruptures. Proceedings of the National Academy of Sciences: "Earthquake Prediction: The Scientific Challenge", 93(9), 3764-3771. doi: 10.1073/pnas.93.9.3764

Sieh, K., Jones, L., Hauksson, E., Hudnut, K., Eberhart-Phillips, D., Heaton, T., ... others (1993). Near-field investigations of the landers earthquake sequence, april to july 1992. Science, 260(5105), 171-176.

Simmetrix Inc. (2017). SimModeler: Simulation Modeling Suite 11.0 Documentation (Tech. Rep.). Simmetrix Inc.

Sleep, N. H. (2012). Site resonance from strong ground motions at lucerne, california, during the 1992 landers mainshock. Bulletin of the Seismological Society of America, 102(4), 1505. Retrieved from +http://dx.doi.org/10.1785/ 0120110267 doi: 10.1785/0120110267

Sowers, J. M., Unruh, J. R., Lettis, W. R., \& Rubin, T. D. (1994). Relationship of the Kickapoo Fault to the Johnson Valley and Homestead Valley Faults, San Bernardino County, California. Bulletin of the Seismological Society of America, 84(3), 528-536.

Spotila, J. A., \& Sieh, K. (1995). Geological investigation of a slip gap in the surficial ruptures of the 1992 Landers earthquake, southern California. Journal of Geophysical Research: Solid Earth, 100(94), 543-559.

Spudich, P., \& Chiou, B. S. (2008). Directivity in nga earthquake ground motions: Analysis using isochrone theory. Earthquake Spectra, 24(1), 279-298.

Strasser, F. O., Abrahamson, N. A., \& Bommer, J. J. (2009). Sigma: Issues, insights, and challenges. Seismological Research Letters, 80(1), 40-56.

Suppe, J. (1985). Principles of structural geology. Prentice Hall.

Tago, J., Cruz-Atienza, V. M., Virieux, J., Etienne, V., \& Sánchez-Sesma, F. J. (2012). A 3D hp-adaptive discontinuous Galerkin method for modeling earthquake dynamics. Journal of Geophysical Research: Solid Earth, 117(3), 1-21. doi: 10.1029/2012JB009313

Ulrich, T., Gabriel, A.-A., Ampuero, J.-P., \& Xu, W. (2019). Dynamic viability of the $2016 \mathrm{Mw} 7.8$ Kaikōura earthquake cascade on weak crustal faults. Nature communications, 10(1), 1213.

Unruh, J. R., Lettis, W. R., \& Sowers, J. M. (1994). Kinematic Interpretation of the 1992 Landers Earthquake. Bulletin of the Seismological Society of America, $84(3), 537-546$.

Uphoff, C., \& Bader, M. (2016). Generating high performance matrix kernels for earthquake simulations with viscoelastic attenuation. In Proceedings of the 2016 International Conference on High Performance Computing and Simulation (pp. 908-916). IEEE.

Uphoff, C., \& Bader, M. (2019). Yet Another Tensor Toolbox for discontinuous Galerkin methods and other applications. arXiv preprint arXiv:1903.11521.

Uphoff, C., Rettenberger, S., Bader, M., Madden, E. H., Ulrich, T., Wollherr, S., \& Gabriel, A.-A. (2017). Extreme scale multi-physics simulations of the tsunamigenic 2004 sumatra megathrust earthquake. In Proceedings of the international conference for high performance computing, networking, storage and analysis (p. 21).

Vallée, M., \& Douet, V. (2016). A new database of source time functions (STFs) extracted from the SCARDEC method. Physics of the Earth and Planetary Interiors, 257, 149-157.

Venkataraman, A., \& Kanamori, H. (2004). Observational constraints on the fracture energy of subduction zone earthquakes. Journal of Geophysical Research: 
Solid Earth, 109(B5).

Vyas, J. C., Mai, P. M., \& Galis, M. (2016). Distance and azimuthal dependence of ground-motion variability for unilateral strike-slip ruptures. Bulletin of the Seismological Society of America, 106(4), 1584-1599. doi: $10.1785 / 0120150298$

Wald, D. J., \& Heaton, T. H. (1994). Spatial and Temporal Distribution of Slip for the 1992 Landers, California, Earthquake. Bulletin of the Seismological Society of America, 84 (3), 668-691.

Wenk, S., Pelties, C., Igel, H., \& Käser, M. (2013). Regional wave propagation using the discontinuous Galerkin method. Solid Earth, 4(1), 43-57. doi: 10.5194/se-4 $-43-2013$

Wesnousky, S. G. (2006). Predicting the endpoints of earthquake ruptures. Nature, $444(7117), 358-360$.

Wollherr, S., Gabriel, A.-A., \& Uphoff, C. (2018). Implementation, verification and application of off-fault plasticity in three-dimensional dynamic rupture simulations on complex fault geometries using a modal Discontinuous Galerkin method. Geophysical Journal International.

Xu, X., Tong, X., Sandwell, D. T., Milliner, C. W. D., Dolan, J. F., Hollingsworth, J., ... Ayoub, F. (2016). Refining the shallow slip deficit. Geophysical Journal International, 204(3), 1867-1886. doi: 10.1093/gji/ggv563

Zeng, Y., \& Anderson, J. G. (2000). Evaluation of numerical procedures for simulating near-fault long-period ground motions using zeng method. Pacific Earthquake Engineering Research Center.

Zielke, O., Galis, M., \& Mai, P. M. (2017). Fault roughness and strength heterogeneity control earthquake size and stress drop. Geophysical Research Letters, 44(2), 777-783. doi: 10.1002/2016GL071700

Zinke, R., Hollingsworth, J., \& Dolan, J. F. (2014). Surface slip and off-fault deformation patterns in the $2013 \mathrm{Mw} 7.7$ Balochistan, Pakistan earthquake: Implications for controls on the distribution of near-surface coseismic slip. Geochemistry, Geophysics, Geosystems, 15(12), 5034-5050. 